\author{
Universidade de São Paulo \\ Instituto de Astronomia, Geofísica e Ciências Atmosféricas
}

André Cozza Sayão

\title{
Estudo da variabilidade sazonal da profundidade óptica do aerossol em São Paulo a partir de radiômetros MFRSR
}

São Paulo 
André Cozza Sayão

\section{Estudo da variabilidade sazonal da profundidade óptica do aerossol em São Paulo a partir de radiômetros MFRSR}

Dissertação apresentada ao Instituto de Astronomia, Geofísica e Ciências Atmosféricas da Universidade de São Paulo para obtenção do título de Mestre em Ciências.

Área de concentração: Meteorologia

Orientador: Prof. Dra. Márcia Akemi Yamasoe

São Paulo 
Dedico este trabalho:

Aos meus pais Rubilar e Marlene e a minha noiva Laura que aceitaram a minha ausência

A minha querida avó Maria Francisca

(in memorian). 


\section{Agradecimentos}

Agradeço a Deus por me propiciar a oportunidade e a força de vontade para enfrentar todas as alegrias e agruras encontradas ao longo do caminho. Agradeço a ele também por ter me propiciado o convívio com tantas pessoas especiais.

À minha família meu Pai, minha Mãe e meu irmão Sandro Sayão por todo o apoio e incentivo em mais esta etapa da minha vida.

À minha querida noiva Laura que em todos os momentos soube compreender e principalmente me estimular a prosseguir.

Aos amigos Kevin, Brad, Cristal e Kita, por todos os momentos de descontração e por sua dedicação ao longo do tempo.

Agradeço ao Prof. Dr. Artêmio Plana-Fattori e ao Dr. Marcelo Corrêa que me acolheram no IAG-USP no começo da minha jornada acadêmica. A eles, eu também agradeço pela iniciativa em adquirir, manter e operar os dois MFRSR, utilizados neste trabalho, quando os mesmos estavam na EM-IAG-USP.

À Prof. Dra. Márcia Akemi Yamasoe que me orientou durante toda a minha IC e Mestrado, sempre dando apoio e principalmente mostrando o rumo a seguir.

Aos amigos que fiz no IAG-USP em especial a Alrenice Cunha, Elizabete do Amaral, Jonathan Mota, Angélica Durigon, Luciene Natali e Guilherme Martins por tantos momentos de alegria e por tantos outros de muita transpiração acadêmica.

Aos amigos Eduardo Nogueira e Celso Manoel pela amizade durante todos estes anos.

Aos amigos e companheiros, do grupo de radiação, Nilton do Rosário e Ricardo Siqueira, pela paciência, pelas discussões teóricas, trocas de idéias e principalmente pelo ótimo convívio e amizade nestes anos de trabalho em conjunto.

Pelo apoio e a amizade do grupo de informática do IAG-USP formado por Luciana Lemos, Sebastião Antonio da Silva e Samuel Reis.

Pelo apoio e a amizade das secretárias do departamento que dão todo o respaldo ao desenvolvimento do nosso trabalho em especial as amigas Marisa Maielo e Regina Iacovelli bem como a Elisabete Flores, Ana Lúcia e Sônia Alonso.

Agradeço também a todos os outros funcionários do IAG, copeiros, motoristas, faxineiros, bibliotecários, auxiliares, porteiros, vigias, em fim a todos que participam indiretamente, mas que são fundamentais na realização deste e de tantos outros trabalhos. 


\section{Agradecimentos}

À rede AERONET, na pessoa do Prof. Dr. Paulo Artaxo Netto, pelo esforço na manutenção e operação da estação em São Paulo.

À equipe técnica da Estação Meteorológica do IAG-USP pelo trabalho acurado na coleta e observação de variáveis meteorológicas e principalmente pela operação e cuidados com os MFRSR durante o seu funcionamento na EM.

À equipe do LNA-OPD na pessoa de seu diretor o Dr. Albert Bruch, por colocar a disposição do nosso grupo de pesquisa as instalações e o corpo técnico do LNA-OPD durante as campanhas de calibração dos MFRSR.

Agradeço a todos os amigos e colegas que de alguma forma me ajudaram na realização deste trabalho.

Aos professores do IAG-USP e demais professores dentro e fora da USP que me forneceram a base para este trabalho.

À FAPESP pelo apoio financeiro durante este projeto de mestrado sob o número 04/11553-1 bem como a toda a população brasileira e em especial a de São Paulo que contribui, todos os dias, para este financiamento público do ensino e da pesquisa científica.

A todos o meu muito obrigado! 
"Não há fé inabalável se não aquela que pode encarar a razão face a face em todas as épocas da humanidade".

Allan Kardec. 


\section{Resumo}

SAYÃO, A. C. - Estudo da variabilidade sazonal da profundidade óptica do aerossol em São Paulo a partir de radiômetros MFRSR. Dissertação de Mestrado apresentada ao Instituto de Astronomia, Geofísica e Ciências Atmosféricas, Universidade de São Paulo, 130p 2008 .

A avaliação dos efeitos dos aerossóis em relação ao balanço radiativo local e global bem como o impacto sobre a saúde humana, principalmente em grandes centros urbanos, demanda que se conheça de forma precisa a sua concentração e distribuição espaço-temporal. Neste contexto, o monitoramento acurado de longo prazo por estações instaladas ao redor do mundo tornou-se um desafio e uma necessidade para várias áreas do conhecimento. Classicamente as estações utilizam a técnica de fotometria solar para inferir a concentração e a distribuição de tamanho dos aerossóis através da profundidade óptica do aerossol (POA) e do coeficiente de Ångström $(\alpha)$. No presente trabalho é sugerida uma metodologia para estimar POA e $(\alpha)$ através de quatro canais espectrais de radiômetros do tipo Multi-Filter Rotating Shadowband Radiometer (MFRSR) que operam em São Paulo desde 1999. Estas estimativas foram avaliadas em relação à rede AErosol RObotic NETwork (AERONET) entre os anos de $2004 \mathrm{a}$ 2006. Os resultados mostram que, em termos de variabilidade temporal da POA, há boa concordância entre os diferentes instrumentos. Entretanto, são encontradas diferenças médias sistemáticas da ordem de 0,03 na magnitude da POA em três dos quatro canais analisados, enquanto que o valor sugerido pela OMM para uma atmosfera limpa é de no máximo 0,02. Este resultado aponta que a metodologia empregada nos MFRSR fornece valores de boa qualidade. Ainda neste trabalho, foram relacionadas variáveis meteorológicas coletadas pela Estação Meteorológica do IAG-USP com a POA e o $(\alpha)$ estimados neste trabalho. Observouse uma relação linear entre o $(\alpha)$ e a umidade relativa (UR), indicando um crescimento do tamanho médio dos aerossóis que integram um grupo com $0,20<\mathrm{POA} \leq 0,60$ no canal $415 \mathrm{~nm}$ com o aumento da umidade relativa. Acredita-se que este grupo tenha predominância de aerossóis de fontes locais. As medidas de longo prazo permitiram também caracterizar, em conjunto com estimativas espaciais de POA pelo sensor Moderate Resolution Imaging Spectroradiometer (MODIS) a bordo do satélite Terra, a influência do transporte de aerossóis de queimadas da região amazônica e do Brasil central em São Paulo, na série de dados analisados. Estes eventos contribuem para o aumento significativo da POA sobre a região metropolitana e trazem partículas ligeiramente menores que as emitidas por fontes locais.

Palavras-chave: Aerossóis; Fotometria solar; Poluição urbana; Profundidade óptica; Processos radiativos na atmosfera; Sensoriamento remoto. 


\section{Abstract}

SAYÃO, A. C. - Study of the seasonal variability of the aerosol optical depth in São Paulo using MFRSR radiometers. Dissertation presented in the Instituto de Astronomia, Geofísica e Ciências Atmosféricas, Universidade de São Paulo, 130p 2008.

The evaluation of the aerosol effects to the local and global radiation budget, as well as the impact on human health, particularly in large urban centers, demands knowing accurately their concentration and spatial-temporal distribution. In this context, the accurate long term monitoring from ground based stations installed around the world has become a challenge and a necessity for various areas of knowledge. Classically, the stations use the technique of Sun photometry to infer the concentration and size distribution of aerosols through the aerosol optical depth (AOD) and Ångström coefficient ( $\alpha$ ). In this paper we suggest a methodology to estimate AOD and $(\alpha)$ through four channels of Multi-Filter Rotating Shadowband Radiometers (MFRSR) operating in Sao Paulo since 1999. These estimates were compared to the results of the AErosol RObotic NETwork (AERONET) between the years of 2004 to 2006. The results showed that the MFRSR can represent well the temporal variability of the AOD, but systematic differences were found with mean values of about 0.03 in AOD, in three of the four analyzed channels. The value suggested by WMO for clean air is at most 0.02 . This result indicates that the methodology employed in MFRSR provides values of quality good. Also in this study, meteorological influences on the aerosol optical properties were analyzed. The meteorological variables were monitored at the Meteorological Station of the IAG-USP There was a linear relationship between $(\alpha)$ and relative humidity $(\mathrm{RH})$, indicating a growth of the average size of aerosols within a group with $0.20<\mathrm{AOD} \leq 0.60$, in the channel $415 \mathrm{~nm}$, with increasing relative humidity. It is believed that this group has predominance of aerosols from local sources. Long term measurements also helped to characterize, together with spatial estimates of AOD by the Moderate Resolution Imaging Spectroradiometer (MODIS) on board the Terra satellite, the influence of the transport of aerosol particles from biomass burning from the Amazon region to São Paulo. It was observed that these events contribute to significant increase in AOD on the metropolitan region and bring slightly smaller particles than the emitted by local sources.

Keywords: Aerosols; Sun photometry; Urban pollution; Optical depth; Radiative processes in the atmosphere; Remote Sensing 


\section{Capítulo I - Introdução}

1.1. O aerossol atmosférico e as mudanças climáticas.............................................................

1.2. A Região Metropolitana de São Paulo..............................................................................

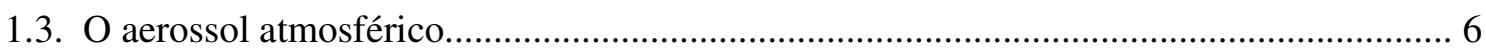

1.3.1. Fontes, classificação e remoção do aerossol atmosférico...........................................6

1.3.2. A interação do aerossol atmosférico com a radiação solar........................................11

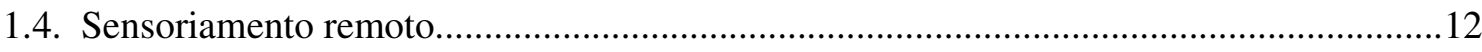

1.4.1. Sensoriamento remoto dos aerossóis.........................................................................13

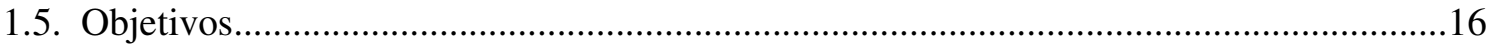

\section{Capítulo II - Fundamentação teórica}

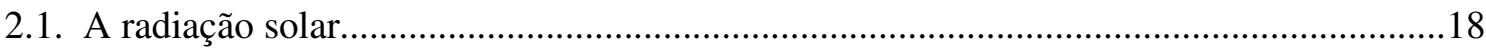

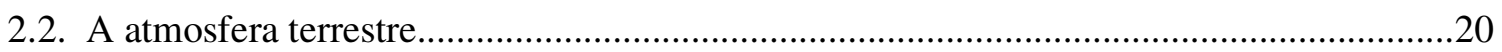

2.3. Interação da atmosfera com a radiação solar.................................................................22

2.3.1. A atenuação molecular - o espalhamento Rayleigh................................................24

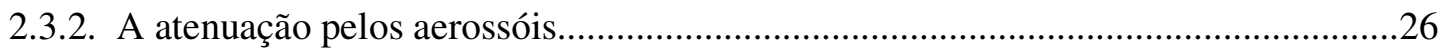

2.3.3. A atenuação exponencial da radiação espectral -

Lei de Beer, Bouguer e Lambert............................................................................ 31

2.4. A lei de Beer, Bouguer e Lambert aplicada à atmosfera.................................................33

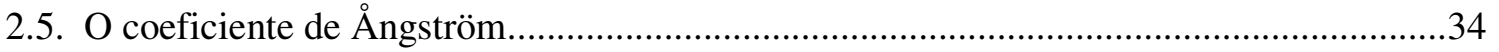

\section{Capítulo III - Materiais e Métodos}

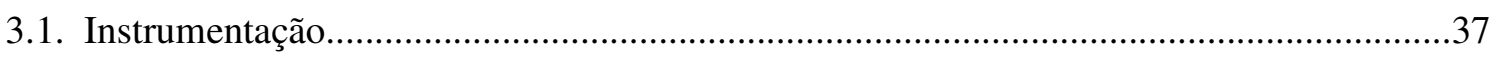

3.1.1. O Multi-Filter Rotating Shadowband Radiometer - MFRSR ..................................37

3.1.2. O fotômetro solar espectral CE318A................................................................... 40

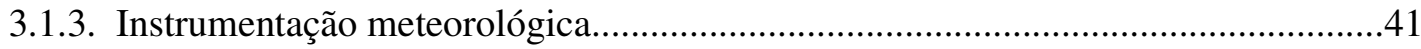

3.2. O cálculo da profundidade óptica espectral do aerossol com medidas de MFRSR..........42

3.2.1. A contribuiçãa do espalhamento Rayleigh.................................................................43

3.2.2. A contribuição devido a absorção pelo ozônio............................................................44

3.2.3. A contribuição da absorção pelo dióxido de nitrogênio.............................................46

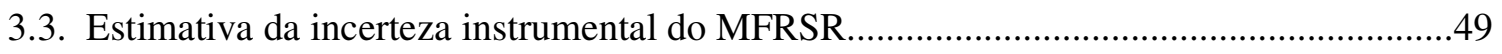




\section{Sumário}

3.4. Calibração dos MFRSR - Determinação da constante solar. .51

3.4.1. Calibração dos MFRSR pelo método Langley...........................................................51

3.4.2. O Método Geral................................................................................................53

3.5. Transferência de calibração entre os MFRSR .................................................................55

3.6. Estimativa da incerteza no cálculo da POA de MFRSR...................................................55

3.7. Pré-Filtro automático para exclusão de nuvens em dados de MFRSR ……………….......56

3.8. Avaliação da POA estimada com os MFRSR e o fotômetro solar da rede AERONET... 60

3.9. Comparação entre variáveis meteorológicas e propriedades ópticas...................................60

\section{Capítulo IV - Resultados}

4.1. A Calibração dos MFRSR .........................................................................................62

4.1.1. Calibração do MFR-434 pelo Método Langley............................................................62

4.1.1.1. Estimativa para o ano de 2000 em Campos do Jordão - SP..................................62

4.1.1.2. Estimativa para o ano de 2006 em Brasópolis - MG..........................................65

4.1.1.3. Transferência de calibração do MFR-434 para o MFR-435 e avaliação da degradação da calibração..................................................................................66

4.1.2. Calibração do MFR-434 pelo Método Geral..............................................................69

4.1.3. Avaliação da calibração com o Método Geral em relação aos dados fornecidos pela rede AERONET.......................................................................71

4.2. Avaliação da sazonalidade das propriedades ópticas do aerossol de São Paulo................79

4.3. Relação entre variáveis meteorológicas e as propriedades ópticas do aerossol..................81

4.3.1 Caracterização da base de dados selecionada...........................................................

4.3.2. Características Meteorológicas............................................................................86

4.3.3. Avaliação da relação entre as propriedades ópticas do aerossol e as variáveis

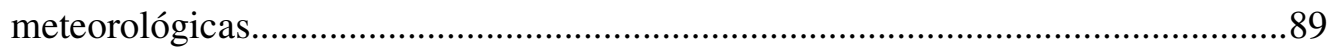

4.3.4 Identificação do transporte de aerossol de queimadas na série analisada..................93

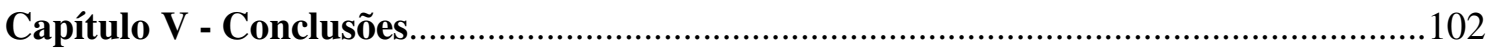

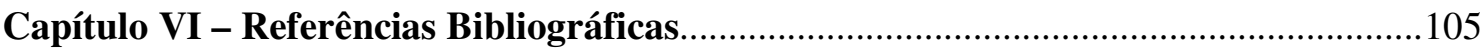




\section{Lista de Figuras}

Figuras 1.1 - Estimativas para a forçante radiativa média global (FR), estimada em 2005, atribuída ao dióxido de carbono $\left(\mathrm{CO}_{2}\right)$, metano $\left(\mathrm{CH}_{4}\right)$, óxido nitroso $\left(\mathrm{N}_{2} \mathrm{O}\right)$, aerossóis bem como para outros agentes e mecanismos significativos. Junto com o valor da forçante em $\left[\mathrm{W} / \mathrm{m}^{2}\right]$ são apresentados também a extensão geográfica típica (escala espacial) da FR e o nível de compreensão científica avaliada (NCC). Adaptado [IPCC,

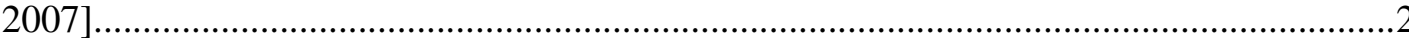

Figura 1.2 - Mancha urbana devido à ocupação do solo na RMSP. A imagem superior apresenta o Estado de São Paulo [Fonte - www.cnpm.embrapa.br, acesso janeiro de 2008] onde a mancha urbana da RMSP já se destaca e na figura inferior é ilustrada a sua ampliação [Fonte - Google Earth, acesso janeiro de 2008] 5

Figura 1.3 - Representação esquemática da distribuição de tamanho das partículas de aerossol atmosférico, ilustrando as várias modas de distribuição de tamanho, algumas fontes, os principais processos envolvidos no crescimento da partícula e formas de remoção. Fonte Andrade [2006]

Figura 2.1 - Representação esquemática do espectro eletromagnético em função do comprimento de onda e da freqüência $(\mathrm{F})$. Na figura é destacada a faixa de radiação correspondente ao visível entre 0,4 a $0,76 \mu \mathrm{m}$ e o espectro do infravermelho. Adaptado Apostila Sensor-Rem-INPE em: http://www.fca.unesp.br/intranet/celia.php. Acesso em: 11 janeiro de 2008.

Figura 2.2 - Distribuição de irradiância espectral $\left(E_{\lambda}\right)$ em $\left[\mathrm{W} / \mathrm{m}^{2} \cdot \mu \mathrm{m}\right]$. Apresentada a irradiância espectral solar no TOA, ao nível médio do mar e a irradiância espectral emitida de um corpo negro à temperatura de $5.900 \mathrm{~K}$ conforme indicado pelas setas na figura. As áreas obscurecidas (pintadas) correspondem a regiões espectrais de forte absorção por alguns gases presentes na atmosfera. Adaptado de Seinfeld e Pandis [1998]

Figura 2.3 - Diagrama que representa as interações entre um feixe de radiação espectral incidente e uma partícula em suspensão na atmosfera. Adaptado de Seinfeld \& Pandis, [1998].

Figura 2.4 - Representação da forma de espalhamento de um feixe de radiação incidente em uma partícula com diversos tamanhos, ilustrando o espalhamento no limite Rayleigh, o espalhamento Mie para partículas de tamanho médio e a forma de espalhamento Mie para partículas muito grandes. Adaptado de - http://hyperphysics.phy-astr.gsu.edu. Acessado em 10 de janeiro de 2007 28

Figura 2.5 - Representação esquemática da definição de caminho óptico, que corresponde à distância efetivamente percorrida por um feixe de radiação incidente ao atravessar um meio opticamente ativo. Onde $(\theta)$ corresponde ao ângulo zenital da orientação de propagação do feixe de radiação e a orientação normal a superfície. Adaptada de Liou [2002].

Figura 2.6 - Representação esquemática da Lei de Beer, Bouguer e Lambert, ao longo de um meio opticamente ativo na orientação de propagação $\left[\Omega^{\prime}=\left(\theta^{\prime}, \varphi^{\prime}\right)\right]$, onde $\left(\theta^{\prime}\right)$ corresponde ao ângulo zenital e ( $\varphi$ ') o ângulo azimutal, Adaptado de Liou [2002]. 


\section{Lista de Figuras}

Figura 2.7 - A aproximação para uma atmosfera plano-paralela, caracterizada por camadas estruturadas verticalmente e homogêneas horizontalmente, onde $(\theta)$ corresponde ao ângulo zenital entre a orientação de propagação de um feixe de radiação e a vertical. Adaptado de Liou [2002] 34

Figura 3.1 - Conjunto de foto-diodo detectores do MFRSR e o mesmo em operação na EMIAG-USP. Fonte - (a) Fabricante e (b) Marcelo Corrêa 38

Figura 3.2 - Representação esquemática do conjunto fotodetector do MFRSR durante o seu funcionamento. Adaptado do manual do fabricante.

Figura 3.3 - Fotômetro solar CE318A em operação automática. Fonte Rosário [2006]

Figura 3.4 - Variabilidade interanual para o conteúdo de ozônio em Unidade Dobson (DU) para a região Metropolitana de São Paulo-SP, entre 1996 e 2004. Valores obtidos a partir de medições com o TOMS, para as coordenadas de $-23,5^{\circ}<$ latitude $<-23,75^{\circ}$ e $-46,45^{\circ}<$ longitude $<-46,30^{\circ}$.

Figura 3.5 - Mapa com as concentrações do NO2 para a troposfera na América do Sul (a) e integrada na coluna atmosférica para o Globo Terrestre (b), ambos em agosto de $2003 \mathrm{em}$ $\left[1015 \mathrm{molec} / \mathrm{cm}^{2}\right]$. Fonte - SCIAMACHY- ESA

Figura 3.6 - Razão entre a irradiância difusa espectral e a global espectral para o MFR-434 (no eixo vertical, das ordenadas) (considerado o valor de referência) em função da mesma razão obtida com o MFR-435 (no eixo horizontal, das abscissas). As razões espectrais correspondem aos canais: (a) $415 \mathrm{~nm}$; (b) $672 \mathrm{~nm}$;(c) $870 \mathrm{~nm}$; (d) $1036 \mathrm{~nm}$ .50

Figura 3.7 - Aplicação do método de Langley em dados de irradiância espectral diretanormal $\left(\mathrm{E}_{\mathrm{d}-\mathrm{n}, \lambda}\right)$ medidos com o MFRSR (MFR-434), e ajustados pelo método dos Mínimos Quadrados. As medidas foram realizadas no dia 28 de julho de 2000 na estação do Departamento de Águas e Energia Elétrica do Estado de São Paulo (DAEE) a 1600 m de altitude localizada em Campos do Jordão. 52

Figura 3.8 ('a' até 'f') - Irradiância global, difusa e direta-normal (D-N) (figuras a, b) , POA em 870nm e 672nm e coeficiente de Ångström (alfa) em 672/870nm (figuras c, d), Razão da irradiância Direta-Normal pela Difusa (R.D-N/Difusa) em 870nm (figuras e, f) em dois dias da base de dados medidos na Estação Meteorológica do IAG/USP nos anos de 1999 e 2002. As figuras 2(a, c, e) correspondem ao dia 29/08/99 e as figuras 2(b, d, f) correspondem ao dia $02 / 06 / 02$. Os pontos em amarelo nas figuras (c, d) correspondem aos pontos excluídos do coeficiente de Ångström.

Figura 4.1 - Ciclo diário de irradiâncias global (E global) e difusa (E difusa), para os períodos de medições em: (a) 24/07, (b)28/07, (c) 29/07 e (d) 30/07, efetuadas em Campos do Jordão durante a calibração do MFRSR (MFR-434) no ano de 2000.

Figura 4.2 - Valores da constante solar $\left(\mathrm{E}_{0 \lambda}\right)$ calculados pelo Método Langley para o MFR434 em (a) nos anos de 2000, 2005 e 2006 e os transferidos para o MFR-435 em (b) para o período entre 1999 a 2006. Os valores em 2005 foram extraídos do trabalho de Rosário [2006]. 


\section{Lista de Figuras}

Figura 4.3 - Constante solar espectral média mensal $\left(\mathrm{E}_{0 \lambda}\right)$ do MFR-434 entre 1999 a 2006 pelo Método Geral adotando o canal $870 \mathrm{~nm}$ como referência. No eixo das abscissas é apresentado o número de dias de funcionamento do MFR-434 (o dia de funcionamento 01 corresponde ao dia 14/07/99). As incertezas correspondem ao desvio padrão da média (barras verticais).É apresentado o coeficiente de determinação $\mathrm{R}^{2}$ do ajuste linear. Os valores da constante solar espectral obtida pelo método Langley são ilustrados em rosa para os anos de 2000, 2005 e 2006. Em 1999, 2001 e 2002 os valores de referência são iguais aos obtidos no ano de 2000 e em 2004 corresponde ao valor estimado em 2005. Os canais analisados correspondem a: (a) $415 \mathrm{~nm}$; (b)672 nm; (c)1036 nm. .70

Figura 4.4 - Ciclo anual dos valores espectrais simultâneos de POA da rede AERONET (440, 675, 870 e $1020 \mathrm{~nm})$ e MFRSR $(415,672,870$ e $1036 \mathrm{~nm})$ para os anos de 2004, 2005 e 2006. São apresentados na figura em vermelho a POA da rede AERONET e em azul a POA do MFRSR (MFR-434) instalados no edifício Pelletron no IF/USP. .72

Figura 4.5 (de "a" a "m") - Evolução diurna da diferença na POA entre os dados da rede AERONET e os MFRSR para os anos de 2004, 2005 e 2006 .75

Figura 4.6 - Comparação entre os valores espectrais de POA com operação simultânea da rede AERONET e MFRSR nos anos de 2004 a 2006. São apresentados na figura a equação do ajuste linear por MMQ (Método dos Mínimos Quadrados), a incerteza no coeficiente angular $(\sigma a)$ e linear $(\sigma b)$, o número de dados empregados no ajuste $[\mathrm{n}(*)$ dados] e o valor do Qui-Quadrado Reduzido.

Figura 4.7 - Valores médios diários de POA (profundidade óptica espectral do aerossol) (medidos na Estação Meteorológica do IAG-USP localizada no bairro da Água Funda capital - SP) para o período de agosto de 1999 a dezembro de 2002 e para os valores medidos no IF-USP entre agosto de 2003 até dezembro de 2006 .79

Figura 4.8 - Valores médios diários do coeficiente de Ångström entre 415/870nm para São Paulo - SP (Estação Meteorológica do IAG-USP localizada no bairro da Água Funda) para o período de agosto de 1999 a dezembro de 2002 e valores medidos no IF-USP entre agosto de 2003 até dezembro de 2006. As barras de erros representam o desvio padrão dos dados nos dias analisados. 80

Figura 4.9 - Valores médios mensais de POA (profundidade óptica espectral do aerossol) para São Paulo - SP (medidos na Estação Meteorológica do IAG-USP localizada no bairro da Água Funda - capital - SP) para o período de agosto de 1999 a fevereiro de 2003. As barras de erro foram suprimidas para facilitar a visualização dos dados. As linhas unindo os pontos são apenas para também ajudar na visualização. 81

Figura 4.10 - Histograma da profundidade óptica do aerossol entre agosto de 1999 até dezembro de 2002 para os canais do MFRSR. São apresentados os valores estatísticos: média (med), desvio padrão (std), mínimo (min), máximo (max) e número de dados empregados ( $\mathrm{n}^{\mathrm{o}}$ dados) para os períodos selecionados sem nuvens 


\section{Lista de Figuras}

Figura 4.11 - Histogramas do coeficiente de Ångström entre agosto de 1999 até dezembro de 2002. São apresentados os valores estatísticos: média (med), desvio padrão (std), mínimo (min), máximo (max) e número de dados empregados ( $\mathrm{n}^{\circ}$ dados) para os períodos selecionados sem nuvens

Figura 4.12 - Avaliação do coeficiente de Ångström entre os canais 415/870nm do MFRSR em função da POA em $415 \mathrm{~nm}$ para o período selecionado sem nuvens entre agosto de 1999 a dezembro de 2002. .85

Figura 4.13 - Histogramas de temperatura do ar, umidade relativa e pressão atmosférica no período selecionado sem nuvens entre agosto de 1999 a dezembro de 2002 medidos na EM-IAG-USP. São apresentados os valores: médio (med), desvio padrão (std), mínimo (min), máximo (max) para um espaço amostral de 312 dados. .86

Figura 4.14 - Distribuição absoluta da orientação (direção e sentido) do vento e a distribuição da velocidade, respectivamente. A orientação do vento é apresentada em [graus] e segundo a sigla da nomenclatura em inglês. A magnitude do vento é apresentada na forma de histograma com a velocidade do vento em $[\mathrm{m} / \mathrm{s}$ ] para a série analisada, medida pela EM - IAG-USP entre agosto de 1999 até dezembro de 2002 87

Figura 4.15 - Distribuição absoluta da orientação (direção e sentido) do vento para o período da manhã e da tarde. A orientação do vento é apresentada em [graus] e segundo a sigla da nomenclatura em inglês, a série analisada foi medida pela EM - IAG-USP entre agosto de 1999 a dezembro de 2002

Figura 4.16 - Comparação da POA em (415; 672; 870 e 1036nm) com a umidade relativa (UR[\%]) e a velocidade do vento. É apresentado no gráfico o ajuste linear obtido entre os parâmetros analisados $(y=a . x \pm b)$ e o módulo do coeficiente de correlação $\left(r^{2}\right)$ para o período de dados selecionados, entre agosto de 1999 a dezembro de 2002. Dados coletados na EM - IAG-USP. .89

Figura 4.17 - Coeficiente de Ångström ( $\alpha$ ) entre os canais 415/870 do MFRSR versus umidade relativa (UR[\%]). No gráfico, o $\alpha$ foi separado em três grupos de dados em relação ao valor da POA no canal 415nm: grupo 1 em vermelho para a POA até 0,20, grupo $2 \mathrm{em}$ azul para o intervalo entre $0,20<\mathrm{POA} \leq 0,60$ e grupo 3 em marrom para os valores com $\mathrm{POA}>0,6$. É apresentado no gráfico o ajuste linear $(y=a x \pm b)$ e o coeficiente de determinação $\left(\mathrm{R}^{2}\right)$ para o conjunto principal de pontos em azul. Dados no período de agosto de 1999 a dezembro de 2002 coletados na EM - IAG-USP 91

Figura 4.18 - Distribuição espacial da POA através do sensor MODIS, abordo do satélite Terra, em $0,55 \mu \mathrm{m} \quad(550 \mathrm{~nm})$ disponíveis no site NASA-Giovanni (http://disc1.sci.gsfc.nasa.gov/daac-bin/G3/gui.cgi).As figuras correspondem ao intervalo entre 06 a 09 de outubro de 2002, a latitude e longitude são apresentadas em [graus] e a régua de cores ao lado da figura indica o valor da POA correspondente nos mapas 


\section{Lista de Figuras}

Figura 4.19 - Imagem RGB no espectro do visível (Visible Composite) através do sensor MODIS a bordo do satélite TERRA, ampliação, para o dia 06/10/2002 na qual é possível observar uma grande pluma de aerossol cobrindo o Uruguai, Rio Grande do Sul, Santa Catarina, Paraná, Mato Grosso do Sul e São Paulo. A seta indica a região metropolitana de São Paulo. Imagem disponível no site LAADS endereço:

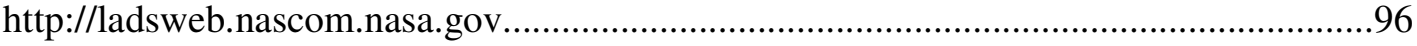

Figura 4.20 - Distribuição espacial da POA através do sensor MODIS, abordo do satélite Terra, em $0,55 \mu \mathrm{m} \quad(550 \mathrm{~nm})$ disponíveis no site NASA-Giovanni (http://disc1.sci.gsfc.nasa.gov/daac-bin/G3/gui.cgi). As figuras correspondem ao intervalo entre 10 a 19 de outubro de 2002, a latitude e longitude são apresentadas em [graus] e a régua de cores ao lado da figura indica o valor da POA correspondente nos mapas.........97

Figura 4.21 - Imagem RGB no espectro do visível (Visible Composite) através do sensor MODIS, abordo do satélite TERRA, ampliação, para o dia 19/10/2002 onde é possível observar uma grande pluma de aerossol cobrindo parte do oceano na costa do Paraná e de São Paulo bem como a região metropolitana de São Paulo. A seta indica a região metropolitana de São Paulo. Imagem disponível no site LAADS Web:

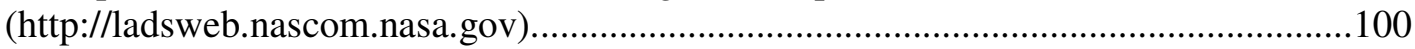




\section{Lista de tabelas}

Tabela 1.1 - Estimativas das contribuições anuais de algumas das principais fontes de aerossol atmosférico, em [Tg/ano]. Adaptado de Horvath [2000]. . .8

Tabela 2.1 - Composição química média da atmosfera. Adaptado de Sokolik [2008]

Tabela 3.1 - Valores de profundidade óptica espectral de Rayleigh para cada canal do MFRSR, e suas respectivas incertezas estimadas segundo Fröhlich \& Shaw (1980).

Tabela 3.2 - Valores de secção de choque de absorção do ozônio $\left(\mathrm{O}_{3}\right)$ para cada canal segundo Shettle \& Anderson [1995]

Tabela 3.3 - Valores médios mensais e incertezas para a concentração do ozônio na Região Metropolitana de São Paulo $\left(-23,5^{\circ}<\right.$ latitude $<-23,75^{\circ}$ e $-46,45^{\circ}<$ longitude $\left.<-46,30^{\circ}\right)$ para o período entre 1999 e 2003 em [DU]. 46

Tabela 3.4 - Valores médios mensais e incertezas para a concentração do $\mathrm{NO}_{2}$ integrado na atmosfera em $\left[10^{15}\right.$ moléculas $\left./ \mathrm{cm}^{2}\right]$. A incerteza corresponde ao desvio padrão das medidas.

Tabela 3.5 - Valor da secção de choque de absorção para o $\mathrm{NO}_{2}$ segundo Orphal [2003] e o valor calculado para a profundidade óptica do $\mathrm{NO}_{2}$ para região Metropolitana de São Paulo no mês de agosto quando se obteve o maior valor médio mensal observado pelo sensor SCIAMACHY com uma concentração de $9 \times 10^{15}$ moléculas $/ \mathrm{cm}^{2}$. .48

Tabela 3.6 - Valores, por canal do MFRSR, da incerteza estatística instrumental (Incerteza) em (\%), dos coeficientes, angular (a) e linear (b), e respectivas incertezas ( $\sigma a$ e $\sigma b)$, todos adimensionais determinados pelo método dos mínimos quadrados..... .50

Tabela 3.7 - Incertezas espectrais das grandezas que fazem parte da propagação de erro no cálculo da incerteza da profundidade óptica do aerossol $\left(\sigma \tau_{\mathrm{a} \lambda}\right)$, o valor percentual corresponde a grandeza apresentada na tabela.

Tabela 4.1 - Valores da constante solar por canal do MFR-434 ajustados pelo método dos

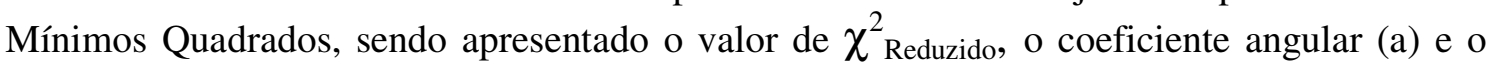
coeficiente linear (b) [adimensional], $[\exp (b)]$ o valor da exponencial do coeficiente angular em $\left[\mathrm{W} / \mathrm{m}^{2} . \mathrm{nm}\right]$, o valor de ajuste para a distância Terra-Sol $\left[(\mathrm{d} / \mathrm{d})^{2}\right]$, o valor obtido para constante solar $\mathrm{E}_{0 \lambda-434} \mathrm{e}$ as respectivas incertezas em [W/m $\left.{ }^{2} . \mathrm{nm}\right]$. $\mathrm{O}$ valor médio corresponde ao novo valor para a constante solar $\left[\mathrm{E}_{0 \lambda-434}\right]$ 64

Tabela 4.2 - Valores da constante Solar obtidos pelo método Langley para o MFR-434 durante a campanha de calibração de 2006. Os valores apresentados na tabela tanto para a constante solar $\left(\mathbf{E}_{\mathbf{0}-\boldsymbol{\lambda}}\right)$ e sua respectiva incerteza $\left(\boldsymbol{\sigma} \mathbf{E}_{\mathbf{0}-\boldsymbol{\lambda}}\right)$ são apresentados em $\left[\mathrm{W} / \mathrm{m}^{2} . \mathrm{nm}\right] . \ldots \ldots . . .66$ 
AERONET - AErosol RObotic NETwork

AOD - Aerosol Optical Depth

ARM - Atmospheric Radiation Measurement

CLAIR - Cooperative LBA Airborne Regional Experiment

CE318A - Cimel Eletronique 318 A

CETESB - Companhia de Tecnologia de Saneamento Ambiental de São Paulo

DAEE - Departamento de Águas e Energia Elétrica do Estado de São Paulo

DCA - Departamento de Ciências Atmosféricas

DU - Dobson Unit

EM - Estação Meteorológica

ESA - European Spacial Agency

FR - Forçante Radiativa

GAW - Global Atmosphere Watch

GOES - Geostationary Operational Environmental Satellites

HG - Henyey-Greenstein

IAG - Instituto de Astronomia, Geofísica e Ciências Atmosféricas

IF-USP - Instituto de Física da Universidade de São Paulo

IPCC - Intergovernmental Panel on Climate Change

LASER - Light Amplification through Stimulated Emission of Radiation

LIDAR - Light Detection and Ranging

LNA - Laboratório Nacional de Astrofísica

MFRSR - Multifilter Rotating Shadowband Radiometer

MODIS - Moderate Resolution Imaging Spectroradiometer

NASA - National Aeronautic Space Agency

OMM - Organização Mundial de Meteorologia

OPD - Observatório do Pico dos Dias

PFR - Precision Filter Radiometer

PMOD - Physikalisch-Meteorolgisches Observatorium

POA - Profundidade óptica do aerossol

RACCI - Radiation, Cloud, and Climate Interactions

RADAR - Radio Detection and Ranging 


\section{Lista de siglas}

RMSP - Região Metropolitana de São Paulo

SCAR- B - Smoke, Clouds and Radiation in Brazil

SCIAMACHY - Scanning Imaging Absorption SpectroMeter for Atmospheric ChartographY

SmoCC - Smoke, Clouds, Rainfall and Climate

SRA - Sensoriamento Remoto Ativo

SRP - Sensoriamento Remoto Passivo

TOA - Top Of Atmosphere

TOMS - Total Ozone Mapping Spectrometer

U.A. - Unidade Astronômica

USDA - U.S. Department of Agriculture

USP - Universidade de São Paulo

UTC - Universal Time, Coordinated

WRC - World Radiation Center

YESDAS - Yankee Environmental System 


\section{Capítulo 1: Introdução}




\subsection{O aerossol atmosférico e as mudanças climáticas}

O último relatório do Intergovernmental Panel on Climate Change (IPCC) divulgado em 2007 é contundente ao afirmar, com 90\% de confiança, que as atividades humanas são a causa principal do aquecimento global observado nos últimos 50 anos. Também aponta que o acúmulo dos gases de efeito estufa, notadamente o dióxido de carbono, o metano e o óxido nitroso, cujas concentrações atmosféricas são as mais altas em pelo menos 650 mil anos de história do planeta, como os principais responsáveis, e que a sua elevada concentração na atmosfera se deve a atuação humana [NOBRE, 2007]. O autor ainda salienta que atualmente a maioria das pessoas tem certeza de que este é um grave problema para a humanidade e que o Brasil tem um papel fundamental no esforço para a mitigação do aquecimento global, que passa obrigatoriamente pela redução das emissões dos desmatamentos e que isto é possível de ser realizado.

A expressão mudanças climáticas empregada pelo IPCC refere-se a qualquer mudança no clima ocorrida ao longo do tempo, devida à variabilidade natural ou decorrente da atividade humana [IPCC, 2007].

O papel do aerossol nos processos atmosféricos e climáticos, já há algum tempo, tem sido salientado pela comunidade científica internacional. Em 1996 o IPCC avaliou em seu relatório o efeito dos aerossóis atmosféricos como sendo uma das principais fontes de incerteza nos modelos prognósticos de mudanças climáticas. O relatório de 2001 reafirmou que o efeito resultante das partículas de aerossol sobre o balanço de radiação atmosférico e sobre o clima constituía uma das principais fontes de incerteza na tentativa de modelar e prever o clima [IPCC, 2001]. No último relatório divulgado em 2007, o IPCC ressalta que os aerossóis atmosféricos, apesar das melhores condições de medições por satélite, na superfície e de uma modelagem numérica mais abrangente, ainda continuam sendo a principal incerteza na forçante radiativa [IPCC, 2007].

A forçante radiativa (FR) em termos gerais significa uma mudança imposta sobre o balanço de radiação planetário. A definição quantitativa mais simples da FR é de uma mudança instantânea do fluxo radiativo na tropopausa [HANSEN et al., 1997]. Para o IPCC, a FR refere-se à medida da influência de um fator que perturbe o equilíbrio da energia que entra e sai do sistema Terra-atmosfera, representando assim um índice da importância deste fator como possível mecanismo de mudança do clima. A forçante radiativa positiva na superfície tende a aquecê-la, enquanto a forçante negativa tende a esfriá-la. No relatório do IPCC de 
2007 os valores da FR estimados em 2005 são relativos às condições pré-industriais estimadas para 1750, sendo expressos em $\left[\mathrm{W} / \mathrm{m}^{2}\right]$.

Como exemplos de perturbações no balanço energético do sistema Terra-atmosfera, podem ser citados: as alterações na quantidade de radiação solar incidente no topo da atmosfera (TOA), mudanças na composição da atmosfera e nas propriedades ópticas da superfície [HANSEN et al., 1997]. A figura 1.1 apresenta a FR e a incerteza associada a cada um dos agentes relevantes aos modelos prognósticos climáticos utilizados pelo IPCC. Cabe frisar as barras de incerteza da FR atribuídas aos aerossóis devido ao efeito direto e indireto.

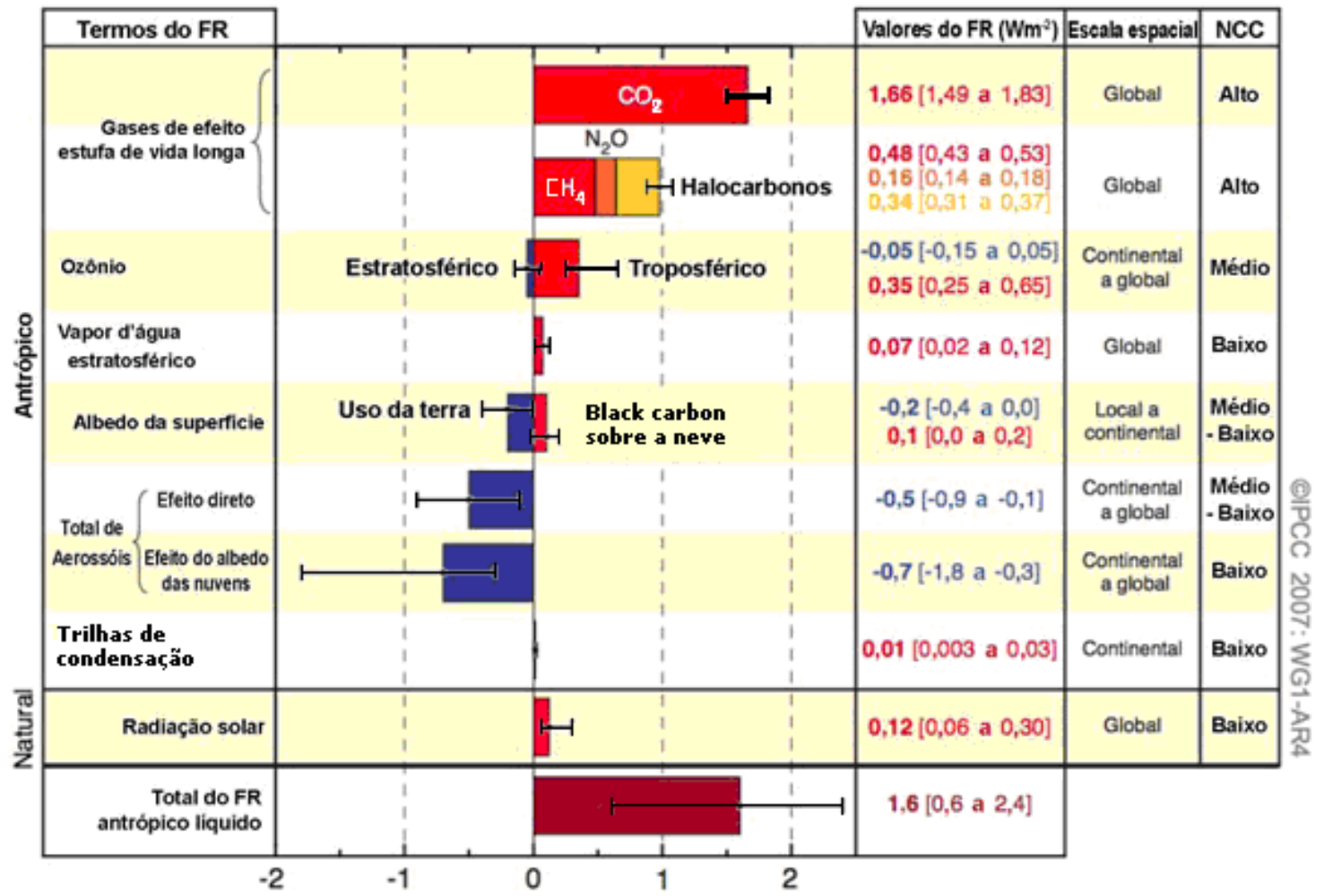

Figuras 1.1 - Estimativas para a forçante radiativa média global (FR), estimada em 2005, atribuída ao dióxido de carbono $\left(\mathrm{CO}_{2}\right)$, metano $\left(\mathrm{CH}_{4}\right)$, óxido nitroso $\left(\mathrm{N}_{2} \mathrm{O}\right)$, aerossóis bem como para outros agentes e mecanismos significativos. Junto com o valor da forçante em $\left[\mathrm{W} / \mathrm{m}^{2}\right]$ são apresentados também a extensão geográfica típica (escala espacial) da FR e o nível de compreensão científica avaliada (NCC). Adaptado -[IPCC, 2007].

No Brasil ao longo destas últimas duas décadas, o papel dos aerossóis nos fenômenos atmosféricos vem despertando a atenção da comunidade científica, principalmente em estudos sobre os aerossóis de queimadas da região amazônica e Brasil central e em menor escala em estudos sobre o aerossol urbano. Alguns destes trabalhos foram auxiliados por campanhas de medições intensivas e extensivas, realizadas no território brasileiro, que contribuíram para uma melhor compreensão das interações das partículas de aerossol 
presentes na atmosfera com a radiação além do estudo e análise de outras variáveis meteorológicas. Cabe salientar algumas das campanhas ocorridas no Brasil como a Smoke, Clouds and Radiation in Brazil (SCAR-B) que ocorreu entre os meses de agosto e setembro de 1995 [TROSNIKOV \& NOBRE, 1995] e as campanhas desenvolvidas no projeto de Large-scale Biosphere-Atmosphere Experiment in Amazon (LBA). Dentro do projeto LBA vale lembrar a campanha de 1998 a Cooperative LBA Airborne Regional Experiment (CLAIRE/LBA), a campanha de 2002 o Radiation, Cloud, and Climate Interactions (RACCI/LBA) e o Smoke, Clouds, Rainfall and Climate (SmoCC/LBA) este último realizado em Rondônia entre os meses de setembro a novembro de 2002 [ANDREAE et al., 2004].

A maior parte dos experimentos e campanhas estava associada, basicamente, ao estudo dos aerossóis atmosféricos de queimadas. O estudo de aerossóis urbanos em amplo espectro e por longo tempo, apesar dos esforços valorosos de alguns grupos de pesquisa acadêmicos e de instituições governamentais, ainda são reduzidos principalmente quanto a estimativas de propriedades ópticas do aerossol no território brasileiro. Trabalhos como os de Miranda [2001] e Corrêa [2003] foram pioneiros em estimar propriedades ópticas espectrais do aerossol em São Paulo obtidas por fotometria solar. Porém, somente nos trabalhos de Castanho [2005] e Rosário [2006] as propriedades ópticas do aerossol urbano de São Paulo obtiveram um tratamento mais sistemático e com uma base de dados maior.

A carência de pesquisas sobre propriedades ópticas espectrais dos aerossóis se deve principalmente a falta de recursos financeiros e humanos na aquisição e principalmente na manutenção (operação, calibração, aferição, conserto, etc) de redes de monitoramento sistemático no território brasileiro principalmente em áreas urbanas densamente povoadas e poluídas. Vale ressaltar os esforços de escassas redes de monitoramento que atuam no Brasil com produtos distintos de aerossóis atmosféricos como os da rede AErosol RObotic NETwork - National Aeronautics and Space Agency (AERONET-NASA) que estima propriedades ópticas do aerossol como a profundidade óptica e o coeficiente de Ångström e de redes como da Companhia de Tecnologia de Saneamento Ambiental de São Paulo (CETESB) que monitora parâmetros da qualidade do ar próximo ao solo como o $\mathrm{MP}_{10}$ (material particulado com diâmetro aerodinâmico menor do que $10 \mu \mathrm{m}), \mathrm{SO}_{2}, \mathrm{NO}_{\mathrm{X}}$, entre outros parâmetros e variáveis meteorológicas [CASTANHO, 2005].

O presente trabalho visa contribuir com os esforços até agora realizados, na tentativa de caracterizar de forma sistemática propriedades ópticas dos aerossóis urbanos de São Paulo e a sua variabilidade sazonal. Esta caracterização foi feita através de metodologia que permite 
estimar a profundidade óptica espectral do aerossol bem como o valor do coeficiente de Ångström via fotometria solar como será detalhado ao longo do trabalho.

\subsection{A Região Metropolitana de São Paulo}

A Região Metropolitana de São Paulo (RMSP), conhecida como Grande São Paulo, reúne 38 municípios mais a capital do Estado de São Paulo apresentando uma configuração chamada de mancha urbana contínua. É o maior centro urbano do Brasil, uma das principais metrópoles da América do Sul e a quinta maior área urbana do mundo. A região metropolitana tem cerca de 19 milhões de habitantes, somando a população dos 39 municípios, ocupando uma área de $8.051 \mathrm{~km}^{2}$ o que a torna a metrópole mais populosa do Brasil. Somente a capital São Paulo tem cerca de 10 milhões de habitantes [SEEP, 2008]. A cidade de São Paulo se localiza aproximadamente no centro da região metropolitana (latitude $-23^{\circ} 32^{\prime}$ e longitude $-46^{\circ} 38^{\prime}$ ) com altitude média de $850 \mathrm{~m}$ acima do nível do mar e cerca de $60 \mathrm{~km}$ de distância do litoral [CASTANHO, 1999].

A configuração espacial da RMSP com a ocupação do solo atual teve como um dos principais fatores determinantes a infra-estrutura de transportes, provocando a transferência ou a instalação de novas fábricas nas suas imediações. Devido a isto, tanto a infra-estrutura rodoviária quanto a ferroviária da região são radiais, centradas no município de São Paulo. A partir da capital originam-se os complexos viários dos Sistemas Anhangüera - Bandeirantes, Dutra - Airton Senna e Anchieta - Imigrantes, além das rodovias Raposo Tavares, Castello Branco, Marechal Rondon e Régis Bittencourt. O movimento de dez grandes rodovias converge para a RMSP unindo-se ao tráfego local. O grande fluxo de veículos que chegam todos os dias a São Paulo e, em grande parte, atravessa a Capital, rumo a outras localidades, ocasiona um imenso gargalo viário, na região. Cabe salientar que o município de São Paulo possui uma das maiores frotas de veículos por habitante do mundo (ao redor de dois habitantes/veículo), o que contribui de forma decisiva para as elevadas concentrações de poluentes na região [CASTANHO, 2005]. A RMSP possui ainda dois dos três maiores aeroportos brasileiros, em movimento de passageiros, o de Cumbica, em Guarulhos, e o de Congonhas, em São Paulo. Em relação aos parâmetros econômicos, o Produto Interno Bruto (PIB) da RMSP representou, em 2003, 49,4\% do PIB do Estado de São Paulo [SEEP, 2008]. A figura 1.2 ilustra o Estado de São Paulo e a mancha urbana nele inserida. 


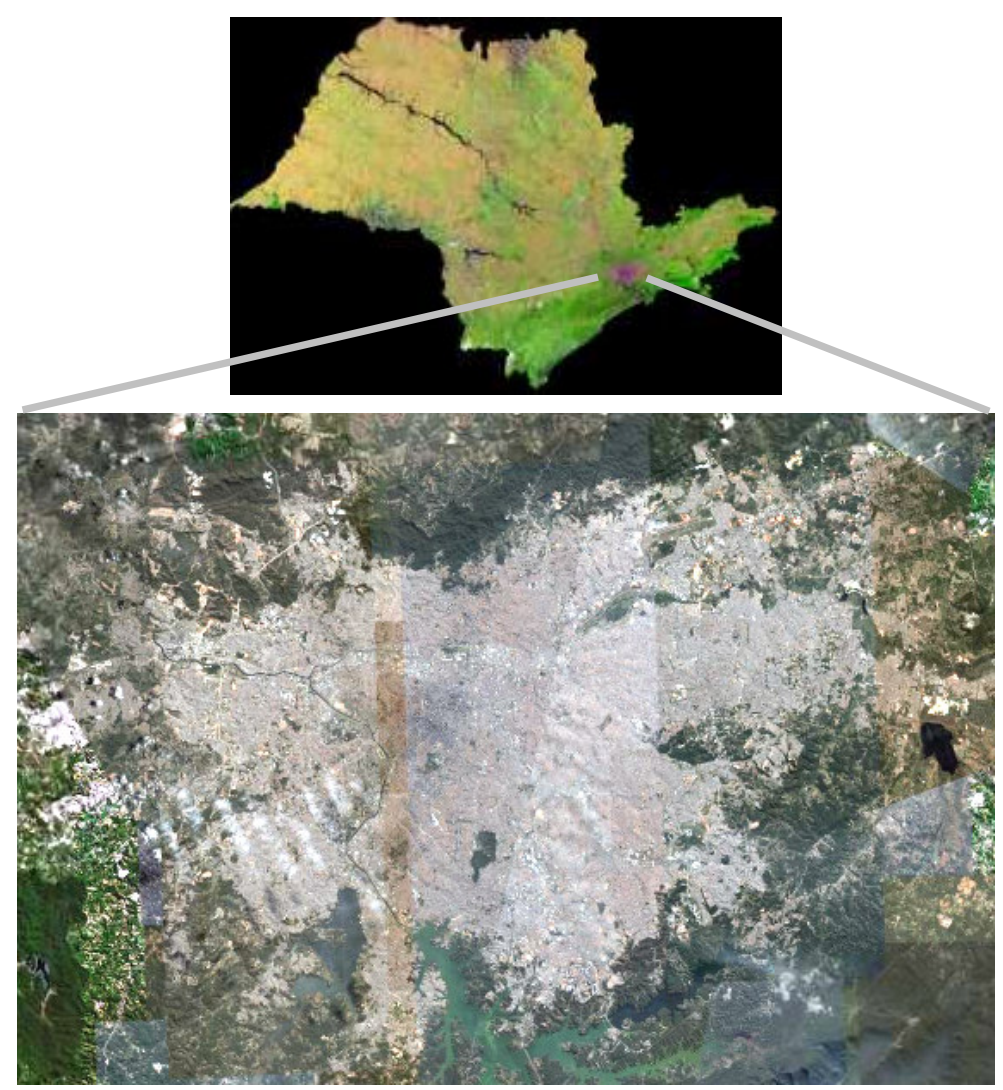

Figura 1.2 - Mancha urbana devido à ocupação do solo na RMSP. A imagem superior apresenta o Estado de São Paulo [Fonte - www.cnpm.embrapa.br, acesso janeiro de 2008] onde a mancha urbana da RMSP já se destaca e na figura inferior é ilustrada a sua ampliação [Fonte - Google Earth, acesso janeiro de 2008].

O clima da RMSP pode ser resumido por duas estações bem marcantes com um verão chuvoso com médias mensais de precipitação acima de $100 \mathrm{~mm}$, de origem marcadamente convectiva, e um inverno seco com precipitação média mensal abaixo de $50 \mathrm{~mm}$ associada, principalmente, ao deslocamento das massas de ar provenientes do sul do país [ROSÁRIO 2006].

Uma característica marcante da região são as chuvas de verão do período úmido. Segundo Pereira Filho et al. [2007] estas têm se intensificado ao longo do tempo na RMSP devido à influência da chamada ilha de calor e também pela circulação da brisa marítima. Os autores também apontam que houve aumento da precipitação, temperatura e redução na umidade relativa do ar média, sugerindo que estas mudanças estejam associadas a influências locais principalmente devido à urbanização horizontal e vertical da região que deu origem a ilha de calor. A região apresenta inverno e outono com dias mais secos, que também são, em média, poluídos e quentes. Ao longo dos anos houve uma mudança na direção dominante das anomalias de vento que até a década de 1970 eram de sudeste com ar mais frio e seco, 
passando para ventos de nordeste trazendo ar mais quente e úmido para a região [PEREIRA FILHO, 2007].

As características climáticas destas duas estações (inverno seco e verão úmido) são determinantes na concentração do material particulado ao longo da coluna atmosférica da RMSP. Quando a região se encontra no período úmido as condições atmosféricas são favoráveis à dispersão e remoção do material particulado, já nas estações secas as condições verificadas não favorecem a dispersão e a remoção dos aerossóis, propiciando concentrações altas de poluentes e de material particulado sobre São Paulo.

\subsection{O aerossol atmosférico}

A definição formal de aerossol é de um sistema constituído de um gás com partículas sólidas ou liquidas em suspensão, com tamanho da ordem de dezenas de nanômetros a centenas de micrômetros [HORVATH, 2000; WALLACE \& HOBBS, 2006]. Porém, classicamente em estudos atmosféricos os constituintes denominados como partículas de aerossol ou simplesmente aerossóis restringem-se apenas às partículas presentes na atmosfera que se distinguem dos hidrometeoros [ROSÁRIO, 2006].

Andrade [2006] considera que, do ponto de vista atmosférico, as partículas mais importantes são aquelas que têm um tempo de residência na atmosfera grande o bastante para interagir com a radiação, na formação de nuvens e com a saúde humana. De uma forma mais rigorosa, são importantes as partículas cujas forças viscosas são significativas no seu movimento.

\subsubsection{Fontes, classificação e remoção do aerossol atmosférico}

O aerossol atmosférico pode ser emitido por diversas fontes que fornecem uma gama de tipos de aerossóis diferentes quanto à geometria, morfologia e composição química.

As fontes podem ser agrupadas basicamente em duas: naturais e antropogênica. As emissões de aerossóis também podem ser caracterizadas por ocorrer por emissão direta a partir de uma fonte poluidora que insere o aerossol na atmosfera ou devido a um processo físico-químico na própria atmosfera onde um gás precursor é convertido em uma partícula (conversão gás-partícula - in situ) [ANDRADE, 2006; WALLACE \& HOBBS, 2006]. A 
composição química do aerossol atmosférico pode ser simples, se ele for homogêneo (constituído por um único composto químico) ou complexa, se heterogêneo, formado por mais de um composto químico. O processo de conversão gás-partícula pode ser resultado de processos homogêneos em fase gasosa, ou pode ser controlado por processos na fase de particulado. Processos na fase gasosa tanto físicos como químicos podem produzir um estado supersaturado que então colapsa para a formação do aerossol [ANDRADE, 2006]. As novas partículas formadas pelo processo de conversão gás-partícula dão origem a aerossóis com diâmetro menor do que $0,01 \mu \mathrm{m}$ [WALLACE \& HOBBS, 2006].

Os aerossóis de emissões naturais podem ser de origem biológica a qual lança para atmosfera sementes, esporos, pólen, fragmentos de animais e plantas que tem um diâmetro entre 1,0 a $250 \mu \mathrm{m}$ bem como bactérias, fungos, algas, protozoários e vírus que normalmente têm diâmetro menor do que $1,0 \mu \mathrm{m}$. Uma importante fonte natural de aerossol são os oceanos que fornecem partículas de aerossol (aerossol marinho) com diâmetro entre 2,0 a $20 \mu \mathrm{m}$ principalmente na forma de sais higroscópicos $\left(\mathrm{NaCl}(\sim 85 \%), \mathrm{KCl}, \mathrm{CaSO}_{4},\left(\mathrm{NH}_{4}\right)_{2} \mathrm{SO}_{4}\right)$ [WALLACE \& HOBBS, 2006]. Vulcões também são importantes fontes de aerossóis na atmosfera. Além de lançarem grandes quantidades de material particulado eles são capazes de transportar estes aerossóis a grandes altitudes em camadas extremamente estáveis termodinamicamente como a estratosfera, o que dificulta a sua remoção e aumenta em muito o seu tempo de residência.

Outra importante fonte natural de aerossóis para a atmosfera são as partículas do solo emitidas devido à ação do vento e da turbulência da atmosfera gerada sobre a superfície. Porém, não só a ação do vento sobre a superfície emite partículas para a atmosfera, queimadas também podem propiciar a emissão de partículas do solo para a atmosfera. Na região amazônica já foi constatado que partículas do solo podem ser emitidas durante a turbulência gerada na própria queimada [YAMASOE, 1999].

As principais fontes antropogênicas de aerossóis são devido ao uso do solo (como a poeira gerada por re-suspensão de estradas e vias), da erosão do vento sobre superfícies cultivadas, queima de biomassa, uso de combustíveis fósseis e processos industriais. $\mathrm{O}$ aerossol de queimadas é lançado na atmosfera diretamente na forma de pequenas partículas de compostos orgânicos primários e de carbono elementar [WALLACE \& HOBBS, 2006]. As queimadas na região amazônica de origem antropogênica, segundo Yamasoe [1999], emitem grandes quantidades de gases e partículas para a atmosfera, estas partículas têm tamanho submicrométrico e são compostas basicamente por material orgânico parcialmente oxidado. 
Em escala global a conversão gás-partícula é mais significativa do que as emissões diretas de aerossóis [HORVATH, 2000; WALLACE \& HOBBS, 2006]. Porém as emissões em áreas urbanas ou em áreas industriais, de caráter antropogênica, são mais significativas que as naturais.

As partículas de aerossol geradas em uma região podem ainda, ser transportadas por centenas a milhares de quilômetros até outras regiões [YAMASOE, 1999; HORVATH, 2000; CASTANHO, 2005; ROSÁRIO, 2006]. Como exemplo de transporte de aerossóis por longas distâncias cabe lembrar o de poeira do deserto do Saara na África até o sul da América do Sul e o aerossol gerado pelo acidente da usina nuclear de Chernobyl que foi detectado a mais de 1000 km de distância do local do acidente [HORVATH, 2000]. O transporte de aerossóis de queimadas da região amazônica e do Brasil central até São Paulo tem sido apontado por alguns autores como Landulfo et al. [2003] e Castanho [2005].

A tabela 1.1 resume algumas estimativas de emissões anuais de aerossóis atmosféricos, sendo agrupadas em fontes antropogênicas e naturais. Cabe frisar que Horvath [2000] agrupa as contribuições anuais de queimadas de floresta e emissões do solo conforme é apresentado na tabela 1.1, como sendo fontes naturais, não separando a contribuição antropogênica da natural.

Tabela 1.1 - Estimativas das contribuições anuais de algumas das principais fontes de aerossol atmosférico, em [Tg/ano]. Adaptado de Horvath [2000].

\begin{tabular}{lc}
\hline Fontes & $\begin{array}{c}\text { Quantidade de partículas produzidas } \\
\text { [ Tg/ano ] }\end{array}$ \\
\hline * Naturais & $100-500$ \\
\hline $\begin{array}{l}\text { Solo } \\
\text { Queimadas de florestas }\end{array}$ & $3-150$ \\
Sal Marinho & 300 \\
Emissões Vulcânicas & $25-150$ \\
Partículas de conversão gás-partícula & \\
$\quad$ Sulfato a partir de $\mathrm{H}_{2} \mathrm{~S}$ & $130-200$ \\
$\quad$ Nitrato a partir de $\mathrm{NO}_{\mathrm{x}}$ & $60-430$ \\
$\quad$ Hidrocarbonetos proveniente de Plantas & $75-200$ \\
Subtotal Natural & $\mathbf{7 7 3 - 2 2 0 0}$ \\
* Antropogênicas & \\
\hline Partículas emitidas diretamente & $10-90$ \\
Partículas de conversão gás-partícula & \\
$\quad$ Sulfatos a partir de $\mathrm{SO}_{2}$ & $130-200$ \\
$\quad$ Nitratos a partir de $\mathrm{NO}_{\mathrm{x}}$ & $30-35$ \\
$\quad$ Hidrocarbonetos & $15-90$ \\
Subtotal Antropogênico & $\mathbf{1 8 5}-\mathbf{4 1 5}$ \\
Total $\quad$ & $\mathbf{9 5 8}$ - 2615 \\
\hline
\end{tabular}

* Onde $1,0 \mathrm{Tg} / \mathrm{ano}=1,0 \times 10^{12} \mathrm{~g}$ de aerossol emitido em um ano. 
Ao contrário dos gases do efeito estufa, cuja concentração e distribuição em todo globo é praticamente constante, a variabilidade de tipos de aerossol, com diferentes propriedades ópticas, ocorre tanto espacial quanto temporal devido à sua curta permanência na atmosfera e também às diversas fontes emissoras [HOLBEN et al., 1996]. O tempo de residência das partículas de aerossóis na atmosfera pode variar de minutos a horas para partículas menores do que $0,001 \mu \mathrm{m}$ e maiores do que $100 \mu \mathrm{m}$ e de uma semana para partículas entre 0,05 a 2,0 $\mu \mathrm{m}$, porém partículas lançadas na estratosfera podem alcançar tempo de residência de meses a anos [HORVATH, 2000].

Com relação ao tamanho das partículas de aerossol e as fontes, de acordo com Castanho [1999], na região metropolitana de São Paulo, as principais fontes de aerossol na fração fina (partículas com diâmetro aerodinâmico menor que 2,0 $\mu \mathrm{m}$ ) são: emissão veicular, poeira do solo, queima de óleo combustível, compostos contendo sulfato e indústrias. Para a fração grossa (partículas de aerossol com diâmetro aerodinâmico de 2,0 e $10 \mu \mathrm{m}$ ), a autora também relaciona a poeira do solo, emissão industrial e sal marinho como as principais fontes em São Paulo.

A figura 1.3 representa a classificação por tamanho dos aerossóis (partículas ultrafinas, núcleos de Aitken, aerossóis da moda de acumulação e partículas grossas), dos principais processos que ocorrem com o aerossol na atmosfera (conversão gás-partícula, coagulação, etc), as principais formas de remoção (seca e úmida) e algumas fontes dos aerossóis . 

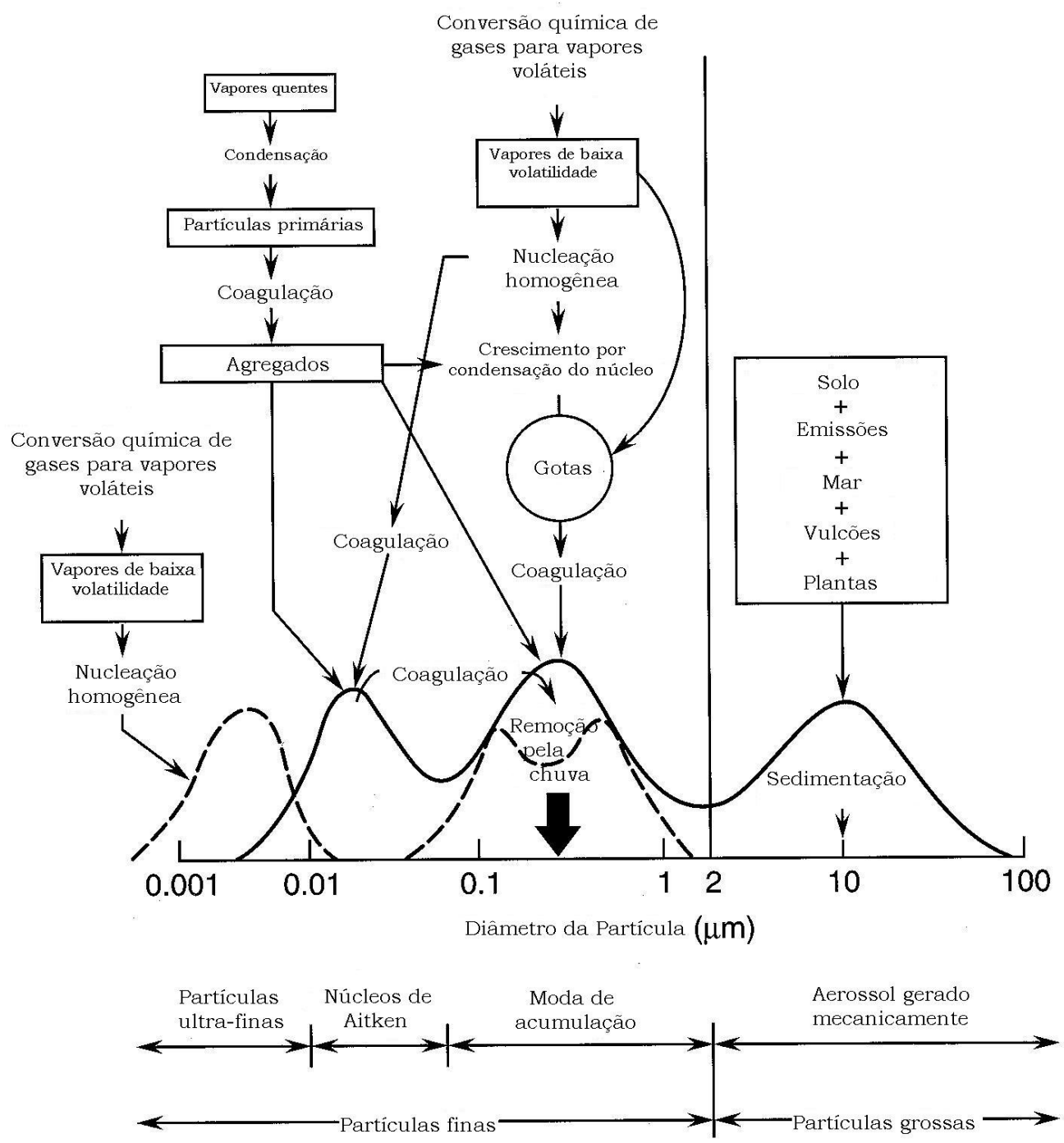

Figura 1.3 - Representação esquemática da distribuição de tamanho das partículas de aerossol atmosférico, ilustrando as várias modas de distribuição de tamanho, algumas fontes, os principais processos envolvidos no crescimento da partícula e formas de remoção. Fonte Andrade [2006].

Andrade [2006] lembra que os processos físicos e químicos que determinam a forma da distribuição de tamanho do aerossol podem ser resumidos em processos ocorrendo dentro do elemento de volume em estudo: nucleação, condensação e coagulação; e os processos de transporte para dentro e fora do elemento de volume como a difusão e a sedimentação. $\mathrm{O}$ tempo de residência do aerossol na atmosfera é regulado pelos processos de remoção que classicamente são divididos em dois: deposição seca e úmida [HORVATH, 2000]. Como exemplos de mecanismos de deposição seca têm-se a sedimentação e a difusão, e de deposição úmida, os processos de remoção que ocorrem dentro e abaixo das nuvens [YAMASOE, 1999]. 


\subsubsection{A interação do aerossol atmosférico com a radiação solar}

As partículas de aerossol interagem direta e indiretamente com a radiação solar. O efeito direto ocorre por sua capacidade em absorver e espalhar a radiação solar, enquanto que o efeito indireto é causado por atuarem como núcleos de condensação de nuvens. Embora o espalhamento e o efeito indireto auxiliem a resfriar a atmosfera e a superfície, agindo no sentido inverso do efeito estufa, a propriedade de absorção pode influenciar o clima de diferentes maneiras, podendo aquecer e tornar a atmosfera mais estável, por um lado, e inibir a evapotranspiração e, por conseguinte, a formação de nuvens, por outro (KOREN et al., 2004).

Em contraste com os gases do efeito estufa que interagem majoritariamente com a radiação em comprimentos de onda no espectro do infravermelho, as partículas de aerossóis podem influir no balanço de radiação na atmosfera tanto por interagir com a radiação solar bem como com a radiação no infravermelho. Em geral partículas com diâmetros menores que 1,0 $\mu \mathrm{m}$ apresentam alta eficiência no espalhamento da radiação solar incidente no topo da atmosfera. Como conseqüência, estas partículas reduzem o valor da energia solar incidente na superfície contribuindo para o resfriamento da Terra [PANDIS \& SEINFELD, 1998]. Os aerossóis ao interagirem com a radiação solar na atmosfera promovem a atenuação do feixe direto da radiação bem como a produção de radiação difusa por espalhamento; a própria absorção atmosférica pode ser intensificada conforme a composição química das partículas em questão [Shaw, 1983].

A magnitude da profundidade óptica do aerossol e a sua dependência com o comprimento de onda da radiação incidente constituem informações necessárias à avaliação dos efeitos do material particulado em suspensão na atmosfera (aerossol) sobre o balanço radiativo e sobre o tempo de exposição do ser humano à radiação ultravioleta [WENNY et al., 1998, 2001]. A relevância da profundidade óptica espectral do aerossol (POA) está na proporcionalidade entre esta e a concentração de partículas em toda coluna vertical da atmosfera. A POA representa, resumidamente, um fator de atenuação exponencial do feixe direto da radiação solar ao atravessar a atmosfera, devido à interação com os aerossóis enquanto que a dependência espectral fornece informações sobre a distribuição de tamanho dos aerossóis [MCARTHUR et al., 2003]. 


\subsection{Sensoriamento remoto}

O sensoriamento remoto basicamente é definido como uma técnica para se obter informações sobre algo através de dados coletados por instrumentos que não estejam em contato físico com os elementos investigados. Assim o sensoriamento remoto é diferente de medições realizadas in situ nas quais as observações específicas são feitas dentro do meio que se estuda (como as realizadas na superfície ou a bordo de aeronaves). Ele envolve a interpretação e inversões de medidas de radiação eletromagnética, tomadas a alguma distância do meio que se quer medir [LIOU, 2002]. Por não haver o contato físico entre o sensor e o elemento que se investiga, a forma de transmissão dos dados (do objeto para o sensor) é obtida por interações da radiação eletromagnética com o elemento em estudo.

O sensoriamento remoto pode ser agrupado em dois tipos: ativo e o passivo e ambos têm sido utilizados no sensoriamento remoto do aerossol a partir da superfície [HOLBEN et al., 1998; LIOU, 2002; LANDULFO et al., 2003]. O sensoriamento remoto ativo (SRA) emprega radiações de fontes artificiais como as geradas pelos Light Amplification through Stimulated Emission of Radiation (LASER) usados em sistemas de detecção do tipo Light Detection and Ranging (LIDAR). Outra forma de SRA é o que emprega fontes de microondas em Radio Detection and Ranging (RADAR) que freqüentemente são empregados em estimativas de precipitação e estudos de micro-física de nuvens. O SRA emprega o princípio de detecção e análise do retro-espalhamento (backscattering) da radiação que foi emitida, interagiu com o meio e o alvo a ser estudado e retornou ao sensor [LIOU, 2002].

O sensoriamento remoto passivo (SRP) emprega no seu processo de detecção fontes naturais de radiação (radiação solar) ou a emitida pelo sistema Terra-atmosfera (radiação de onda longa). O SRP permite estimativas globais tanto para informações da superfície como para a atmosfera [LIOU, 2002]. O SRP é uma das técnicas mais empregadas em estimativas de propriedades ópticas dos aerossóis tanto com a instrumentação instalada na superfície (fotometria solar) quanto por sensores abordo de satélites. O emprego de sensoriamento remoto passivo por fotometria solar será um dos principais objetos de estudo deste trabalho sendo detalhado no capítulo que tratará sobre a instrumentação empregada. 


\subsubsection{Sensoriamento remoto dos aerossóis}

O monitoramento de aerossóis atmosféricos pode ser feito por medidas realizadas na superfície, porém este tipo de monitoramento fornece resultados localizados e representativos somente dos níveis atmosféricos mais próximos da superfície, pois várias características das partículas de aerossol podem apresentar variações com a vertical [YAMASOE, 1999]. Estas medidas são empregadas principalmente em estudos que envolvem poluição atmosférica e saúde humana. Outra característica importante é que em geral medidas realizadas em aeronaves e na superfície alteram as propriedades das partículas, seja por secá-las ou por causa da volatização de certos compostos constituintes das partículas de aerossol. O sensoriamento do aerossol ainda pode ser feito por sensores abordo de satélites. Apesar da sua abrangência espacial, o emprego desta técnica de monitoramento exige a elaboração de modelos físicos para as partículas de aerossol [YAMASOE, 1999].

Dentro deste contexto a fotometria solar tem sido amplamente utilizada no monitoramento do aerossol a partir de fotômetros solares e radiômetros multi-espectrais [SHAW, 1983]. Isso se deve à simplicidade de sua base conceitual associada à alta qualidade dos seus dados [ROSÁRIO, 2006]. A vantagem da fotometria solar reside no fato de permitir a determinação de parâmetros micro-físicos das partículas presentes em toda a coluna vertical da atmosfera em condições ambientais, ou seja, sem alterar o ambiente ou as partículas nele inseridas além de propiciar estudos de longo prazo. A desvantagem da fotometria solar está na falta de informações quanto à distribuição vertical das partículas de aerossol [YAMASOE, 1999].

Historicamente, a observação da redução da intensidade da luz (atenuação) ao atravessar a atmosfera, foi quantificada pela primeira vez em 23 de novembro de 1725, na Bretanha (França) por Pierre Bouguer. Avanços tecnológicos no século XIX proporcionaram a substituição de estimativas visuais da atenuação da luz por medidas de sensores constituídos por termo-pilhas. No século XX, com o desenvolvimento da indústria química e de lentes, foram construídos os primeiros filtros empregados em novos sensores termodinâmicos, o que melhorou tanto a qualidade das observações como propiciou refinar o espectro de leitura dos detectores. A evolução tecnológica da óptica e da eletrônica tem contribuído no desenvolvimento da fotometria solar principalmente a partir da década de 1960, com o advento dos sensores foto-diodo, fabricados a partir de materiais semicondutores [SHAW, 1983]. Vale lembrar que o precursor dos modernos fotômetros solares foi originalmente 
desenvolvido em 1959, sendo chamado de Voltz hand-held photometer, e possuía apenas duas bandas espectrais especificamente desenhadas para medir a turbidez atmosférica [ROLLIN, 2003].

Os instrumentos empregados na técnica de fotometria solar, atualmente são constituídos por um radiômetro capaz de medir o componente direto da radiação solar incidente por um estreito campo de visão (da ordem de $1^{\circ}$ a $3^{\circ}$ ) passando também por filtros de interferência com bandas de transmissão estreitas, da ordem de 6,0 a $10 \mathrm{~nm}$ [ROLLIN, 2003]. Outros instrumentos são capazes de estimar o componente direto espectral da radiação solar empregando técnicas de sombreamento do disco solar, sem restringir o campo visual de detecção, denominados como radiômetros multi-espectrais [HARRISON \& MICHALSKY, 1994].

Nas últimas décadas, observações de irradiância solar espectral direcional, efetuadas com radiômetros do tipo Multi-Filter Rotating Shadowband Radiometer (MFRSR) têm sido analisadas de forma a estimar propriedades atmosféricas integradas acima do plano de observação, como a profundidade óptica espectral do aerossol (POA), o conteúdo atmosférico do vapor d'água, do ozônio e do dióxido de nitrogênio [MICHALSKY et al., 1995; ALEXANDROV et al., 2002a, 2002b].

A acurácia nas estimativas de propriedades ópticas da atmosfera obtidas por fotometria solar depende também de características físicas instrumentais dos detectores empregados, principalmente com relação à sensibilidade e a estabilidade na detecção da radiação solar ao longo do tempo. A estabilidade da detecção ainda continua sendo um dos principais desafios da fotometria solar [SHAW, 1983; ROLLIN, 2003; ROSÁRIO, 2006]. A calibração consiste em estimar a chamada constante solar espectral que é o valor da radiação solar monocromática estimada para o topo da atmosfera com um determinado instrumento segundo a sua função filtro espectral. Classicamente, segundo Shaw [1983], a constante solar espectral é estimada pelo método de Langley Plot, aplicável em localidades com atmosfera limpa como em topo de montanha, o que restringe o seu uso, como será discutido no trabalho. Este fato pode exigir o emprego de outras metodologias, como o Método Geral, proposto por Forgan [1994], para a estimativa da constante solar com medidas no local de operação do instrumento. Segundo recomendações da Organização Mundial de Meteorologia (OMM) a incerteza aceitável na estimativa espectral da POA deve ficar em torno de 0,02 e sugere como valor ideal 0,01 . Por este motivo erros maiores do que $2,0 \%$ na constante solar podem acarretar erros maiores do que o recomendado pela OMM [SHAOCAI et al., 2000]. Quanto à estabilidade dos detectores, cabe salientar que a resposta espectral dos mesmos, a 
sensibilidade térmica e a eficiência de transmissão dos filtros espectrais podem comprometêla [ROSÁRIO, 2006].

Algumas redes mundiais de monitoramento da atmosfera empregam fotômetros solares e radiômetros multi-espectrais. Entre as mais conhecidas, em escala global, se destaca a rede AERONET - NASA, que também atua no Brasil, empregando fotômetros solares Cimel Eletronique 318A e a rede Global Atmosphere Watch programme (GAW) que pertence a World Meteorological Organization (WMO ou em português OMM) a qual utiliza instrumentos do tipo Precision Filter Radiometers (PFRs) desenvolvidos e fabricados pela Physikalisch-Meteorolgisches Observatorium / World Radiation Center (PMOD/WRC) de Davos, Suiça [MCARTHUR et al., 2003]. Redes de monitoramento nos Estados Unidos (USA) têm empregado também radiômetros do tipo MFRSR como a rede do U.S. Department of Agriculture (USDA) [MCARTHUR et al., 2003]. Outras redes regionais têm utilizado os radiômetros MFRSR como instrumento padrão para o monitoramento de propriedades ópticas dos aerossóis entre elas cabe citar a Quantitative Links Program e a Atmospheric Radiation Measurement (ARM) [MICHALSKY et al., 2001].

Em São Paulo as primeiras medidas de radiação solar espectral que permitissem estimativas de propriedades ópticas do aerossol de forma sistemática, contínua e acurada só foram obtidas a partir de agosto de 1999 [PLANA-FATTORI, 2004]. Nesta data o primeiro MFRSR pertencente ao Departamento de Ciências Atmosféricas (DCA) do Instituto de Astronomia, Geofísica e Ciências Atmosféricas da Universidade de São Paulo (IAG-USP) foi instalado junto ao prédio da Estação Meteorológica (EM) do IAG-USP localizado no bairro da Água Funda (Latitude -2339'03', e Longitude -46³7'19'’). Posteriormente outro radiômetro do mesmo tipo também foi instalado neste mesmo sítio operando em conjunto, e por vezes, de forma intercalada até janeiro de 2003. Estes radiômetros serão chamados no decorrer do trabalho pelo seu respectivo número de série 434 e 435 ou simplesmente como MFR-434 e MFR-435. No final do ano de 2000 foi instalado no topo Edifício Pelletron, que faz parte do Instituto de Física da USP, localizado na Cidade Universitária (Latitude $-23^{\circ} 33^{\prime} 42^{\prime \prime}$ e Longitude $\left.-46^{\circ} 44^{\prime} 06^{\prime \prime}\right)$, um fotômetro solar Cimel (CE318A) pertencente a rede AERONET. No período que compreende a instalação e operação do fotômetro solar da rede AERONET e o final do ano de 2002 foi possível monitorar simultaneamente características ópticas do aerossol entre os dois sítios que distam um do outro cerca de $15 \mathrm{~km}$. Em abril de 2003, após conserto e calibração no fabricante, o MFR-435 foi instalado junto ao sítio do fotômetro solar na Cidade Universitária aproximadamente a três metros um do outro, e em de julho de 2004 o MFR-434 também foi instalado no mesmo sítio, possibilitando estudos que 
compararam as duas bases de dados como os realizados por Rosário [2006] e alguns, de forma complementar, no presente trabalho.

\subsection{Objetivos}

O presente trabalho visou, através de observações de irradiância solar espectral direcional, medidas por radiômetros do tipo MFRSR em quatro regiões do espectro solar (415; 672; 870 e 1036nm), estimar valores espectrais de profundidade óptica do aerossol e coeficiente de Ångström seguindo procedimentos clássicos no tema [SHAW, 1976, 1983], admitindo-se a validade da Lei de Beer, Bouguer e Lambert para regiões espectrais com largura da ordem de 10nm e pouco influenciadas pela absorção gasosa.

Objetivou-se também estudar e adaptar uma metodologia de calibração que forneça valores acurados e precisos para a constante solar espectral permitindo correções da degradação da calibração dos radiômetros MFRSR, de forma independente, ao longo do tempo. Com isso possibilitar o estudo da variabilidade sazonal da POA e do coeficiente de Ångström em São Paulo no período de agosto de 1999 a dezembro de 2006.

Como objetivo complementar verificou-se a relação entre propriedades ópticas do aerossol urbano de São Paulo e variáveis meteorológicas, medidas na EM-IAG-USP no período entre 1999 a dezembro de 2002, enquanto os MFRSR permaneceram lá instalados. Neste estudo também buscou-se identificar dias nos quais ocorreram transporte de aerossóis de queimadas em São Paulo distinguindo-os dos dias quando as fontes locais eram predominantes, através das características ópticas estimadas para estes aerossóis. 


\section{Capítulo II: Fundamentação Teórica}




\subsection{A radiação solar}

O processo mais importante responsável pela transferência de energia na atmosfera ocorre através da radiação eletromagnética. A luz visível (de comprimento de onda entre 0,4 a $0,76 \mu \mathrm{m})$, raios $\mathrm{X}$ e gama, luz ultravioleta, radiação infravermelha, microondas, sinais de televisão e de rádio constituem o espectro eletromagnético [LIOU. 2002]. Apesar da variabilidade do espectro eletromagnético em relação a suas propriedade e fontes, as radiações mantêm características em comum podendo ser descritas como resultado da combinação de um campo elétrico e de um campo magnético que se propagam através do vácuo à mesma velocidade (a velocidade da luz). Essa é a descrição clássica da teoria do eletromagnetismo de Maxwell [HALLIDAY et al., 1996]. A figura 2.1 apresenta uma representação esquemática do espectro eletromagnético.

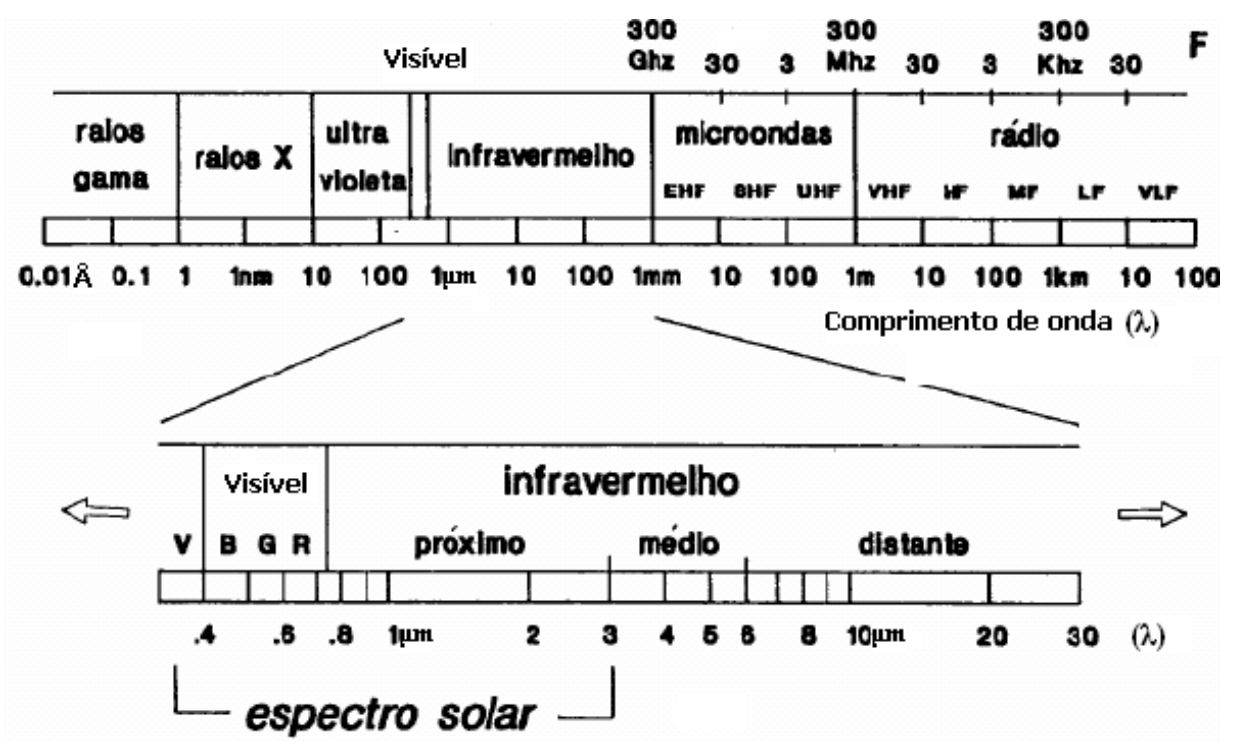

Figura 2.1 - Representação esquemática do espectro eletromagnético em função do comprimento de onda e da freqüência $(F)$. Na figura é destacada a faixa de radiação correspondente ao visível entre 0,4 a $0,76 \mu \mathrm{m}$ e o espectro do infravermelho. Adaptado Apostila Sensor-Rem-INPE em: http://www.fca.unesp.br/intranet/celia.php. Acesso em: 11 janeiro de 2008.

Em 1900, o cientista alemão Max Planck com a intenção de conciliar as leis de radiação existentes com as curvas de distribuição espectrais obtidas experimentalmente desenvolveu uma teoria que resultou na equação de corpo negro, com a criação da constante que recebe o seu nome $\left[\mathrm{h}=6,63 \times 10^{-34} \mathrm{~J} . \mathrm{s}\right]$ e a idéia de quanta de energia. Planck conseguiu assim unir os resultados positivos obtidos com as teorias idealizadas por Lorde Rayleigh e 
James Jeans (Rayleigh-Jeans) com base na teoria clássica e a de Wilhelm Wien que tem como princípio a distribuição de velocidade de Maxwell para moléculas de um gás ideal.

Porém, somente em 1905 é que Albert Einstein fez uma suposição notável, a partir da teoria de Planck, sobre a natureza da luz e sua interação com a matéria, de que sob certas circunstâncias ela se comporta como se sua energia estivesse concentrada de forma discreta em pacotes, os fótons, e não de forma contínua como descrita até então pela teoria clássica [HALLIDAY et al., 1996]. Einstein definiu assim que a energia $\left[\mathrm{E}_{\mathrm{f}}\right]$ de cada fóton era igual ao produto da constante de Planck [h] e de sua freqüência de oscilação (v), lembrando que $(v=c / \lambda)$ e c é a velocidade da luz no vácuo, obtendo assim a expressão:

$$
E_{f}=h v=\frac{h \cdot c}{\lambda}
$$

Com as descobertas dos primórdios da Física Quântica e o seu desenvolvimento, foi possível descrever e determinar com precisão e acurácia a distribuição espectral da radiação solar que chega ao topo da atmosfera opticamente ativa [TOA, do inglês Top Of Atmosphere] bem como aprimorar os modelos e teorias que descrevem a geração da radiação emitida pelo Sol.

Vale ressaltar que a radiação solar é emitida em todo espectro eletromagnético, porém ela é mais intensa na região do visível com um pico ao redor de $550 \mathrm{~nm}$ [HALLIDAY et al., 1996]. O valor da constante solar integrada em todo espectro solar é de $\left(1367 \pm 3 \mathrm{~W} / \mathrm{m}^{2}\right)$ do qual aproximadamente $50 \%$ deste valor corresponde à radiação no infravermelho, $40 \%$ no visível e $10 \%$ em comprimentos de onda mais curtos do que o visível (ultravioleta, raios X e gama). Um ponto importante a ser ressaltado é a não linearidade do espectro de radiação emitido pelo Sol que chega ao TOA. Isto se deve ao fato de algumas linhas do espectro de radiação solar serem extintas antes de chegar a Terra, ou seja, no próprio Sol. Esta extinção decorre da absorção de compostos como metais, hidrogênio, cálcio, magnésio e outros elementos presentes na fotosfera e coroa solar. Esses espectros de absorção são denominados como Linhas de Fraunhofer, em homenagem ao seu descobridor [KEPLER, 2004]. Já no interior da atmosfera, a radiação solar espectral incidente e a refletida pela superfície, sofre um conjunto de processos radiativos que depende dos constituintes atmosféricos opticamente ativos e de sua distribuição ao longo do tempo e do espaço, ou seja, depende do meio de propagação. 


\subsection{A atmosfera terrestre}

A atmosfera terrestre é composta por um grupo de gases com concentração praticamente constante e outro grupo com concentração variável. A fração seca da atmosfera (sem vapor d'água) é formada por $99 \%$ de nitrogênio $\left(\mathrm{N}_{2}\right)$ e oxigênio $\left(\mathrm{O}_{2}\right)$ e de $1 \%$ de argônio e outros gases, como ilustra a Tabela 2.1. Os demais constituintes gasosos da atmosfera são os chamados gases traço, que apesar da sua baixa concentração são importantes nos processos radiativos [WALLACE \& HOBBS, 2006].

O dióxido de carbono $\left(\mathrm{CO}_{2}\right)$ embora constitua apenas cerca de $0,03 \%$ da atmosfera da Terra é essencial para a fotossíntese, além de participar do efeito estufa que propicia a estabilidade da temperatura média da superfície da Terra. Isto se deve à propriedade do $\mathrm{CO}_{2}$ em absorver radiação no infravermelho e reter parte desta energia, que seria perdida para o espaço, dentro do sistema Terra-atmosfera. O percentual de dióxido de carbono vem crescendo principalmente devido à ação antropogênica com a queima de biomassa e combustíveis fósseis como o carvão, petróleo e gás natural, intensificando assim o seu papel no efeito estufa, o que vem causando um desequilíbrio no sistema [IPCC, 2007].

O vapor d'água é um dos constituintes mais variáveis na atmosfera. Nos trópicos pode representar mais do que $4 \%$ do volume da baixa atmosfera, enquanto que sobre os desertos e regiões polares pode representar apenas $1 \%$. O vapor d'água também tem grande capacidade de absorver a radiação disponível, tanto a de onda longa quanto em algumas faixas do espectro solar [SOKOLIK, 2008]. 
Tabela 2.1 - Composição química média da atmosfera. Adaptado de Sokolik [2008]

\begin{tabular}{|c|c|c|}
\hline Gases & Volume $(\%)$ & Características \\
\hline \multicolumn{3}{|c|}{ Gases Constantes } \\
\hline Nitrogênio, $\mathrm{N}_{2}$ & 78,08 & $\begin{array}{c}\text { Alta dissociação fotoquímica na } \\
\text { ionosfera, bem misturado para baixos } \\
\text { níveis }\end{array}$ \\
\hline Oxigênio, $\mathrm{O}_{2}$ & 20,95 & $\begin{array}{l}\text { Dissociação fotoquímica acima de } \\
90 \mathrm{~km} \text {, misturado nos baixos níveis }\end{array}$ \\
\hline Argônio, Ar & 0,93 & Bem misturado acima de $110 \mathrm{~km}$ \\
\hline Neônio, $\mathrm{Ne}$ & 0,0018 & \multirow{4}{*}{$\begin{array}{l}\text { Mistura em maior parte na média } \\
\text { atmosfera }\end{array}$} \\
\hline Hélio, He & 0,0005 & \\
\hline Criptônio, $\mathrm{Kr}$ & 0,0001 & \\
\hline Xenônio, Xe & 0,000009 & \\
\hline \multicolumn{3}{|c|}{ Gases variáveis } \\
\hline Vapor d'água, $\mathrm{H}_{2} \mathrm{O}$ & $\begin{array}{c}\text { 4,0\% (trópicos) } \\
0,0001 \% \text { (Pólo sul) }\end{array}$ & $\begin{array}{l}\text { Altamente variável; } \\
\text { fotodissociado acima de } 80 \mathrm{~km}\end{array}$ \\
\hline $\begin{array}{l}\text { Dióxido de Carbono, } \\
\qquad \mathrm{CO}_{2}\end{array}$ & $\begin{array}{c}0,0365 \% \text { (tendência de } \\
\text { aumento a uma taxa de } 0,4 \% \\
\text { por ano) }\end{array}$ & $\begin{array}{l}\text { Pouco variável à superfície; bem } \\
\text { misturado acima de } 100 \mathrm{~km}\end{array}$ \\
\hline Metano, $\mathrm{CH}_{4}$ & $\begin{array}{c}0,00018 \% \text { (tendência de } \\
\text { aumento devido à agricultura) }\end{array}$ & $\begin{array}{c}\text { Misturado na troposfera; dissociado na } \\
\text { estratosfera }\end{array}$ \\
\hline Hidrogênio, $\mathrm{H}_{2}$ & $0,00006 \%$ & Produto de reaçôes fotoquímicas \\
\hline Óxido Nitroso, $\mathrm{N}_{2} \mathrm{O}$ & $0,00003 \%$ & $\begin{array}{c}\text { Pouco variável à superfície; dissociado } \\
\text { na estratosfera e mesosfera }\end{array}$ \\
\hline $\begin{array}{l}\text { Monóxido de carbono, } \\
\text { CO }\end{array}$ & $0,000009 \%$ & Variável \\
\hline Ozônio, $\mathrm{O}_{3}$ & $0,000001 \%-0,0004 \%$ & $\begin{array}{l}\text { Altamente variável; } \\
\text { de origem fotoquímica }\end{array}$ \\
\hline $\begin{array}{l}\text { Clorofluorcarbonetos, } \\
\qquad \mathrm{CF}_{2} \mathrm{Cl}_{2}\end{array}$ & $\sim 0,00000005 \%$ & $\begin{array}{c}\text { Misturado na troposfera; dissociado na } \\
\text { estratosfera }\end{array}$ \\
\hline
\end{tabular}

Outro importante gás na atmosfera é o ozônio $\left(\mathrm{O}_{3}\right)$, mesmo que apresente baixa concentração em relação a outros gases e de sua distribuição espacial e temporal não uniforme. O ozônio concentra-se majoritariamente entre 10 e $50 \mathrm{~km}$ e é encontrado em quantidades bem menores na baixa atmosfera entre o ar poluído das cidades onde é gerado 
principalmente por processos fotoquímicos entre a radiação solar e gases precursores como os óxidos de nitrogênio $\left(\mathrm{NO}_{\mathrm{x}}\right)$ e os compostos orgânicos voláteis (COVs) [ANDRADE, 2006]. Ele apresenta um pico de concentração em torno de $30 \mathrm{~km}$ na região da estratosfera e sua distribuição também varia com a latitude, estação do ano, horário, padrões de tempo e variabilidade da atividade solar. A formação do ozônio na camada entre 10 e $50 \mathrm{~km}$ é resultado de uma série de processos que envolvem a absorção de radiação solar e dissociação do oxigênio molecular em atômico após interação com a radiação solar na faixa do ultravioleta.

O conteúdo total de ozônio integrado na coluna atmosférica é comumente expresso em Unidades Dobson (DU) que corresponde à espessura que a coluna de ozônio poderia ocupar à temperatura e pressão padrão $(273 \mathrm{~K}$ e 1,0 atm). Assim 1,0 DU vale $\left(1,0 \times 10^{-3}\right.$ atm.cm) que corresponde aproximadamente a $\left(2,69 \times 10^{16}\right.$ moléculas $\left./ \mathrm{cm}^{2}\right)$, lembrando que $\left(1 \mathrm{ppb}=2,5 \times 10^{10}\right.$ moléculas $\left./ \mathrm{cm}^{3}\right)$, ao nível do mar e à temperatura de $298 \mathrm{~K}$.

A atmosfera também mantém em suspensão partículas de aerossóis emitidas por fontes naturais e antropogênicas. Uma vez na atmosfera, elas podem participar de vários processos, de acordo com as suas características físicas e morfológicas, como a formação de gotas de nuvens (como núcleos de condensação de nuvens - NCN ou $\mathrm{CCN}$ ) e nas interações com a radiação solar e terrestre. Com exceção do aerossol inserido na estratosfera principalmente pela ação de vulcões, os demais ficam confinados nas primeiras camadas mais densas da atmosfera, principalmente na troposfera. Como já foi comentado, os aerossóis atmosféricos, apresentam alta variabilidade tanto espacial quanto temporal além de um importante impacto na FR [IPCC, 2007] o que justifica os investimentos no seu monitoramento e estudo.

\subsection{Interação da atmosfera com a radiação solar}

Os fenômenos físicos de espalhamento e absorção da radiação por gases e partículas de aerossóis contribuem para a extinção da radiação solar e terrestre que atravessa a atmosfera [WALLACE \& HOBBS, 2006]. A extinção da radiação pode ocorrer pela mudança de direção da radiação incidente, por espalhamento, evitando desta forma que a mesma chegue à superfície da Terra, o que também produz radiação difusa. A atenuação ocorre também pela absorção de faixas do feixe direto da radiação incidente transformando-o em uma nova forma 
de energia (térmica, cinética, etc). Assim, a radiação solar que se propaga através da atmosfera, sofre o fenômeno de atenuação ao interagir com os constituintes atmosféricos.

Entre os constituintes atmosféricos absorvedores é importante citar o ozônio, vapor d'água e partículas de aerossóis absorvedoras. A atenuação da radiação solar incidente, pelo processo de espalhamento, ocorre principalmente pela interação com as moléculas de oxigênio e nitrogênio presentes na atmosfera (espalhamento Rayleigh), por pequenas partículas de aerossóis e gotas de nuvens. Estes processos físicos são linearmente dependentes da concentração local dos gases e partículas ao longo do caminho óptico da radiação [WALLACE \& HOBBS, 2006]. A figura 2.2 ilustra as curvas de irradiância solar espectral que incide no TOA, a que incide no solo ao nível médio do mar depois de sofrer atenuação atmosférica, representada pelas depressões na curva e a emissão de um corpo negro à temperatura de $5.900 \mathrm{~K}$.

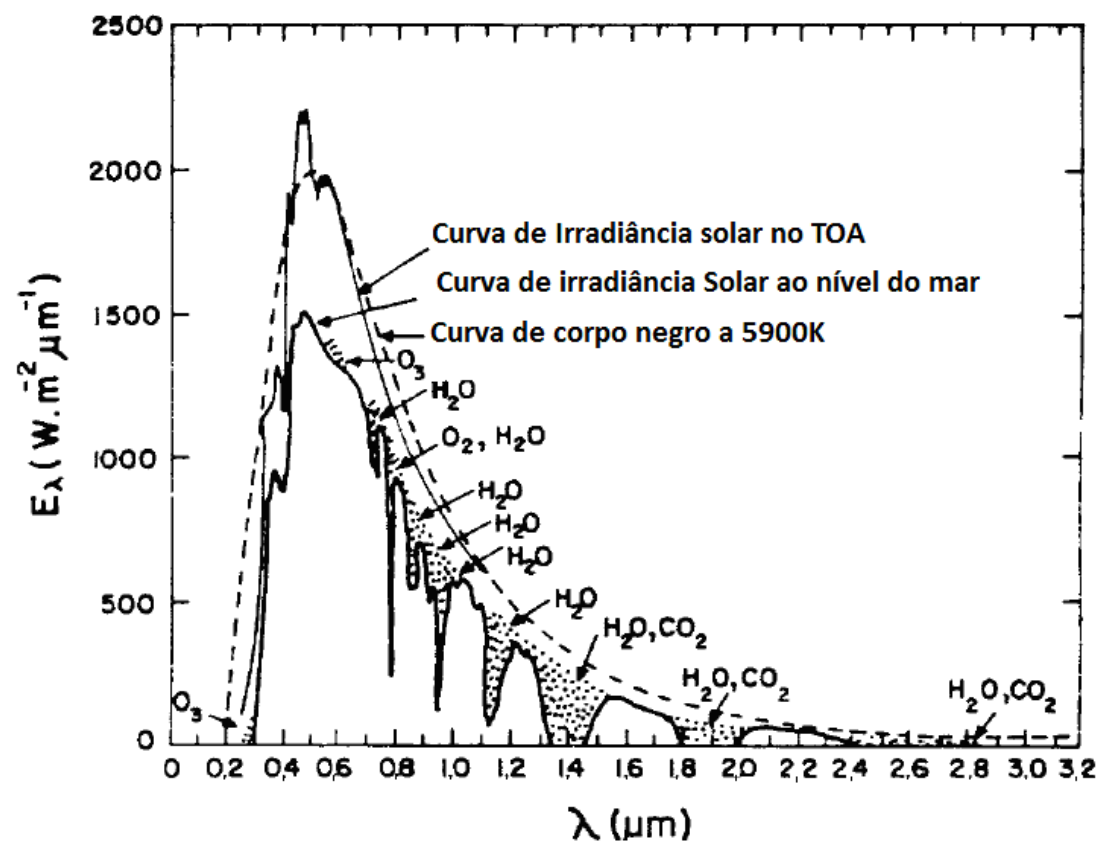

Figura 2.2 - Distribuição de irradiância espectral $\left(\mathrm{E}_{\lambda}\right)$ em $\left[\mathrm{W} / \mathrm{m}^{2} . \mu \mathrm{m}\right]$. Apresentada a irradiância espectral solar no TOA, ao nível médio do mar e a irradiância espectral emitida de um corpo negro à temperatura de $5.900 \mathrm{~K}$ conforme indicado pelas setas na figura. As áreas obscurecidas (pintadas) correspondem a regiões espectrais de forte absorção por alguns gases presentes na atmosfera. Adaptado de Seinfeld e Pandis [1998].

Os principais atenuadores atmosféricos, no espectro da radiação solar, atuam em bandas espectrais bem definidas como é indicado na figura 2.2. Os gases, oxigênio $\left(\mathrm{O}_{2}\right)$ e ozônio $\left(\mathrm{O}_{3}\right)$, absorvem no ultravioleta (de 0,12 a $\left.0,40 \mu \mathrm{m}\right)$ onde a absorção pelo $\mathrm{O}_{2}$ é dominante até $0,2 \mu \mathrm{m}$ e o $\mathrm{O}_{3}$ em comprimentos de onda maiores. No espectro do visível (de $0,4$ a $0,76 \mu \mathrm{m})$ o $\mathrm{O}_{3}$ também tem um importante papel como absorvedor, em função da banda 
de Chappuis que se estende aproximadamente de $0,4 \mu \mathrm{m}$ até o infravermelho próximo, com um máximo em torno de 0,6 $\mu \mathrm{m}$ [LIOU, 2002]. Ainda na região do espectro visível ocorre também absorção por alguns outros gases traço como é o caso do dióxido de nitrogênio $\left(\mathrm{NO}_{2}\right)$ que apresenta uma banda de absorção entre 0,30 a 0,55 $\mu \mathrm{m}$ [SHAW, 1976b]. A região do infravermelho próximo (de 0,76 a 4,0 $\mu \mathrm{m}$ ) apresenta diversas bandas de absorção sendo as principais associadas ao dióxido de carbono $\left(\mathrm{CO}_{2}\right), \mathrm{O}_{3}$ e ao vapor d'água $\left(\mathrm{H}_{2} \mathrm{O}\right)$. Existem outros gases minoritários que também contribuem em menor escala para atenuação da radiação solar incidente, como é o caso do monóxido de nitrogênio II $\left(\mathrm{N}_{2} \mathrm{O}\right)$, o metano $\left(\mathrm{CH}_{4}\right)$ e o monóxido de carbono (CO) [LIOU, 2002]. Em contraste com a absorção gasosa, o espalhamento não é um processo discreto (em bandas estreitas e bem definidas), ocorrendo em amplo espectro da radiação solar, porém pode apresentar uma significativa dependência espectral, como no caso do espalhamento molecular.

A atmosfera, entretanto permite a passagem de grande parte da radiação em regiões chamadas de 'janelas' espectrais, ilustradas na figura 2.2 em setores de baixa atenuação pelos constituintes atmosféricos. A atmosfera é praticamente transparente à radiação em torno do visível e em algumas faixas do espectro do infravermelho térmico entre 8 e $13 \mu \mathrm{m}$ (o infravermelho térmico não está ilustrado na figura 2.2). O conhecimento preciso das bandas de absorção de moléculas de gases é extremamente importante para a análise do sensoriamento remoto. Os novos sensores de aerossóis com alta resolução espectral buscam as janelas para a análise dos aerossóis, que possuem a menor absorção por outros constituintes, para evitar grandes correções. A maioria dos sensores opera na região do ultravioleta, visível e infravermelho próximo $(0,34$ a 2,1 $\mu \mathrm{m})$, pois são comprimentos de onda equivalentes ao tamanho dos aerossóis que interagem com a radiação [CASTANHO, 2005].

\subsubsection{A atenuação molecular - o espalhamento Rayleigh}

O espalhamento molecular ou Rayleigh é um fenômeno óptico que causa a atenuação do feixe de radiação incidente que atravessa a atmosfera, além de produzir radiação difusa. Ele ocorre devido à interação da radiação incidente com partículas muito menores do que o seu comprimento de onda. Este fenômeno óptico é causado majoritariamente por átomos e moléculas de gases presentes na atmosfera (nitrogênio e oxigênio) as quais apresentam diâmetro muito menor que o comprimento de onda da radiação incidente com a qual interagem. O perfil destas partículas na atmosfera apresenta concentração praticamente 
estável, variando proporcionalmente em relação à pressão atmosférica na superfície (HANSEN \& TRAVIS, 1974). Para se obter o valor da energia espalhada durante este fenômeno é exigido um tratamento matemático clássico que passa necessariamente pela solução das equações de Maxwell, da Teoria do Eletromagnetismo, em coordenadas polares considerando, como primeira aproximação, as partículas com geometria esférica [LIOU, 2002].

O espalhamento da radiação na atmosfera começou a ser estudado no século XIX, por Lord Rayleigh, para observações da luz e da coloração do céu e em sua homenagem recebeu o seu nome [CORREA, 2003]. Rayleigh determinou uma solução particular para o caso no qual a partícula é muito menor que o comprimento de onda da radiação eletromagnética incidente [IQBAL, 1983]

A solução particular para o espalhamento Rayleigh admite que o campo magnético da radiação espectral incidente interage com uma molécula que funciona como um dipolo oscilante. Com esta hipótese obtém-se pela expressão 2.2 a seção de choque de espalhamento $\left(\sigma_{\text {esp }, \lambda}\right)$ para uma molécula [LIOU, 2002]:

$$
\sigma_{e s p, \lambda}=\alpha^{2} \frac{128}{3} \frac{\pi^{5}}{\lambda^{4}}
$$

onde $\alpha$, resumidamente, corresponde à polarização da partícula, e é obtida pela razão entre o campo elétrico produzido pela radiação incidente na molécula e o dipolo elétrico induzido (oscilante) gerado pelo respectivo campo elétrico sobre a molécula. Ainda, a expressão (2.2) ilustra que a eficiência de uma partícula em espalhar a radiação incidente é maior em comprimentos de onda menores. A partir da secção de choque de espalhamento, é possível determinar a profundidade óptica Rayleigh $\left(\tau_{\mathrm{R}, \lambda}\right)$ integrando a concentração de moléculas $\left(\mathrm{N}_{\mathrm{z}}\right)$ [moléculas $/ \mathrm{m}^{2}$ ] ao longo da atmosfera, ou seja, do TOA até a superfície (ao nível do mar), como representa a expressão 2.3 .

$$
\tau_{R, \lambda}=\sigma_{e s p, \lambda} \int_{0}^{\infty} N(z) d z
$$

A solução proposta por Lord Rayleigh e que resulta na profundidade óptica espectral molecular ou de Rayleigh está fundamentada no fato da eficiência de espalhamento espectral ser diretamente proporcional ao $\left(\lambda^{-4}\right)$ [WALLACE \& HOBBS, 2006]. A dependência observada implica que radiação espectral solar de menor comprimento de onda é mais eficazmente espalhada que a de maior comprimento de onda, com isso nos comprimentos de 
onda maiores, a atenuação pelas moléculas do ar cai rapidamente. Esse fato explica, por exemplo, a origem da coloração azul do céu.

Uma série de estudos propõe relações simplificadas para a estimativa da profundidade óptica espectral de Rayleigh, como uma função do comprimento de onda [HANSEN \& TRAVIS, 1974; FRÖHLICH \& SHAW, 1980; BUCHOLTZ, 1995]. A expressão (2.4) representa uma das soluções para se calcular a profundidade óptica espectral de Rayleigh, segundo Hansen e Travis [1974] e Alexandrov et al. [2002a], que também é corrigido pela pressão atmosférica local pois a expressão está ajustada para atenuação ao nível do mar.

$$
\tau_{\text {Rayleigh }}=0,008569 \cdot \lambda^{-4}\left(1+0,0113 \cdot \lambda^{-2}+0,00013 \cdot \lambda^{-4}\right)\left(\frac{\mathrm{P}}{\mathrm{P}_{0}}\right)
$$

onde $(\mathrm{P})$ corresponde a pressão atmosférica do local de medições em $[\mathrm{hPa}],\left(\mathrm{P}_{0}\right)$ a pressão ao nível do mar $(1.013,0 \mathrm{hPa})$ e $(\lambda)$ corresponde ao comprimento de onda em [ $\mu \mathrm{m}]$ da radiação solar incidente

\subsubsection{A atenuação pelos aerossóis}

A figura 2.3 ilustra a interação de um feixe de radiação espectral incidente sobre uma partícula em suspensão na atmosfera. Nesta interação, pode ocorrer uma série de fenômenos distintos, simultaneamente. Entre os fenômenos apresentados na figura, somente a absorção e o espalhamento elástico (reflexão, difração e refração) da radiação monocromática incidente, são significativos no estudo da interação entre radiação solar e os aerossóis. Os outros fenômenos, como o espalhamento Raman e a fluorescência (exemplos típicos de espalhamento inelástico no qual a radiação emitida possui um comprimento de onda diferente da radiação incidente) não são significativos neste estudo, já que não têm influência relevante sobre os mecanismos atmosféricos [CORRÊA, 2003; ROSÁRIO, 2006]. 


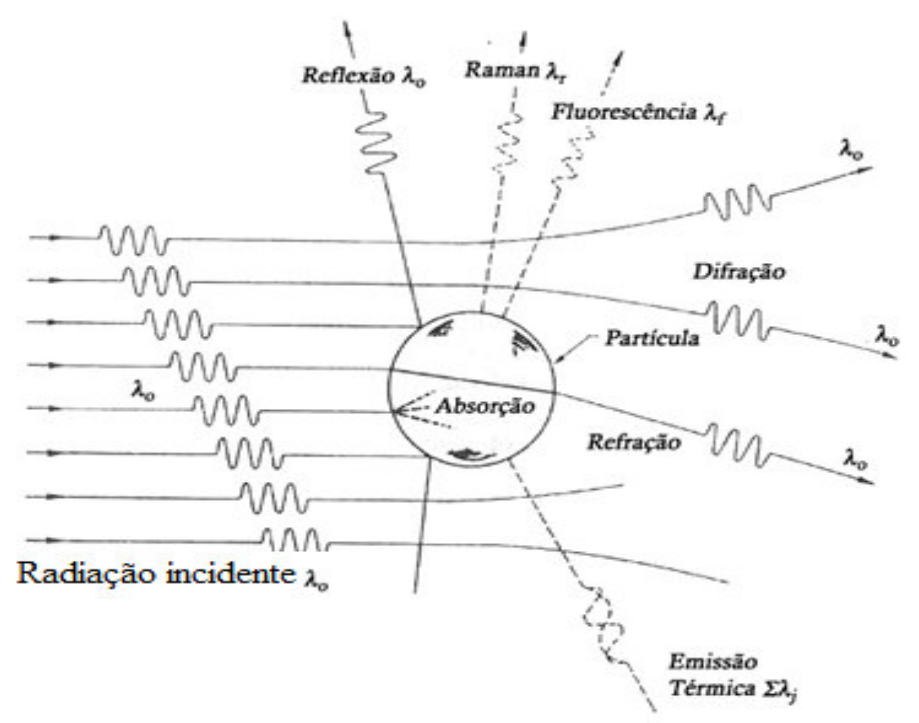

Figura 2.3 - Diagrama que representa as interações entre um feixe de radiação espectral incidente e uma partícula em suspensão na atmosfera. Adaptado de Seinfeld \& Pandis, [1998].

De uma forma geral a descrição do processo de espalhamento fundamenta-se em determinar a probabilidade da radiação incidente ser desviada para uma orientação qualquer. O padrão de espalhamento não ocorre de forma aleatória, isto é, a distribuição da radiação emergente em diferentes orientações depende de algumas características das partículas que constituem o meio no qual a radiação se propaga. Uma dessas características é o parâmetro de tamanho $(\eta)$ que determina o tipo de atenuação, por espalhamento, que a partícula de aerossol provoca no feixe incidente da radiação. Este parâmetro é definido como $(\eta=2 . \pi . r / \lambda)$, onde $(r)$ corresponde ao raio da partícula, $(\lambda)$ o comprimento de onda da radiação incidente. Quando $(\eta<<1)$ o fenômeno de espalhamento Rayleigh é dominante, para $(\eta \sim 1)$ o fenômeno dominante corresponde ao espalhamento Mie e para $\eta>>1$ domina o espalhamento geométrico [LIOU, 2002; WALLACE \& HOBBS, 2006].

Uma partícula muito pequena irá espalhar a radiação monocromática nas direções frontal e traseira na mesma proporção (de forma simétrica), ao passo que, conforme a partícula aumenta de tamanho, a radiação espalhada concentra-se cada vez mais nas direções frontais que coincidem com a direção de propagação do feixe de radiação incidente, apresentando padrões cada vez mais complexos como ilustrado na figura 2.4. 


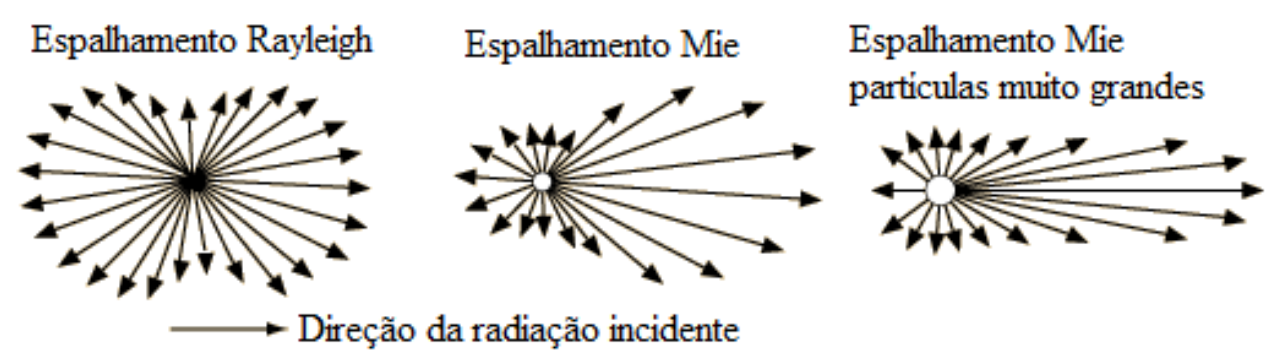

Figura 2.4 - Representação da forma de espalhamento de um feixe de radiação incidente em uma partícula com diversos tamanhos, ilustrando o espalhamento no limite Rayleigh, o espalhamento Mie para partículas de tamanho médio e a forma de espalhamento Mie para partículas muito grandes. Adaptado de - http://hyperphysics.phy-astr.gsu.edu. Acessado em 10 de janeiro de 2007.

A Teoria Mie, que descreve o espalhamento de uma partícula, é construída a partir da hipótese de que elas são esferas homogêneas de raio (r) e com intensa descontinuidade do índice de refração em sua superfície [CORRÊA, 2003]. Neste caso, também para se obter o valor da energia espalhada durante este fenômeno é exigido um tratamento matemático que resolva as equações de Maxwell, que descrevem a interação da partícula com a radiação eletromagnética. Este formalismo matemático não será apresentado neste trabalho, apenas serão introduzidos os conceitos básicos que descrevem a interação da partícula com a radiação incidente. Maiores detalhes podem ser encontrados em textos como de Goody \& Yung [1989], Liou [2002] entre outros.

O índice de refração complexo (n) de uma partícula, expressão 2.5, é definido pela composição química da partícula de aerossol e determina a fração da contribuição dos processos de absorção e espalhamento na atenuação da radiação pela partícula.

$$
n=n_{R}+i . n_{i m}
$$

onde $\left(\mathrm{n}_{\mathrm{R}}\right)$ é a parte real do índice de refração e $\left(\mathrm{n}_{\mathrm{im}}\right)$ é a parte imaginária. A parte real do índice de refração determina a fração espalhada, durante a atenuação, pela partícula e o componente imaginário, a fração absorvida na interação. Quanto mais absorvedora for uma partícula, maior é o valor da parte imaginária.

A atenuação do feixe, provocada pelo espalhamento da radiação incidente em diversas direções e pela absorção da energia pela partícula, é proporcional à seção de choque eficaz de extinção $\left(\sigma_{e x t, \lambda}\right)$ (com unidade de $\mathrm{m}^{2}$ no S.I.) da partícula. Ela representa a área da partícula que efetivamente provoca a extinção da radiação em determinado comprimento de onda, conforme a expressão 2.6.

$$
\sigma_{e x t, \lambda}=\sigma_{e s p, \lambda}+\sigma_{a b s, \lambda}
$$


onde $\left(\sigma_{\text {esp }, \lambda}\right)$ corresponde à seção de choque eficaz espectral de espalhamento e $\left(\sigma_{a b s, \lambda}\right)$ corresponde à seção de choque eficaz espectral de absorção.

A eficiência de extinção de uma partícula $\left(Q_{e x t, \lambda}\right)$ é determinada pela razão entre a $\left(\sigma_{\text {ext, }, \lambda}\right)$ e a área geométrica (A) da partícula. E por analogia, tem-se a eficiência de absorção $\left(\mathrm{Q}_{\mathrm{abs}, \lambda}\right)$ e de espalhamento $\left(\mathrm{Q}_{\mathrm{esp}, \lambda}\right)$, todos adimensionais.

$$
Q_{e x t, \lambda}=\frac{\sigma_{e x t, \lambda}}{A} \Rightarrow Q_{e x t, \lambda}=Q_{e s p, \lambda}+Q_{a b s, \lambda}
$$

Considerando que a partícula seja esférica e homogênea, o valor da eficiência de espalhamento $\left(\mathrm{Q}_{\mathrm{esp}, \lambda}\right)$ e de extinção $\left(\mathrm{Q}_{\mathrm{ext}, \lambda}\right)$ podem ser obtidas pela teoria Mie, que resulta nas expressões 2.8 e 2.9 respectivamente [LIOU, 2002]:

$$
\begin{aligned}
& Q_{e s p, \lambda}(\eta, n)=\frac{2}{\eta^{2}} \sum_{i=1}^{\infty}(2 i+1)\left[\left|a_{i}\right|^{2}+\left|b_{i}\right|^{2}\right] \\
& Q_{e x t, \lambda}(\eta, n)=\frac{2}{\eta^{2}} \sum_{i=1}^{\infty}(2 i+1) \operatorname{Re}\left[a_{i}+b_{i}\right]
\end{aligned}
$$

onde $\left(\mathrm{a}_{\mathrm{i}}\right)$ e $\left(\mathrm{b}_{\mathrm{i}}\right)$ são coeficientes da solução obtida pela teoria Mie, ou simplesmente coeficientes Mie, sendo dependentes do índice de refração complexo e do parâmetro de tamanho da partícula.

A forma do espalhamento da radiação monocromática incidente em uma partícula guarda também uma dependência com o seu tamanho, como ilustrou a figura 2.4. A função que busca descrever a dependência angular da radiação espalhada pela partícula, é chamada de função de fase $\left[\mathrm{P}_{\operatorname{COS}(\Theta)}\right]$, onde $(\Theta)$ corresponde ao ângulo formado entre o feixe incidente e o emergente. Para valores $\left(\Theta=0^{\circ}\right)$ o feixe é espalhado na mesma direção do feixe incidente (espalhamento frontal) e para $\left(\Theta=180^{\circ}\right)$ teremos a inversão da direção do feixe incidente (ou retro-espalhamento). A função de fase normalizada corresponde a expressão 2.10 [LIOU, 2002]:

$$
\int_{0}^{2 \pi} \int_{0}^{\pi} \frac{P(\cos \Theta)}{4 \pi} \cdot \operatorname{sen} \theta \cdot d \theta d \varphi=1
$$

Um importante parâmetro na avaliação do espalhamento de partículas é o parâmetro de assimetria $\left(\mathrm{g}_{\lambda}\right)$ que é uma das grandezas derivadas diretamente da função de fase. Este 
parâmetro corresponde ao valor médio do cosseno do ângulo de espalhamento, ponderado pela função de fase, que descreve o grau de assimetria do espalhamento [LIOU, 2002].

$$
g_{\lambda}=\frac{1}{2} \int_{-1}^{1} P(\cos \Theta) \cdot \cos \Theta \cdot d(\cos \Theta)
$$

O parâmetro de assimetria, teoricamente, pode variar entre (-1) a (1), desta forma valores negativos de $(\mathrm{g})$ apresentam predomínio de espalhamento em sentidos contrários ao feixe incidente e valores positivos no mesmo sentido (frontal). Desta forma, a variabilidade do $\left(\mathrm{g}_{\lambda}\right)$ descreve o balanço entre a quantidade de radiação espalhada entre os lóbulos frontal e traseiro da função de fase. Vale ressaltar dois casos para o valor do $\left(\mathrm{g}_{\lambda}\right)$, quando ele assume o valor positivo igual a (1) temos o espalhamento totalmente frontal (pró-espalhamento), que corresponde, por exemplo, ao espalhamento por partículas grandes de aerossol. O espalhamento é simétrico entre os dois hemisférios quando $\left(\mathrm{g}_{\lambda}\right)$ for nulo, como no caso do espalhamento Rayleigh.

Uma das funções analíticas usuais para simplificar a representação matemática da função de fase real de uma partícula de aerossol emprega o parâmetro de assimetria (g) e é denominada função de fase de Henyey-Greenstein $\left[\mathrm{P}_{\mathrm{HG}}(\cos (\Theta)]\right.$, sendo apresentada na expressão 2.12 [LIOU, 2002].

$$
P_{H G}(\cos (\Theta))=\frac{1-g^{2}}{\left[1+g^{2}-2 g \cdot \cos (\Theta)\right]^{3 / 2}}
$$

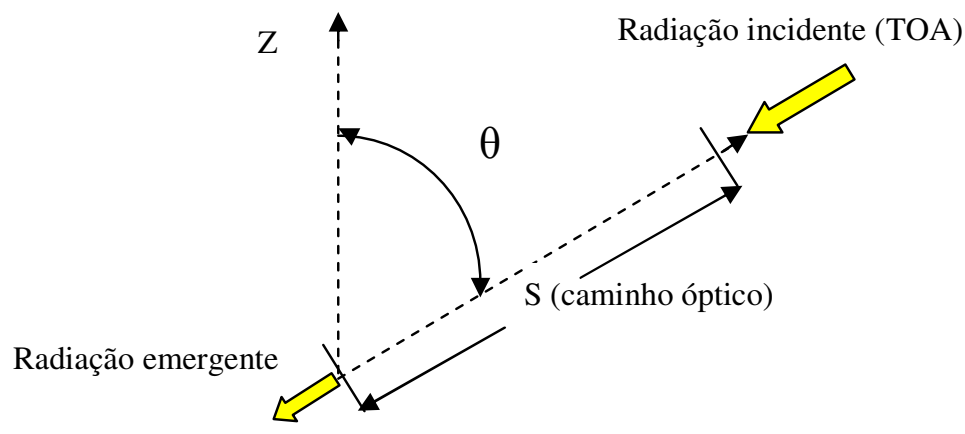

Figura 2.5 - Representação esquemática da definição de caminho óptico, que corresponde à distância efetivamente percorrida por um feixe de radiação incidente ao atravessar um meio opticamente ativo. Onde $(\theta)$ corresponde ao ângulo zenital da orientação de propagação do feixe de radiação e a orientação normal a superfície. Adaptada de Liou [2002].

O coeficiente linear de extinção $\left(\beta_{\text {ext, }, \lambda,\left(s^{\prime}\right)}\right)$ representa uma medida da extinção da radiação incidente pelas partículas presentes em um determinado ponto (s') do caminho óptico (figura 2.5). Em analogia aos parâmetros obtidos para uma partícula, também é 
possível estimar os coeficientes lineares espectrais de espalhamento $\left(\beta_{\mathrm{esp}, \lambda,\left(\mathrm{s}^{\prime}\right)}\right)$ e o de absorção $\left(\beta_{\mathrm{abs}, \lambda,\left(\mathrm{s}^{\prime}\right)}\right)$ a partir das respectivas eficiências de extinção $\left(\mathrm{Q}_{\mathrm{esp}, \lambda}, \mathrm{Q}_{\mathrm{abs}, \lambda}\right)$ e da concentração de partículas $\left[\mathrm{N}\left(\mathrm{r}, \mathrm{s}^{\prime}\right)\right]$ neste mesmo nível do caminho óptico. A expressão 2.13 fornece o valor integrado para o coeficiente linear espectral de extinção de uma população de aerossóis de raio (r) em um determinado ponto (s') do caminho óptico.

$$
\beta_{e x t, \lambda,\left(s^{\prime}\right)}=\int_{r \cdot \text { mínimo }}^{r \max } Q_{e x t, \lambda}(\eta, n) \cdot \pi \cdot r^{2} N\left(r, s^{\prime}\right) \cdot d(r)
$$

Como mencionado, os aerossóis além de espalhar a radiação, podem também absorver, dependendo do seu índice de refração. O albedo simples $\left(\omega_{0, \lambda}\right)$ é um parâmetro que quantifica quanto da radiação atenuada ou extinta pelos aerossóis sofreu espalhamento, isto é, a fração da radiação que foi atenuada por espalhamento ao interagir com as partículas de aerossol. $\mathrm{O}$ albedo simples $\left(\omega_{0}, \lambda\right)$ pode ser expresso a partir do coeficiente linear de extinção:

$$
\omega_{0, \lambda}=\frac{\beta_{e s p, \lambda,\left(s^{\prime}\right)}}{\beta_{e s p, \lambda,\left(s^{\prime}\right)}+\beta_{a b s, \lambda,\left(s^{\prime}\right)}}
$$

Finalmente, define-se a espessura óptica de extinção $\left(\tilde{\tau}_{\text {ext }, \lambda}\right)$ que representa quantitativamente a atenuação provocada pelos aerossóis integrada ao longo do caminho óptico da atmosfera do TOA ( $\infty$ ) até um nível (s) de interesse, como é apresentado em 2.15. Vale lembrar que, obtidos os valores de $\left(\beta_{\mathrm{esp}, \lambda,\left(\mathrm{s}^{\prime}\right)}\right)$ e $\left(\beta_{\mathrm{abs}, \lambda,\left(\mathrm{s}^{\prime}\right)}\right)$ também é possível calcular a espessura óptica devido ao espalhamento $\left(\tilde{\tau}_{e s p, \lambda,\left(s^{\prime}\right)}\right)$ e devido a absorção $\left(\tilde{\tau}_{a b s, \lambda,\left(s^{\prime}\right)}\right)$.

$$
\tilde{\tau}_{e x t, \lambda}=\int_{\infty}^{s} \beta_{e x t, \lambda,\left(s^{\prime}\right)} \cdot d\left(s^{\prime}\right)
$$

\subsubsection{A atenuação exponencial da radiação espectral - Lei de Beer, Bouguer e Lambert}

A lei de Beer, Bouguer e Lambert descreve a atenuação exponencial da radiação eletromagnética ao atravessar um meio homogêneo opticamente ativo. Esta lei pode ser expressa como a atenuação ou extinção da radiância espectral $L_{\lambda}\left(\Omega^{\prime}, s^{\prime}\right)$ na orientação [ $\left.\Omega^{\prime}\right]$ ao 
interagir com um volume elementar de matéria de comprimento (ds') situado à posição (s') de um caminho óptico, conforme ilustra a figura 2.6.

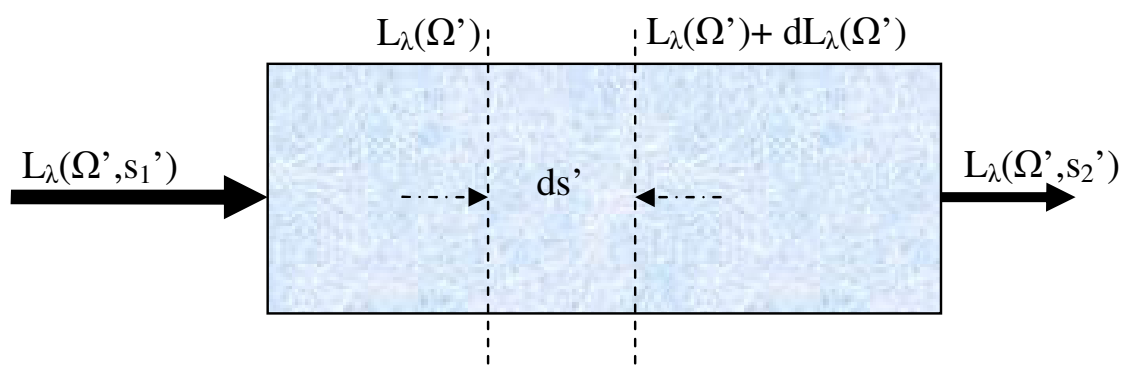

Figura 2.6 - Representação esquemática da Lei de Beer, Bouguer e Lambert, ao longo de um meio opticamente ativo na orientação de propagação $\left[\Omega^{\prime}=\left(\theta^{\prime}, \varphi^{\prime}\right)\right]$, onde $\left(\theta^{\prime}\right)$ corresponde ao ângulo zenital e ( $\left.\varphi^{\prime}\right)$ o ângulo azimutal, Adaptado de Liou [2002].

A atenuação da radiância que atravessa um comprimento infinitesimal (ds') do caminho óptico é proporcional à extinção que os elementos deste meio propiciam, e pode ser expressa como 2.16 .

$$
d L_{\lambda}\left(\Omega^{\prime}, s^{\prime}\right)=-L_{\lambda}\left(\Omega^{\prime}, s^{\prime}\right) \cdot \beta_{e x t, \lambda,\left(s^{\prime}\right)} d s^{\prime}
$$

onde $\left(\beta_{\text {ext, } \lambda,\left(s^{\prime}\right)}\right)$ é o coeficiente linear de extinção à posição (s') do caminho óptico .

A atenuação da radiância entre $\left(s^{\prime}=s_{1}\right.$ e s' $\left.=s_{2}\right)$ é obtida integrando a expressão 2.16.

$$
\int_{s 1}^{s 2} \frac{d L_{\lambda}\left(\Omega^{\prime}, s^{\prime}\right)}{L_{\lambda}\left(\Omega^{\prime}, s^{\prime}\right)}=-\int_{s 1}^{s 2} \beta_{e x t, \lambda,\left(s^{\prime}\right)} d s^{\prime} \Rightarrow L_{\lambda, S 2}\left(\Omega^{\prime}\right)=L_{\lambda, S 1}\left(\Omega^{\prime}\right) \exp \left(-\int_{s 1}^{s 2} \beta_{\lambda,\left(s^{\prime}\right)} d s^{\prime}\right)
$$

A expressão 2.17 ajuda a definir outra importante grandeza, a transmitância direta espectral $\left(\mathrm{T}_{\lambda, \mathrm{d}}\right)$ :

$$
T_{d, \lambda(s 1 \rightarrow s 2)}=\frac{L_{\lambda, S 2}\left(\Omega^{\prime}\right)}{L_{\lambda, S 1}\left(\Omega^{\prime}\right)}=\exp \left(-\int_{s 1}^{s 2} \beta_{\lambda,\left(s^{\prime}\right)} d s^{\prime}\right)
$$

Vale lembrar que a integral da exponencial é semelhante à expressão 2.15, porém neste caso está representada toda a atenuação atribuída ao meio opticamente ativo o que corresponde à espessura óptica espectral total $\left(\tilde{\tau}_{\lambda}\right)$.

A radiância espectral $\left(\mathrm{L}_{\lambda}\right)$ é uma medida da quantidade de energia (intensidade radiante espectral), recebida por um ponto ou emitida por uma fonte também pontual, em uma determinada direção. A intensidade radiante espectral $\left(\mathrm{I}_{\lambda}\right)$ de uma fonte (pontual) em uma determinada direção corresponde ao quociente entre a potência emitida em [W], em determinado comprimento de onda $(\lambda)$, em uma dada direção do espaço e o ângulo sólido 
infinitesimal $[\mathrm{d} \Omega]$ de um cone que representa essa direção. Desta forma a quantidade diferencial de energia radiante espectral $\left(\mathrm{dI}_{\lambda}\right)$, restrita em um elemento de ângulo sólido $(\mathrm{d} \Omega)$ direcionado em um ângulo $(\theta)$, e que atravesse um elemento de área (dA) em um intervalo de tempo $(\mathrm{dt})$ define a $\left(\mathrm{L}_{\lambda}\right)$ e é expressa em 2.19

$$
L_{\lambda}=\frac{d I_{\lambda}}{\cos (\theta) \cdot d \Omega \cdot d t \cdot d A \cdot d \lambda}
$$

A irradiância espectral $\left(\mathrm{E}_{\lambda}\right)$ é definida como a razão entre o fluxo de radiação incidente em um de elemento de superfície infinitesimal. Assim conhecendo a $\left(\mathrm{L}_{\lambda}\right)$ da expressão 2.19 em todas as direções, torna-se possível determinar a irradiância total incidente em um hemisfério integrando-a em ângulo sólido sobre um hemisfério como em 2.20:

$$
E_{\lambda}=\int_{\Omega} L_{\lambda} \cdot \cos (\theta) \cdot d \Omega \Rightarrow \int_{0}^{2 \pi} \int_{0}^{\frac{\pi}{2}} L_{\lambda}(\theta, \phi) \cdot \cos (\theta) \cdot \operatorname{sen}(\theta) \cdot d \theta \cdot d \varphi
$$

\subsection{A lei de Beer, Bouguer e Lambert aplicada a atmosfera}

A atmosfera, para a aplicação da Lei de Beer, Bouguer e Lambert, sofre uma aproximação para uma atmosfera formada por camadas plano-paralelas, homogêneas e não refratárias como ilustra a figura 2.9 [Shaw, 1983]. Nesta hipótese, a proporção geométrica diminuta entre a espessura da atmosfera opticamente ativa (aproximadamente de $100 \mathrm{~km}$ ) e o raio da Terra é considerada. A hipótese admite que variações de parâmetros verticais como pressão, temperatura, número de partículas e coeficiente linear de extinção, horizontalmente não são significativas em relação às variações verticais. Assim os parâmetros ópticos definidos primeiramente em termos do caminho óptico no referencial (s) podem ser definidos também para uma atmosfera plano-paralela, em relação à orientação vertical (z). Um deles é a espessura óptica espectral de extinção da atmosfera $\left(\tilde{\tau}_{\lambda}\right)$, que quando definida em relação a (z) passa a ser chamada de profundidade óptica de extinção da atmosfera $\left(\tau_{\lambda}\right)$. 


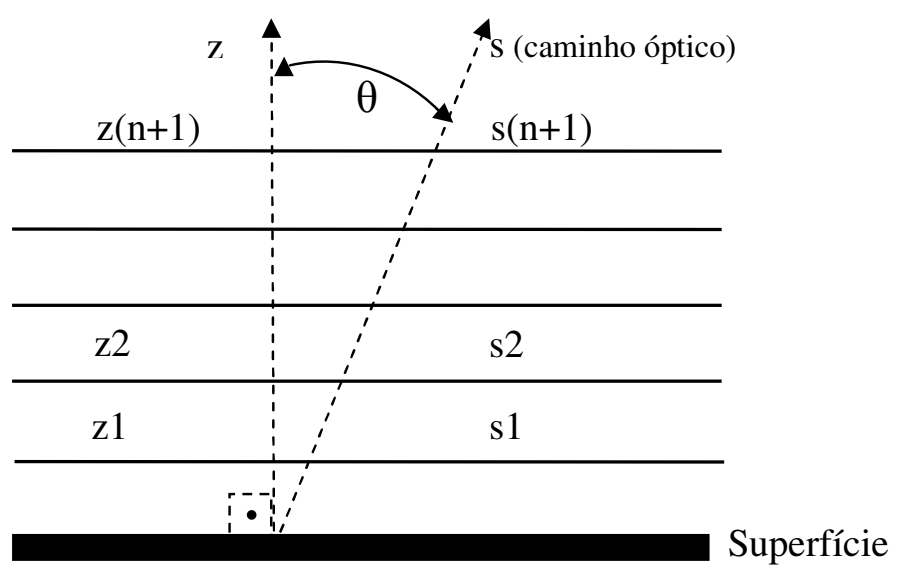

Figura 2.7 - A aproximação para uma atmosfera plano-paralela, caracterizada por camadas estruturadas verticalmente e homogêneas horizontalmente, onde $(\theta)$ corresponde ao ângulo zenital entre a orientação de propagação de um feixe de radiação e a vertical. Adaptado de Liou [2002].

\subsection{O coeficiente de Ångström}

Um parâmetro importante para análise do aerossol é obtido através do valor do coeficiente de Ångström $\left[\alpha_{(\lambda 1, \lambda 2)}\right]$ o qual permite avaliar o tamanho médio das partículas de aerossol que interagem com o feixe de radiação solar quando o mesmo atravessa a atmosfera.

Em 1929, Ångström sugeriu uma aproximação empírica conhecida como a fórmula da turbidez de Ångström para descrever a dependência espectral da profundidade óptica do aerossol, expressa em 2.23 [IQBAL, 1983; MCARTHUR et al., 2003]:

$$
\tau_{a, \lambda}=\beta \cdot(\lambda)^{-\alpha}
$$

onde $\left(\tau_{\mathrm{a}, \lambda}\right)$ corresponde à profundidade óptica espectral do aerossol (POA), $(\beta)$ é o coeficiente de turbidez e representa a quantidade de aerossóis presentes na coluna vertical da atmosfera e o $(\alpha)$ é chamado de coeficiente de Ångström. Para valores de $(\lambda=1,0 \mu \mathrm{m})$ o $(\beta)$ é equivalente a POA neste comprimento de onda.

O valor para o coeficiente de Ångström pode ser obtido também a partir do valor da POA em dois comprimentos de onda distintos como é apresentado em 2.22. Quanto maior é o valor do coeficiente de Ångström, maior a dependência espectral e por conseqüência menor é o tamanho predominante das partículas de aerossol na atmosfera. Valores do coeficiente de 
Ångström em torno de dois $\left[\alpha_{(\lambda 1, \lambda 2)} \cong 2\right]$ indicam que há predominância de partículas da moda fina ao passo que valores próximos de "zero" $\left(\alpha_{(\lambda 1, \lambda 2)} \cong 0\right)$ indicam predominância de aerossóis da moda grossa [MCARTHUR et al., 2003].

$$
\alpha_{\left(\lambda_{1} \lambda_{2}\right)}=\frac{-\ln \left(\tau_{\lambda_{1}} / \tau_{\lambda_{2}}\right)}{\ln \left(\lambda_{1} / \lambda_{2}\right)}
$$




\section{Capítulo III: Materiais e Métodos}


Neste capítulo será descrita a instrumentação empregada neste trabalho, a estimativa da incerteza instrumental espectral do MFRSR, a metodologia para estimar a profundidade óptica de aerossóis e suas incertezas a partir de medidas de irradiância solar dos MFRSR e a metodologia empregada na sua calibração. Também é apresentada a metodologia empregada no filtro de nuvens.

\subsection{Instrumentação}

\subsubsection{O Multi-Filter Rotating Shadowband Radiometer - MFRSR}

O MFRSR é o principal instrumento empregado no presente trabalho, ele é um radiômetro que permite medir irradiâncias, global e difusa em incidência horizontal e direta normal, integradas sobre seis regiões espectrais relativamente estreitas. Os MFRSR, empregados neste trabalho, tem canais centrados em 415, 672, 870 e $1036 \mathrm{~nm}$ (com largura de $10 \mathrm{~nm}$ ) e dois canais de $940 \mathrm{~nm}$ (um com largura de $10 \mathrm{~nm}$ e outro com $35 \mathrm{~nm}$ ). Além de medidas realizadas nos canais de banda estreita, o MFRSR ainda realiza medidas em banda larga em um canal integrado entre $0,35 \mu \mathrm{m}$ a $1,1 \mu \mathrm{m}$. No processo de medição, o MFRSR emprega um conjunto de detectores (do tipo fotodiodo) independentes e filtros de interferência espectrais, instalados no interior de uma cavidade isolada do ambiente externo, iluminada através de um difusor horizontal [HARRISON et al.,1994]. Os dois canais de 940nm são utilizados em estimativas de conteúdo de vapor d'água integrado na coluna vertical atmosférica [PLANA-FATTORI et al., 2004], porém, estes dois canais não serão utilizados neste trabalho. O MFRSR também possui um sensor de temperatura instalado junto aos demais sensores e um conjunto de resistências elétricas dentro da cavidade isolada que em conjunto monitoram e procuram manter estável a temperatura do instrumento em torno de $40^{\circ} \mathrm{C}$.

Classicamente, os processos de atenuação do feixe direto ao penetrar na atmosfera (sofrendo espalhamento e absorção) e a própria radiação difusa, podem ser caracterizados (sofrerem medições) diretamente com uso de um radiômetro [SHAW, 1976; TOMASI et al., 1998].

As observações de irradiância solar difusa são realizadas com o funcionamento de um sistema automático de sombreamento do disco solar, programado de forma a efetuar observações a cada 15 segundos e a armazenar valores médios a cada minuto. A figura 3.1 
ilustra respectivamente, em detalhe a cavidade isolada onde se encontram dispostos o conjunto de filtros e os fotodiodos detectores e o MFRSR em operação na Estação Meteorológica IAG-USP com a tira metálica na posição de sombreamento:
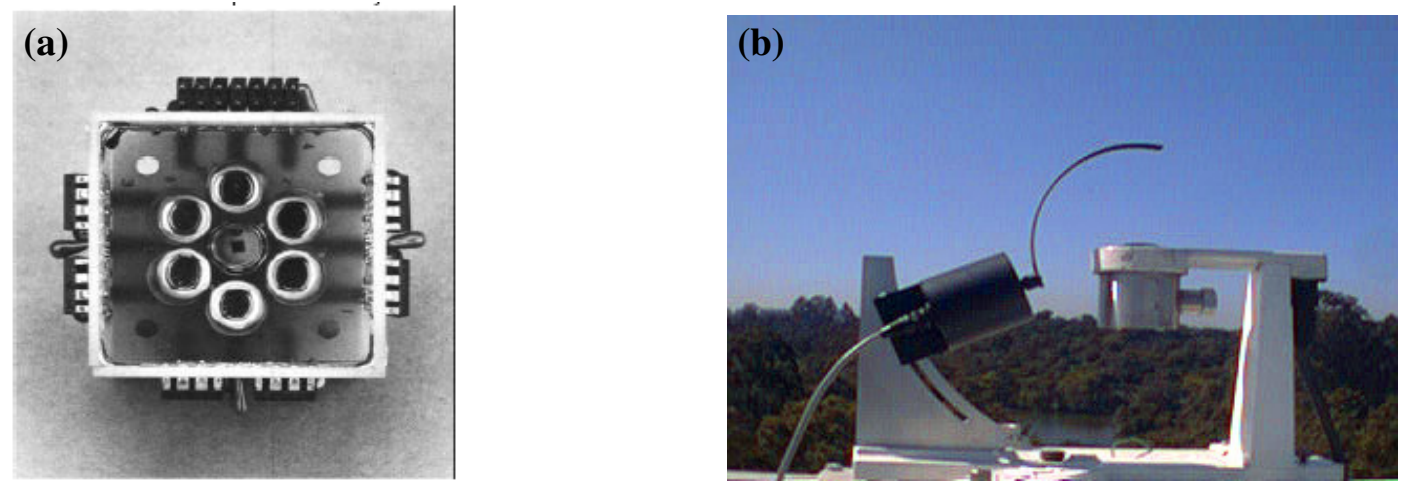

Figura 3.1 - Conjunto de foto-diodo detectores do MFRSR e o mesmo em operação na EMIAG-USP. Fonte - (a) Fabricante e (b) Marcelo Corrêa.

O funcionamento do MFRSR tem como principal característica à atuação de uma tira (ou haste) de metal sombreadora (shadowband), com a forma de um arco circular montada ao longo de um meridiano celestial no eixo do motor de passo, estando o difusor no ponto central do raio deste mesmo arco. A tira metálica obstrui uma parte do céu com um ângulo de $3,27^{\circ}$ que é suficientemente grande para formar um efeito de sombreamento obstruindo o Sol [HARRISON, 1994]. A banda sombreadora pode ser posicionada com uma acurácia de $0,4^{\circ}$ pelo microprocessador (Yesdas Datalogger) que além de armazenar os dados referentes às medições, comanda o motor de passo. O motor é ajustado para a latitude do local no qual o instrumento é instalado e alinhado conforme a orientação do pólo geográfico norte ou sul, dependendo do hemisfério (o motor terá a sua parte traseira direcionada para o norte geográfico, para latitudes sul). O microprocessador executa a cada intervalo de medição (de 15 segundos aproximadamente) o cálculo da posição do disco solar tomando por base parâmetros previamente ajustados que são: a hora em UTC (Universal Time, Coordinated), dia, mês, ano, latitude, longitude e altitude do local de medições.

Durante o procedimento de medição, a primeira medida é feita com a tira metálica (shadowband) na sua posição do nadir (posição inferior da banda de sombreamento) efetuando a medida de irradiância global horizontal. A tira metálica, após esta primeira medida, é movimentada realizando três intervalos de sombreamento antes de completar o giro completo. A segunda medição executada visa obter o valor de irradiância horizontal difusa, ou simplesmente a irradiância difusa, que é medida quando o disco solar é obstruído completamente. Outras duas medições são feitas com rotações de $9,0^{\circ}$, uma anterior à 
medição central e outra após, ou seja, de ambos os lados do sombreamento central total do difusor. Estas medidas laterais permitem que as obstruções adicionais do céu pela tira metálica durante a medida central sejam corrigidas. O programa do MFRSR (YESDAS) efetua esta correção, subtraindo o valor médio das duas medidas adicionais de irradiância com sombreamento do valor de irradiância global e somando a diferença ao valor da irradiância difusa, o que corrige a sub-estimativa inicial [HARRISON et al.,1994]. Na figura 3.2, são apresentadas outras características do instrumento.

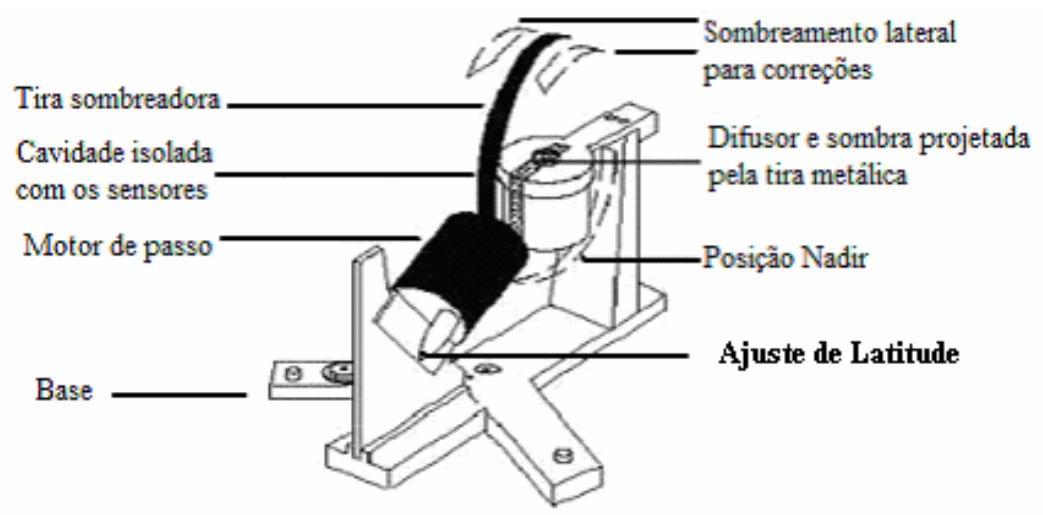

Figura 3.2 - Representação esquemática do conjunto fotodetector do MFRSR durante o seu funcionamento. Adaptado do manual do fabricante.

$\mathrm{O}$ valor da irradiância solar direta-normal $\left(\mathrm{E}_{\mathrm{d}-\mathrm{n}}\right)$ é obtidos segundo Harrison, et al. (1994) pela expressão 3.1:

$$
E_{d-n}=\frac{E_{\text {global }}-E_{\text {difusa }}}{\cos \left(\theta_{0}\right)}
$$

onde: $\left(\theta_{0}\right)$ corresponde ao ângulo zenital solar, ( $\left.E_{\text {Global }}\right)$ irradiância global sem sombreamento do difusor; $\left(\mathrm{E}_{\mathrm{difusa}}\right)$ a irradiância difusa . Todos os valores são obtidos em $\left[\mathrm{W} / \mathrm{m}^{2}\right]$ e os respectivos valores espectrais em cada canal do MFRSR em $\left[\mathrm{W} / \mathrm{m}^{2} . \mathrm{nm}\right]$ [HARRISON et al.,1994].

O fabricante do MFRSR declara que a incerteza instrumental é estimada em 5\% para a resposta do cosseno do ângulo zenital solar e de $1 \%$ após a sua correção. A resposta do cosseno (ou erro do cosseno) ocorre, pois a superfície de detecção do radiômetro não é perfeitamente lambertiana. Em uma superfície horizontal idealmente lambertiana, a irradiância incidente é proporcional ao cosseno do ângulo zenital solar, sendo assim, as medições são corrigida por uma curva de resposta do cosseno, específica para cada instrumento, fornecida pelo fabricante. Outras informações podem ser obtidas junto ao fabricante do MFRSR (http://www.yesinc.com/) bem como em Harrison et al. [1994]. 


\subsubsection{O fotômetro solar espectral CE318A}

A rede AERONET-NASA em parceria com o Instituto de Física da Universidade de São Paulo (IF-USP) mantém em operação um fotômetro solar CE318A fabricado pela Cimel Eletronique. Este fotômetro encontra-se operacional, desde novembro de 2000, no topo do Edifício Pelletron do IF-USP. Outros instrumentos como este estão instalados no Brasil e ao redor do mundo em cooperação com diversas instituições internacionais de pesquisa. $\mathrm{O}$ CE318A possui um sistema óptico de detecção formado por dois tubos colimadores com o mesmo campo de visão de $1,2^{\circ}$ e um conjunto de sensores que medem radiância espectral solar, proveniente diretamente do sol e do céu. Estas medidas podem ser feitas com o auxílio de um sistema robotizado movido por um motor de passo que permite ao instrumento apontar em uma determinada direção do céu com grande acurácia [HOLBEN et al., 1998]. A figura 3.3 ilustra o conjunto detector do fotômetro CE318A em operação automática.

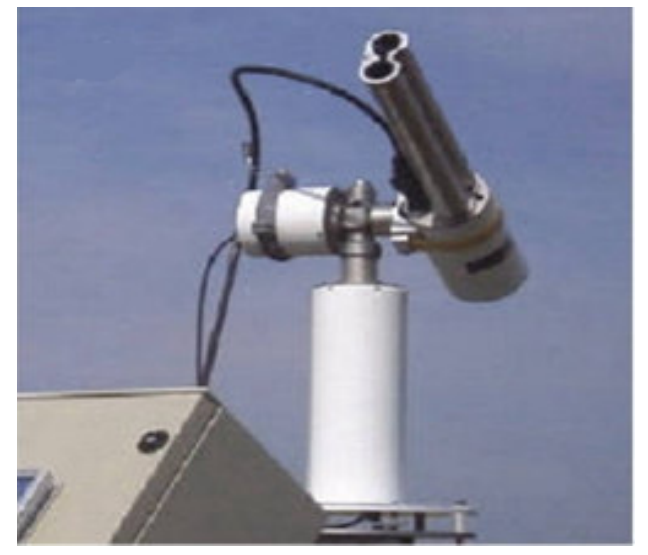

Figura 3.3 - Fotômetro solar CE318A em operação automática. Fonte Rosário [2006]

O fotômetro solar mede radiância solar direta em oito comprimentos de onda (1020, 940, 870, 670, 500, 440, 380 e $340 \mathrm{~nm}$ ), a cada 15 minutos. A largura dos canais varia entre 2,5 nm para os canais próximos da região do ultravioleta (340 e $380 \mathrm{~nm}$ ) e $10 \mathrm{~nm}$ para os demais. O radiômetro ainda mede radiância difusa em quatro comprimentos de onda (1020, 870,670 e $440 \mathrm{~nm}$ ) em intervalos de uma hora. O fotômetro possui um sensor de umidade que procura detectar a precipitação e em caso de ocorrência, desabilita a seqüência de medições para proteger o sistema óptico. A temperatura do sistema também é monitorada permitindo correções nas medidas efetuadas. Mais detalhes, podem ser obtidas em Holben et al. [1998] e Yamasoe [1999]. Neste trabalho serão utilizados os produtos de aerossóis já 
processados (corrigidos, filtrados, etc) da rede AERONET para o nível 2.0 não sendo manipulados dados brutos deste instrumento.

\subsubsection{Instrumentação meteorológica}

As variáveis meteorológicas (VM) analisadas neste trabalho são valores instantâneos coletados de hora em hora por uma estação convencional (registrada na Organização Meteorológica Mundial sob o número 83004) operada pela equipe técnica da Estação Meteorológica (EM) do IAG-USP. Neste trabalho foram utilizadas medidas de temperatura $(\mathrm{T})$, pressão atmosférica $(\mathrm{P})$, umidade relativa (UR) e dados de vento (velocidade média e direção predominante). A Estação Meteorológica (EM) do IAG-USP completou em 2007, 75 anos de existência, inaugurada em 22 de novembro de 1932, começando a operar regularmente a partir de $1^{\circ}$ de janeiro de 1933, no local atual [PEREIRA FILHO et al., 2007].

A pressão atmosférica, em [hPa], é estimada na EM por um barômetro de mercúrio de cuba fixa tipo Kew (marca Fuess) instalado numa das salas do terraço da Estação (sala do observador) à altitude de 799,2 m. As medições são feitas a cada hora entre as $07 \mathrm{~h}$ e as $24 \mathrm{~h}$. As medidas recebem correções de temperatura e de gravidade.

A temperatura do ar, em $\left[{ }^{\circ} \mathrm{C}\right]$, é monitorada em observações, também horárias, pela leitura do capilar de mercúrio que constitui o bulbo seco de um psicrômetro de aspiração tipo Assmann, com motor elétrico (marca Fuess) [PEREIRA FILHO et al., 2007].

$\mathrm{O}$ vento é medido, em [m/s], por um anemógrafo, tipo universal, modelo Dines 82-b (marca Fuess) instalado na torre da Estação, onde está localizada uma haste com um conjunto de pás em concha e uma pá direcional. Este instrumento é empregado para a observação da direção predominante e da velocidade instantânea do vento, a cada hora, possibilitando a estimativa final, após análise dos técnicos da EM, de valores médios ao longo de uma hora de medições [PEREIRA FILHO et al., 2007]. Neste trabalho foram empregados valores médios ao longo de cada hora. O vento é denominado a partir da direção de onde ele se origina, por exemplo: o vento proveniente da direção sul seguindo para o norte é denominado de vento sul. Assim, a orientação do vento (direção e sentido) é composta pelo ponto cardeal de onde o vento se origina e, por convenção, seu símbolo é designado pela primeira letra de sua denominação segundo a sua grafia na língua inglesa, os principais pontos são: Norte - North, Sul - South, Leste - East e Oeste - West, as siglas das demais orientações são combinações destas quatro. 
A umidade do ar é obtida através de medidas indiretas relacionadas à presença de vapor d'água na atmosfera, obtidas a cada hora a partir da leitura dos capilares de mercúrio que constituem os bulbos seco e úmido de um psicrômetro, já citado. Este e os demais instrumentos encontram-se instalados no abrigo principal do cercado meteorológico na EM. Maiores detalhes e informações podem ser obtidos em Pereira Filho et al. [2007], bem como junto à equipe técnica da EM do IAG-USP.

\subsection{O cálculo da profundidade óptica espectral do aerossol com medidas de MFRSR}

O cálculo da profundidade óptica do aerossol é obtido empregando a lei de Beer, Bouguer e Lambert considerando a atmosfera plano-paralela. Neste método é necessário conhecer o valor do feixe de radiação solar (irradiância espectral direta) incidente no TOA, bem como o valor da irradiância solar direta espectral medida na superfície terrestre pelo radiômetro $\left(\mathrm{E}_{\lambda, \mathrm{d}}\right)$, ambas as grandezas medidas em uma superfície horizontal ao feixe de radiação.

A radiação solar direta incidente na superfície da Terra terá sua transmissão decrescente com o aumento da distância zenital solar, isto é, há aumento do chamado caminho óptico com o ângulo zenital solar $\left(\theta_{0}\right)$, que dá origem ao termo massa óptica (m) e particularmente quando a concentração de constituintes atmosféricos opticamente ativos aumenta (partículas de aerossol, gases traço, etc) [PALTRIDGE \& PLATTE, 1976]. A equação 3.2 representa a lei de Beer, Bouguer e Lambert aplicada à atmosfera via fotometria solar:

$$
\mathrm{T}_{\lambda, d}=\mathrm{e}^{-\tau_{\lambda} \cdot \mathrm{m}}=\frac{\mathrm{E}_{\lambda, \mathrm{d}}}{\mathrm{E}_{\left(\lambda, d, \theta_{0}\right)}}
$$

onde $\left(\mathrm{E}_{(\lambda, \mathrm{d}, \theta 0)}\right)$ é o valor da irradiância solar espectral direta no TOA para uma superfície horizontal, $\left(\mathrm{E}_{\lambda, \mathrm{d}}\right)$ a irradiância espectral solar direta na superfície e $(\mathrm{m})$ é massa óptica.

Neste trabalho foi adotada uma massa óptica única para todos os constituintes atmosféricos, segundo a aproximação de Kasten \& Young [1989], a qual leva em consideração a variabilidade da densidade dos gases com a altitude. Os autores admitem (m) com incerteza $(\sigma \mathrm{m} \leq 0,5 \%)$ e propõe a expressão 3.6 onde (el) corresponde ao ângulo de elevação solar $\left(90^{\circ}-\theta_{0}\right)$. 


$$
\mathrm{m}=[\operatorname{sen}(\mathrm{el})+0,50572 \bullet(6,07995+\mathrm{el})-1,6364]^{-1}
$$

A irradiância solar espectral direta no TOA $\left(\mathrm{E}_{(\lambda, \mathrm{d}, \theta 0)}\right)$ é dada por :

$$
\mathrm{E}_{\left(\lambda, \mathrm{d}, \theta_{0}\right)}=\mathrm{E}_{0 \lambda} \cdot\left(\frac{\overline{\mathrm{d}}}{\mathrm{d}}\right)^{2} \cdot \cos \left(\theta_{0}\right)
$$

onde $\left(\frac{\bar{d}}{\mathrm{~d}}\right)^{2}$ é a correção devido à variação da distância Terra-Sol segundo Paltridge \& Platt [1976] e $\left(\mathrm{E}_{0, \lambda}\right)$ é a irradiância direta normal incidente no TOA. Com isso, $\left(\tau_{\lambda}\right)$ pode ser estimado segundo:

$$
\tau_{\lambda}=-\ln \left(\frac{\mathrm{E}_{\lambda, \mathrm{d}-n}}{\mathrm{E}_{0, \lambda} \cdot\left(\frac{\overline{\mathrm{d}}}{\mathrm{d}}\right)^{2}}\right) \cdot \frac{1}{m}
$$

onde $\left(\mathrm{E}_{\lambda, \mathrm{d}-\mathrm{n}}\right)$ é a irradiância espectral solar direta-normal efetivamente estimada pelo MFRSR.

Os dados dos MFRSR, para o cálculo da profundidade óptica do aerossol, sofrem ainda uma restrição com relação ao ângulo zenital solar, somente valores menores do que $75^{\circ}$ serão utilizados nos cálculos, visto que a aproximação plano-paralela não é válida em ângulos maiores [TOMASI et al., 1998].

Finalmente a profundidade óptica espectral do aerossol $\left(\tau_{\mathrm{a}, \lambda}\right)$ (POA) é obtida subtraindo de $\left(\tau_{\lambda}\right)$ as contribuições provenientes de espalhamento Rayleigh $\left(\tau_{\lambda, \text { Rayleigh }}\right)$, da atenuação devido às interações com o ozônio $\left(\tau_{\lambda, \mathrm{O}_{3}}\right)$, com o dióxido de nitrogênio $\left(\tau_{\left.\lambda, \mathrm{NO}_{2}\right)}\right.$ [ALEXANDROV et al., 2002a];

$$
\tau_{a, \lambda}=\tau_{\lambda}-\tau_{\lambda, \text { Rayleigh }}-\tau_{\lambda,\left(O_{3}\right)}-\tau_{\lambda,\left(N O_{2}\right)}
$$

\subsubsection{A contribuição do espalhamento Rayleigh}

O espalhamento Rayleigh é o principal fator a contribuir no cálculo da POA, pois apresenta valores significativos em relação à profundidade óptica do aerossol dependendo da região espectral analisada [FRÖHLICH \& SHAW, 1980]. O cálculo da profundidade óptica Rayleigh é realizado, neste trabalho, segundo o algoritmo algébrico de Hansen \& Travis [1974] e Alexandrov et al. [2002a], corrigido pela pressão atmosférica local. O valor de 
pressão atmosférica utilizado, é um valor climatológico para a cidade de São Paulo referente a um de 30 anos, fornecido pelo Instituto Nacional de Meteorologia (INMET) que corresponde a $\mathrm{P}=926,0 \mathrm{hPa}$.

A profundidade óptica de Rayleigh, para cada canal do MFRSR, é apresentada na tabela 3.1, os valores são significativos nos cálculos de profundidade óptica do aerossol, principalmente perante outras contribuições que serão discutidas nos tópicos subseqüentes, sendo a mais importante no canal $415 \mathrm{~nm}$.

Tabela 3.1- Valores de profundidade óptica espectral de Rayleigh para cada canal do MFRSR, e suas respectivas incertezas estimadas segundo Fröhlich \& Shaw [1980].

\begin{tabular}{ccc}
\hline $\begin{array}{c}\text { Canais } \\
(\mathbf{n m})\end{array}$ & $\boldsymbol{\tau}_{\text {Rayleigh }}$ & $\begin{array}{c}\text { Incerteza } \\
(\boldsymbol{\%})\end{array}$ \\
\hline $\mathbf{4 1 5}$ & 0,28 & $\pm 0,7$ \\
$\mathbf{6 7 2}$ & 0,04 & $\pm 0,7$ \\
$\mathbf{8 7 0}$ & 0,01 & $\pm 0,7$ \\
$\mathbf{1 0 3 6}$ & 0,007 & $\pm 0,7$ \\
\hline
\end{tabular}

\subsubsection{A contribuição devido à absorção pelo ozônio}

Vale lembrar que o ozônio interage com a radiação solar em comprimentos de onda do ultravioleta ao visível, e sua concentração é relativamente alta na estratosfera, apresentando valores muito baixos na troposfera [TOMASI et al.,1998]. Para o cálculo da profundidade óptica espectral de um gás qualquer é necessário obter a distribuição de moléculas integrada do TOA até a altura (z) na qual estão instalados os MFRSR, ou seja o valor de $\left(\mathrm{N}_{\mathrm{Z}}, \mathrm{O}_{3}\right)$ em [moléculas/ $\mathrm{cm}^{2}$ ] e o valor da secção de choque de absorção espectral $\left(\sigma_{\lambda}, \mathrm{O}_{3}\right)$. Foi adotado o valor fornecido por Shettle \& Anderson [1995] para a $\sigma_{\lambda}$ do ozônio. Conhecendo estes dois parâmetros calcula-se a profundidade óptica devido à absorção do ozônio de forma simples segundo a expressão 3.7 [ALEXANDROV et al., 2002 a].

$$
\tau_{\lambda, \mathrm{O}_{3}}=\mathrm{N}_{Z, \mathrm{O}_{3}} \cdot \sigma_{\lambda, \mathrm{O}_{3}}
$$

O valor da concentração do ozônio adotado foi estimado através de medidas do sensor TOMS-NASA (Total Ozone Mapping Spectrometer), expressa em Unidade Dobson (DU). A figura 3.4 ilustra a variabilidade da concentração do ozônio para a cidade de São 
Paulo ao longo de alguns anos (de 1996 a 2004), onde é visível certa regularidade na concentração do $\mathrm{O}_{3}$ integrado na coluna atmosférica:

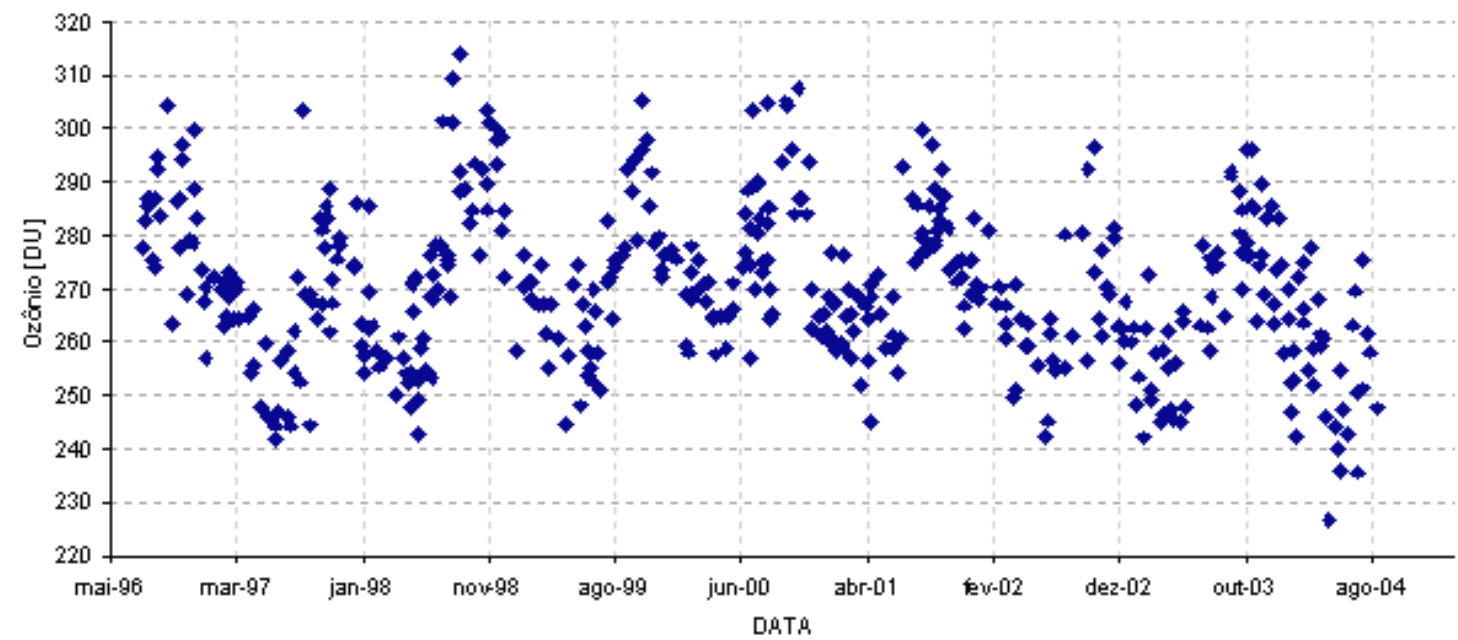

Figura 3.4 - Variabilidade interanual para o conteúdo de ozônio em Unidade Dobson (DU) para a região Metropolitana de São Paulo-SP, entre 1996 e 2004. Valores obtidos a partir de medições com o TOMS, para as coordenadas de $-23,5^{\circ}<$ latitude $<-23,75^{\circ}$ e $-46,45^{\circ}<$ longitude $<-46,30^{\circ}$.

O valor da contribuição do ozônio no cálculo da profundidade óptica espectral do aerossol se torna relevante apenas no canal $672 \mathrm{~nm}$, pois a secção de choque de absorção da molécula do ozônio não é significativa nos demais canais do MFRSR, como é apresentado na tabela 3.2.

Tabela 3.2 - Valores de secção de choque de absorção do ozônio $\left(\mathrm{O}_{3}\right)$ para cada canal segundo Shettle \& Anderson [1995].

\begin{tabular}{ccc}
\hline $\begin{array}{c}\text { Canais } \\
(\mathrm{nm})\end{array}$ & $\begin{array}{c}\sigma_{(\lambda)} \\
\left(10^{-24} \mathrm{~cm}^{2} / \text { molécula }\right)\end{array}$ & $\begin{array}{c}\text { Incerteza } \\
\left(10^{-24} \mathrm{~cm}^{2} / \text { molécula }\right)\end{array}$ \\
\hline 415 & 14,00 & 0,05 \\
672 & 1617,20 & 0,05 \\
870 & 52,03 & 0,05 \\
1036 & 1,76 & 0,05 \\
\hline
\end{tabular}

A tabela 3.2 mostra que nos outros canais, a influência do ozônio é pequena, como no caso do canal $870 \mathrm{~nm}$. Para este canal, com um valor médio mensal de $\mathrm{N}_{\mathrm{O} 3}=257 \mathrm{DU}$ (menor valor de concentração média mensal para o mês de abril, tabela 3.3) a profundidade óptica do ozônio é da ordem de $\tau_{870}\left(\mathrm{O}_{3}\right) \cong 0,00036$, ao passo que, para esta mesma concentração o valor da profundidade óptica para o ozônio no canal $672 \mathrm{~nm}$ é de $\tau_{672}\left(\mathrm{O}_{3}\right) \cong 0,0112$, ou seja, 
aproximadamente duas ordens de grandeza maior do que o do canal 870nm. Dessa forma, somente em $673 \mathrm{~nm}$ o seu efeito é importante.

Os valores médios mensais da concentração de ozônio foram calculados com dados fornecidos pelo sensor TOMS-NASA para a Região Metropolitana de São Paulo, restritos nas coordenadas $\left(-23,5^{\circ}<\right.$ latitude $<-23,75^{\circ}$ e $-46,45^{\circ}<$ longitude $\left.<-46,30^{\circ}\right)$, para uma climatologia de 05 anos de dados (de 1999 a 2003), na qual se encontra o período de medições dos MFRSR e é ilustrado na tabela 3.3:

Tabela 3.3 - Valores médios mensais e incertezas para a concentração do ozônio na Região Metropolitana de São Paulo $\left(-23,5^{\circ}<\right.$ latitude $<-23,75^{\circ}$ e $-46,45^{\circ}<$ longitude $\left.<-46,30^{\circ}\right)$ para o período entre 1999 e 2003 em [DU]

\begin{tabular}{cccccc}
\hline Mês & $\mathbf{N}_{\mathrm{Z}}\left(\mathbf{O}_{3}\right)$ & Incerteza & Mês & $\mathbf{N}_{\mathbf{Z}}\left(\mathbf{O}_{3}\right)$ & Incerteza \\
\hline Janeiro & 267 & 9 & Julho & 274 & 11 \\
Fevereiro & 266 & 5 & Agosto & 279 & 8 \\
Março & 262 & 7 & Setembro & 287 & 7 \\
Abril & 257 & 9 & Outubro & 285 & 11 \\
Maio & 262 & 6 & Novembro & $\mathbf{2 8 0}$ & 7 \\
Junho & 264 & $\mathbf{8}$ & Dezembro & $\mathbf{2 6 8}$ & 5 \\
\hline
\end{tabular}

\subsubsection{A contribuição da absorção pelo dióxido de nitrogênio}

$\mathrm{O}$ dióxido de nitrogênio $\left(\mathrm{NO}_{2}\right)$ presente na atmosfera interage com radiação em comprimentos de onda no intervalo entre $300<\lambda<550 \mathrm{~nm}$, ou seja, do ultravioleta ao visível [SHAW, 1976b]. Os óxidos de nitrogênio $\left(\mathrm{NO}_{\mathrm{x}}\right)$ são introduzidos na atmosfera através da ação de bactérias na deterioração de material orgânico e pela queima de combustíveis fósseis, estando presente tanto na troposfera quanto na estratosfera. Um dos processos ao qual o dióxido de nitrogênio presente na atmosfera está sujeito é a fotodissociação, que ocorre ao redor do comprimento de onda de 420nm o que contribui na formação de ozônio na atmosfera [ORPHAL, 2003].

O cálculo da profundidade óptica de absorção do dióxido de nitrogênio é semelhante à expressão 3.7, segundo Alexandrov et al. [2002a], apenas trocando os índices das variáveis.

Para o cálculo da profundidade óptica do $\mathrm{NO}_{2}$ serão empregados os valores de concentração obtidos por satélite, através do sensor Scanning Imaging Absorption Spectrometer for Atmospheric Chartography (SCIAMACHY) da European Space Agency 
(ESA). A figura 3.5 ilustra a distribuição espacial da concentração do $\mathrm{NO}_{2}$ troposférico e a integrada na coluna atmosférica respectivamente:
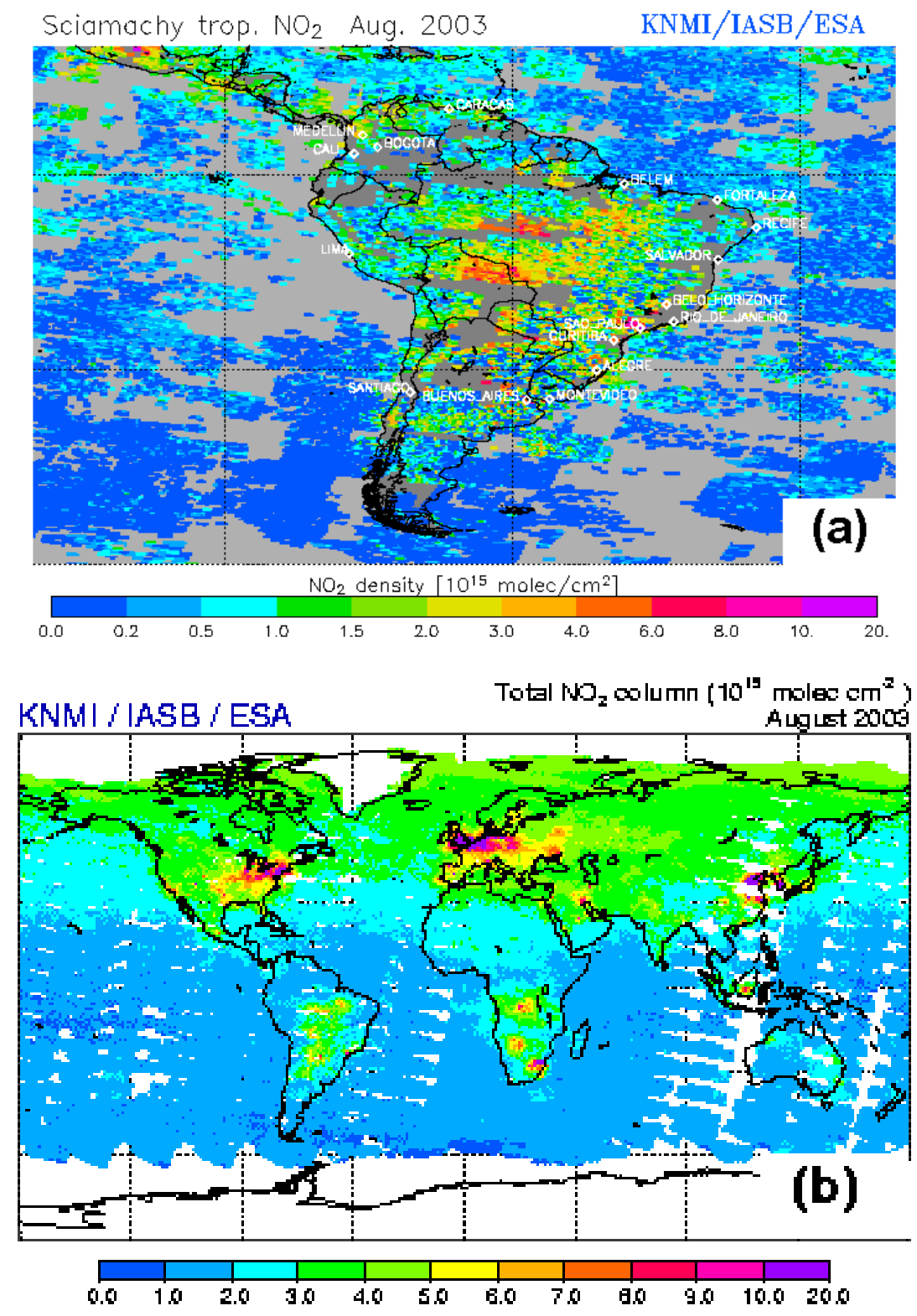

Figura 3.5 - Mapa com as concentrações do $\mathrm{NO}_{2}$ para a troposfera na América do Sul (a) e integrada na coluna atmosférica para o Globo Terrestre (b), ambos em agosto de 2003 em $\left[10^{15} \mathrm{molec} / \mathrm{cm}^{2}\right]$. Fonte - SCIAMACHY- ESA.

Dados diários deste sensor ainda são escassos para a Região Metropolitana de São Paulo, desta forma foram considerados valores médios mensais para a concentração do $\mathrm{NO}_{2}$ integrado na coluna atmosférica gerados pelo sensor SCIAMACHY, com base em resultados obtidos para o ano de 2003. Os valores médios mensais são apresentados na tabela 3.4. 
Tabela 3.4 - Valores médios mensais e incertezas para a concentração do $\mathrm{NO}_{2}$ integrado na atmosfera em $\left[10^{15}\right.$ moléculas $\left./ \mathrm{cm}^{2}\right]$. A incerteza corresponde ao desvio padrão das medidas.

\begin{tabular}{cccccc}
\hline Mês & $\mathbf{N}_{(\text {NO2 })}$ & Incerteza & Mês & $\mathbf{N}_{(\text {NO2 })}$ & Incerteza \\
\hline Janeiro & $\mathbf{7 , 0}$ & $\mathbf{2 , 0}$ & Julho & $\mathbf{9 , 0}$ & $\mathbf{2 , 0}$ \\
Fevereiro & $\mathbf{7 , 0}$ & $\mathbf{2 , 0}$ & Agosto & $\mathbf{9 , 0}$ & $\mathbf{2 , 0}$ \\
Março & $\mathbf{5 , 0}$ & $\mathbf{2 , 0}$ & Setembro & $\mathbf{9 , 0}$ & $\mathbf{2 , 0}$ \\
Abril & $\mathbf{7 , 0}$ & $\mathbf{2 , 0}$ & Outubro & $\mathbf{9 , 0}$ & $\mathbf{2 , 0}$ \\
Maio & $\mathbf{9 , 0}$ & $\mathbf{2 , 0}$ & Novembro & $\mathbf{5 , 0}$ & $\mathbf{2 , 0}$ \\
Junho & $\mathbf{9 , 0}$ & $\mathbf{2 , 0}$ & Dezembro & $\mathbf{5 , 0}$ & $\mathbf{2 , 0}$ \\
\hline
\end{tabular}

$\mathrm{O}$ valor da secção de choque de absorção para o $\mathrm{NO}_{2}$ foi obtido segundo Orphal [2003], sendo significativa no intervalo que vai de 240 a 790nm, portanto, o $\mathrm{NO}_{2}$ deverá ser levado em conta apenas nos canais $415 \mathrm{~nm}$ e $672 \mathrm{~nm}$. Os valores da seção de choque nesses comprimentos de onda são apresentados na tabela 3.5, bem como o valor da profundidade óptica do $\mathrm{NO}_{2}$ estimado para uma concentração máxima observada .

Tabela 3.5 - Valor da secção de choque de absorção para o $\mathrm{NO}_{2}$ segundo Orphal [2003] e o valor calculado para a profundidade óptica do $\mathrm{NO}_{2}$ para região Metropolitana de São Paulo no mês de agosto quando se obteve o maior valor médio mensal observado pelo sensor SCIAMACHY com uma concentração de $9 \times 10^{15}$ moléculas $/ \mathrm{cm}^{2}$.

\begin{tabular}{ccccc}
\hline $\begin{array}{c}\text { Canais } \\
(\mathbf{n m})\end{array}$ & $\begin{array}{c}\boldsymbol{\sigma}_{\lambda, \mathbf{N O}_{2}} \\
\left(\mathbf{c m}^{2} / \mathbf{m o l e ́ c u l a s}\right)\end{array}$ & $\begin{array}{c}\text { Incerteza } \\
\left(\mathbf{c m}^{2} / \text { moléculas }\right)\end{array}$ & $\boldsymbol{\tau}_{\lambda\left(\mathbf{N O}_{2}\right)}$ & Incerteza \\
\hline $\mathbf{4 1 5}$ & $5,31 \times 10^{-19}$ & $\pm 0,05 \times 10^{-19}$ & 0,0049 & 0,0005 \\
$\mathbf{6 7 2}$ & $0,08 \times 10^{-19}$ & $\pm 0,05 \times 10^{-19}$ & 0,0007 & 0,0005 \\
\hline
\end{tabular}

Comparando os valores de profundidade óptica do $\mathrm{NO}_{2}$ da tabela 3.5 com a profundidade óptica Rayleigh da tabela 3.1 nota-se que o maior valor de $\tau_{\lambda \mathrm{NO}_{2}}$ obtido para o canal $415 \mathrm{~nm}$ representa apenas $2 \%$ do valor da profundidade óptica Rayleigh no mesmo canal com a concentração de $\mathrm{NO}_{2}$ integrada na coluna para a Região Metropolitana de São Paulo fornecida pelo sensor SCIAMACHY. Este fato confirma o efeito majoritário, no cálculo da profundidade óptica do aerossol, do espalhamento Rayleigh. Como, de acordo com a OMM, a acurácia esperada na determinação de POA é de 0,02 observa-se que o $\mathrm{NO}_{2}$ praticamente não interfere na sua determinação, podendo ser desconsiderado nos cálculos de POA, considerando-se as concentrações médias mensais encontradas na Região Metropolitana de São Paulo até o momento. 


\subsection{Estimativa da incerteza instrumental do MFRSR}

A incerteza instrumental para cada canal dos dois MFRSR (MFR-434 e 435) foi estimada para permitir avaliar o erro referente aos valores de POA. A incerteza em cada canal não é informada pelo fabricante dos radiômetros. O método envolvido para estimar as incertezas espectrais dos MFRSR consiste em uma análise estatística pelo método dos Mínimos Quadrados que, de uma forma geral: determina a melhor reta média que passe por um conjunto de pontos experimentais, tal que se minimize a soma das distâncias deste conjunto de pontos à reta obtida, possibilitando um bom ajuste das incertezas dos pontos experimentais à reta de ajuste. A descrição com todo formalismo matemático e estatístico, pode ser encontrada em Vuolo [1996].

As incertezas foram consideradas iguais entre os dois MFRSR, pois os valores analisados são obtidos através de canais com valores nominais muito próximos e mesma resolução espectral (largura de 10nm). O teste estatístico foi aplicado utilizando valores da razão entre a irradiância difusa espectral e a irradiância global espectral medidas pelo mesmo sensor de cada MFRSR. Este procedimento garante que a calibração absoluta de cada instrumento e sua degradação ao longo do tempo não influenciem nos resultados, permitindo uma estimativa da incerteza instrumental dos MFRSR.

Os dias selecionados para a análise:

$\checkmark \quad 13 / 08 / 99 ; 24 / 08 / 99 ; 06 / 06 / 00 ; 07 / 06 / 00 ; 14 / 04 / 00 ; 16 / 04 / 00 ; 28 / 04 / 00 ; 29 / 04 / 00$; 05/05/01; 18/05/01 .

Apenas os resultados de dias que apresentaram mais de três horas de medições sem nuvens foram incluídos na análise. As razões espectrais obtidas com o MFR-435 foram confrontadas com as obtidas pelo MFR-434, considerado como instrumento de referência. Um ajuste linear pelo Método dos Mínimos Quadrados com tais resultados foi realizado, no qual as incertezas dessas razões foram estimadas impondo que o valor do $\left(\chi^{2}{ }_{\text {Reduzido }}\right)$ do ajuste estatístico fosse igual a um (o melhor ajuste possível para um conjunto de dados). O ajuste para os canais utilizados dos MFRSR é ilustrado na figura 3.6: 

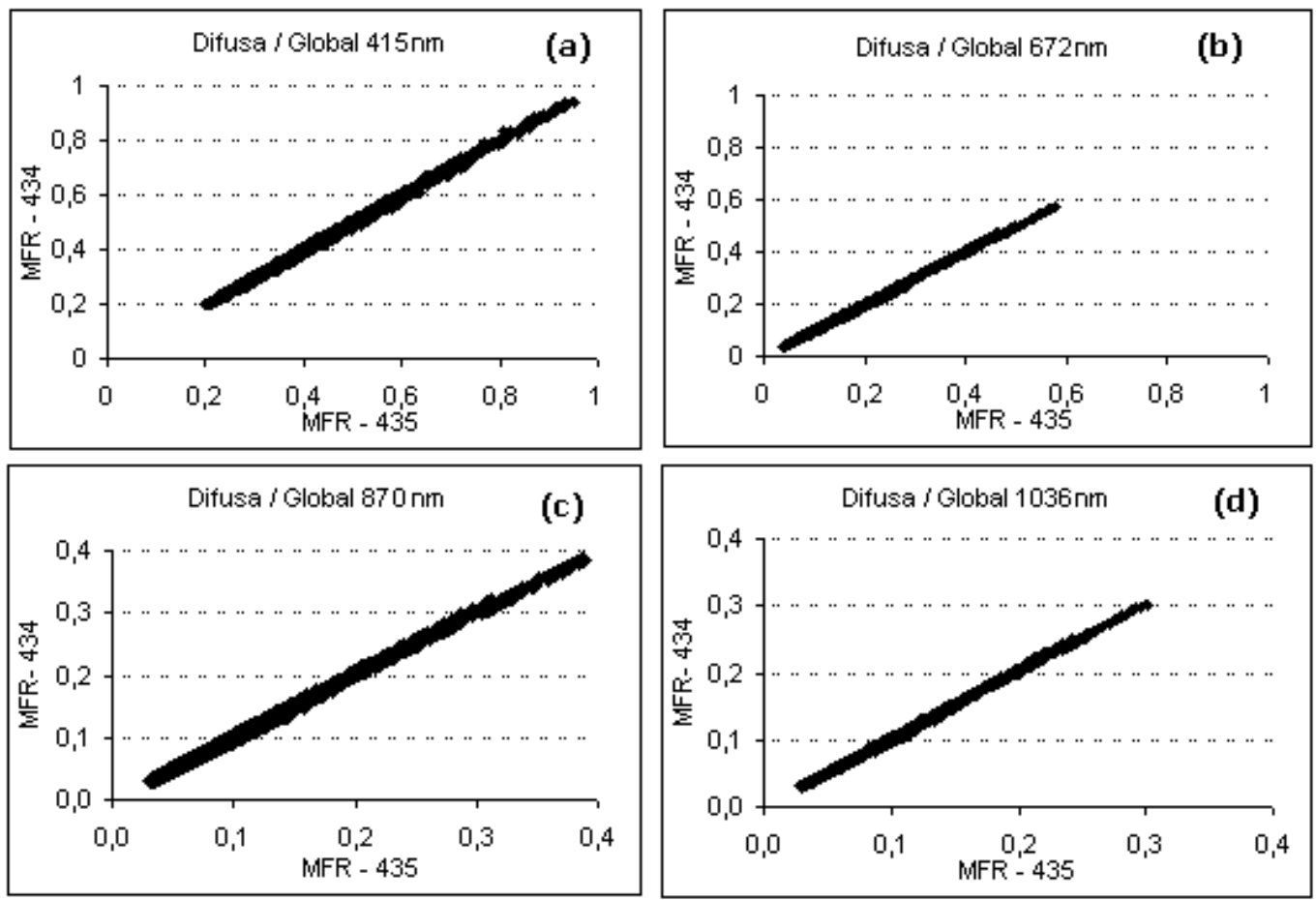

Figura 3.6 - Razão entre a irradiância difusa espectral e a global espectral para o MFR-434 (no eixo vertical, das ordenadas) (considerado o valor de referência) em função da mesma razão obtida com o MFR-435 (no eixo horizontal, das abscissas). As razões espectrais correspondem aos canais: (a) $415 \mathrm{~nm}$; (b) $672 \mathrm{~nm}$;(c) $870 \mathrm{~nm}$; (d) $1036 \mathrm{~nm}$.

Na figura 3.6 é ilustrada a boa concordância entre as razões espectrais dos dois instrumentos mesmo após três anos de operação. A qualidade dos resultados obtidos corrobora para que as eventuais divergências nos valores de irradiância espectral obtidas com os radiômetros se devam principalmente à degradação da sua calibração e não à incerteza instrumental. Os valores da incerteza instrumental espectral são apresentados na tabela 3.6.

Tabela 3.6 - Valores, por canal do MFRSR, da incerteza estatística instrumental (Incerteza) em (\%), dos coeficientes, angular (a) e linear (b), e respectivas incertezas ( $\sigma \mathrm{a}$ e $\sigma \mathrm{b}$ ), todos adimensionais determinados pelo método dos mínimos quadrados.

\begin{tabular}{cccccc}
\hline $\boldsymbol{\lambda}(\mathbf{n m})$ & $\begin{array}{c}\text { Incerteza } \\
(\mathbf{\%})\end{array}$ & $\mathbf{a}$ & $\boldsymbol{\sigma a}$ & $\mathbf{b}$ & $\boldsymbol{\sigma b}$ \\
\hline $\mathbf{4 1 5}$ & 1,0 & 1,0080 & 0,0007 & $-0,0076$ & 0,0003 \\
$\mathbf{6 7 2}$ & 1,2 & 1,0021 & 0,0005 & $-0,00207$ & 0,00005 \\
$\mathbf{8 7 0}$ & 1,3 & 1,0103 & 0,0006 & $-0,00195$ & 0,00005 \\
$\mathbf{1 0 3 6}$ & 1,2 & 1,0088 & 0,0006 & 0,00015 & 0,00005 \\
\hline
\end{tabular}




\subsection{Calibração dos MFRSR - Determinação da constante solar}

Os radiômetros do tipo MFRSR devem ser calibrados constantemente, como qualquer outro equipamento científico, para que efetivamente forneçam valores acurados e precisos. Para tanto existem algumas formas para calibrá-los, como por exemplo, comparando os dados gerados com um instrumento de referência e comparar os valores medidos (transferência de calibração) ou enviando ao fabricante. No caso dos MFRSR, o fabricante recomenda o seu retorno periódico ao laboratório de origem, localizado nos Estados Unidos. Porém este procedimento envolve problemas de ordem burocrática e principalmente de tempo no qual o monitoramento contínuo da profundidade óptica do aerossol ficaria prejudicado.

Assim, com o intuito de melhorar a precisão e exatidão dos valores estimados de POA através dos MFRSR, foi empregado, inicialmente o método de calibração chamado de "Langley Plot Intercept", ou simplesmente de método Langley. Este método se mostra adequado, pois não sofre dependência da função filtro e da calibração absoluta do instrumento [HARRISON et al., 1994] não exigindo que o instrumento seja enviado ao fabricante. Posteriormente foi empregado outro método de calibração, o Método Geral proposto por Forgan [1998], com dados medidos no próprio sítio de operação do MFRSR. A aferição

periódica da calibração permitiu estimar um ajuste linear que pudesse representar a degradação da calibração dos MFRSR ao longo tempo, conforme será detalhado ainda neste capítulo.

\subsubsection{Calibração dos MFRSR pelo método Langley}

O método de Langley consiste basicamente em considerar a atmosfera sendo planoparalela onde a Lei de Beer, Bouguer e Lambert é válida [Liou, 2002]. Construindo-se gráficos do valor medido da irradiância solar espectral direta normal em cada canal do MFRSR ( $\left.E_{\lambda, d-n}\right)$ em função da respectiva massa óptica, é possível determinar a irradiância espectral no TOA $\left(\mathrm{E}_{0 \lambda}\right)$ através de uma equação linear. A expressão 3.8 representa a Lei de Beer para aplicação do método de Langley.

$$
\ln \left(E_{\lambda, d-n}\right)=-m \tau_{\lambda}+\ln \left(E_{0 \lambda \text {-diário }} \cdot\left(\frac{\overline{\mathrm{d}}}{\mathrm{d}}\right)^{-2}\right)
$$

onde $\left(\mathrm{E}_{0 \lambda \text {-diário }}\right)$ corresponde à irradiância espectral incidente no TOA obtida para cada dia no qual é aplicado o método de Langley. A irradiância no topo varia de dia para dia devido à 
variação da distância Terra-Sol. Para a obtenção da constante solar propriamente dita, correções para a distância Terra-Sol, devem ser efetuadas.

$\mathrm{O}$ método de Langley resulta em um ajuste linear do tipo $(\mathrm{y}=\mathrm{ax}+\mathrm{b})$ onde (a) é o coeficiente angular e (b) o linear. Assim os parâmetros do ajuste linear corresponderão aos termos da equação 3.8 onde $\left[\mathrm{b}=\ln \left(\mathrm{E}_{0 \lambda \text {-diário }}\right) ; \mathrm{a}=\tau_{\lambda} ; \mathrm{x}=\mathrm{m}\right]$. Desta maneira obtemos o valor de $\left(\mathrm{E}_{0 \lambda}\right)$ simplesmente admitindo o valor da massa óptica valendo zero no TOA e efetuando a correção da distância Terra-Sol. Da expressão 3.8, como a variável independente é (m), é necessário que a atmosfera seja homogênea, isto é, $\left(\tau_{\lambda}\right)$ deve ser constante durante o período de medição, para a aplicação do método, que em geral corresponde a uma manhã ou tarde sem nuvens. A figura 3.7 ilustra um dos dias para os quais foi aplicado o método de Langley com medidas efetuadas no ano de 2000 em Campos do Jordão.

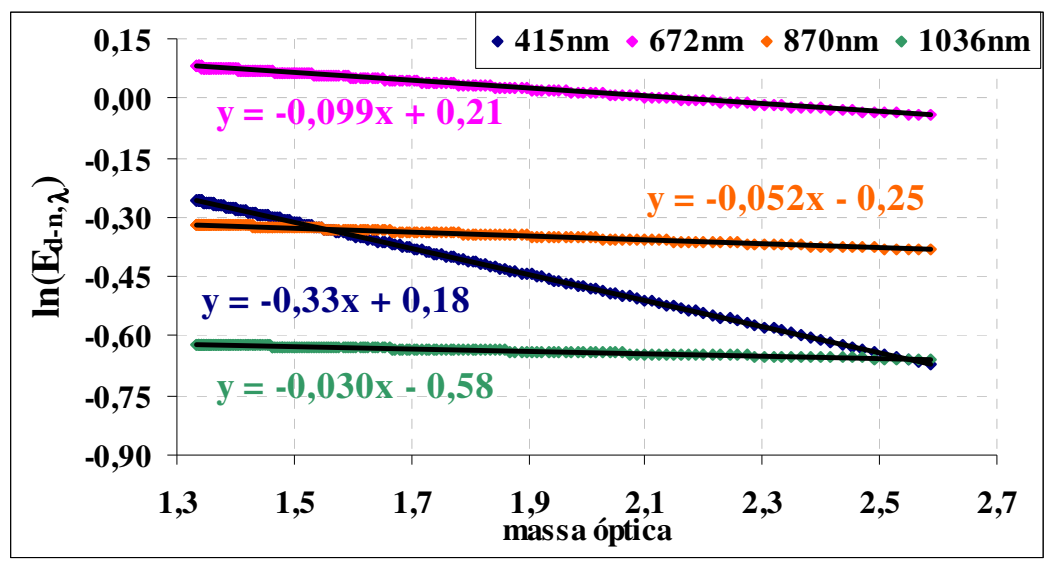

Figura 3.7 - Aplicação do método de Langley em dados de irradiância espectral direta-normal $\left(\mathrm{E}_{\mathrm{d}-\mathrm{n}, \lambda}\right)$ medidos com o MFRSR (MFR-434), e ajustados pelo método dos Mínimos Quadrados. As medidas foram realizadas no dia 28 de julho de 2000 na estação do Departamento de Águas e Energia Elétrica do Estado de São Paulo (DAEE) a $1600 \mathrm{~m}$ de altitude localizada em Campos do Jordão.

Para a aplicação do método de Langley é necessário que a atmosfera seja estável e homogênea horizontalmente durante o período de medições, considerando-se diferentes ângulos de elevação do sol. Esta restrição, de estabilidade temporal da atmosfera, é uma condição difícil de ser atendida em grandes cidades e perto de centros poluidores. Shaw [1983] sugere que esta calibração pode ser efetuada em regiões com altitudes mais elevadas, longe de fontes de poluição como encontrado em topos de montanhas. 


\subsubsection{O Método Geral}

O "Método Geral” proposto por Forgan [1994] visa relaxar as restrições que o método Langley Plot impõe às condições atmosféricas, bem como oferecer uma alternativa ao uso de lâmpadas padrão que geram erros que variam entre 2 a $5 \%$, possibilitando calibrações no próprio sítio de operação dos radiômetros. $\mathrm{O}$ erro na constante solar com aquela magnitude, em dias com profundidade óptica do aerossol baixa, gera erros na POA de até $100 \%$. No Método Geral, não é necessário que as condições de extinção permaneçam constantes no período de aplicação do método. É necessário apenas que a distribuição de tamanho relativa do aerossol permaneça constante durante as observações. Outra condição para a implementação da calibração através do Método Geral é que o componente de extinção do aerossol $\left\{m_{a}(t) \tau_{a}\left(t, \lambda_{0}\right)\right\}$ para um dos canais espectrais $\left(\lambda_{0}\right)$ deve ser conhecido, isto é, a constante de calibração para um dos canais do radiômetro, canal de referência para a calibração, deve ser bem conhecida [Forgan,1994]. A descrição matemática do Método Geral segundo Forgan [1994] é descrita a seguir:

A distribuição do tamanho do aerossol pode ser descrita como sendo:

$$
\partial N(t) / \partial \ln r=A(t) f(r)
$$

onde: $f(r)$ é a distribuição de tamanho relativa, que é dependente apenas do raio das partículas (r) e $A(t)$ é o fator necessário para recuperar o número total de partículas para um tempo qualquer $(t)$.

A profundidade óptica do aerossol para esta distribuição para o tempo (t) é dada como:

$$
\tau_{a}(t, \lambda)=\int_{\infty}^{z^{\prime}} \pi A(t) \int Q_{e x t}(r, \lambda) r^{2} f(r) d(\ln r) d(z)
$$

onde $Q_{\text {ext }}$ é a eficiência de extinção, que é dependente apenas do comprimento de onda $\lambda$, do índice de refração e do raio da partícula.

Uma vez que $A(t)$ é independente do comprimento de onda e do raio, a POA para qualquer tempo $(t)$ pode ser obtida como:

$$
\tau_{a}(t, \lambda)=\tau_{a}\left(t_{0}, \lambda\right) A(t) / A\left(t_{0}\right)
$$

Para quaisquer dois comprimentos de onda $\lambda_{1}$ e $\lambda_{0}$ teremos:

$$
\begin{aligned}
& \tau_{a}\left(t, \lambda_{1}\right)=\tau_{a}\left(t_{0}, \lambda_{1}\right) A(t) / A\left(t_{0}\right) \\
& \tau_{a}\left(t, \lambda_{0}\right)=\tau_{a}\left(t_{0}, \lambda_{0}\right) A(t) / A\left(t_{0}\right)
\end{aligned}
$$


onde: $\lambda_{0}$ é o comprimento de onda (canal) de referência para o qual conhecemos a constante solar; $\lambda_{l}$ é o canal que desejamos calibrar.

Portanto teremos que:

$$
\tau_{\mathrm{a}}\left(\mathrm{t}, \lambda_{1}\right) / \tau_{\mathrm{a}}\left(\mathrm{t}_{0}, \lambda_{1}\right)=\tau_{\mathrm{a}}\left(\mathrm{t}, \lambda_{0}\right) / \tau_{\mathrm{a}}\left(\mathrm{t}_{0}, \lambda_{0}\right)=\mathrm{A}(\mathrm{t}) / \mathrm{A}\left(\mathrm{t}_{0}\right)
$$

para qualquer tempo $(t)$, manipulando a equação (3.14) teremos:

$$
\tau_{a}\left(t, \lambda_{1}\right) / \tau_{a}\left(t, \lambda_{0}\right)=\tau_{a}\left(t_{0}, \lambda_{1}\right) / \tau_{a}\left(t_{0}, \lambda_{0}\right)=\text { const. }=\psi_{01}
$$

O componente de extinção do aerossol para os dois comprimentos de onda pode ser obtido considerando que o valor referência para o topo da atmosfera é $\left(E_{0 i}\right)$ e que o valor medido em superfície é $\left(E_{i}(t)\right)$, onde $(i)$ pode ser qualquer um dos comprimentos de onda, $\lambda_{0}$ ou $\lambda_{1}$. Assim temos que:

$$
\mathrm{m}_{\mathrm{a}} \tau_{\mathrm{a}}\left(\mathrm{t}, \lambda_{\mathrm{i}}\right)=\ln \mathrm{E}_{0 \mathrm{i}}-\left[\ln \mathrm{E}_{\mathrm{i}}(\mathrm{t})+\mathrm{m}_{\mathrm{m}}(\mathrm{t}) \tau_{\mathrm{m}}\left(\mathrm{t}, \lambda_{\mathrm{i}}\right)+\mathrm{m}_{\mathrm{g}}(\mathrm{t}) \tau_{\mathrm{g}}\left(\mathrm{t}, \lambda_{\mathrm{i}}\right)\right]
$$

onde $m_{a}, m_{m}$ e $m_{g}$ são as massas ópticas relativas do aerossol, das moléculas e do gás absorvedor em questão, respectivamente.

Da equação (3.15) temos que a razão entre a POA dada para dois comprimentos de onda é uma constante quando a distribuição de tamanho relativa do aerossol é constante no tempo. Portanto temos que:

$$
\psi_{01}\left[m_{a}(t) \tau_{a}\left(t, \lambda_{0}\right)\right]-\ln E_{01}=-\left[\ln E_{1}(t)+m_{m}(t) \tau_{m}\left(t, \lambda_{1}\right)+m_{g}(t) \tau_{m}\left(t, \lambda_{1}\right)\right]
$$

$\operatorname{Assim}\left(E_{01}\right)$ é a solução requerida para a calibração do fotômetro. Se $\left(E_{00}\right), \lambda_{0}, \lambda_{1} \mathrm{e}$ as profundidades ópticas de extinção $\left(\tau_{g}\right)$ e $\left(\tau_{m}\right)$ são conhecidos ou podem ser calculados então a expressão (3.17) pode ser resolvida através de uma regressão linear para derivar a constante $\left(\psi_{01}\right)$ (coeficiente angular) e $\left(-\ln E_{01}\right)$ (coeficiente linear). Desta forma a equação (3.17) pode ser reescrita da seguinte forma:

$$
A x(t)+B=y(t)
$$

onde teremos os seguintes termos:

$$
\begin{array}{ll}
\checkmark & x(t)=\left[m_{a}(t) \tau_{a}\left(t, \lambda_{0}\right)\right] ; \\
\checkmark & \mathrm{y}(\mathrm{t})=-\left[\ln \mathrm{E}_{1}(\mathrm{t})+\mathrm{m}_{\mathrm{m}}(\mathrm{t}) \tau_{\mathrm{m}}\left(\mathrm{t}, \lambda_{1}\right)+\mathrm{m}_{\mathrm{g}}(\mathrm{t}) \tau_{\mathrm{g}}\left(\mathrm{t}, \lambda_{1}\right)\right] ; \\
\checkmark & A=\psi_{01} ; \\
\checkmark & \mathrm{B}=-\ln \mathrm{E}_{01} .
\end{array}
$$

Essencialmente neste método, conhecendo de forma acurada a profundidade óptica de extinção do aerossol (POA) para um comprimento de onda é possível derivar a constante de calibração para um segundo comprimento de onda. Esse método pode ser aplicado entre diferentes canais de um mesmo instrumento. Uma variante é utilizar a POA obtido a partir de 
um fotômetro bem calibrado para calibrar outro instrumento. Segundo Forgan [1994] o método geral produz uma variância significativamente menor do que o Langley Plot nos resultados da calibração efetuada no sítio de operação do instrumento se os mesmos períodos e dados empregados no Método Geral forem utilizados.

No Método Geral algumas fontes de erros podem afetar a estimativa da constante de calibração $\left(E_{01}\right)$ obtida.Uma possível fonte de erro é a utilização da POA de referência não acurada. Outras fontes de erro estão associadas à correção dos componentes de extinção, ou seja, a profundidade óptica molecular e absorção gasosa [FORGAN,1994].

\subsection{Transferência de calibração entre os MFRSR}

Obtido os valores para a constante solar espectral para um dos radiômetros, é possível transferir a calibração de um instrumento para o outro, ou seja, realizar um processo de calibração indireta [HOLBEN et al., 1998]. Isto pode ser feito, selecionando alguns dias em que os dois radiômetros operaram simultaneamente no período subseqüente à última calibração efetuada e comparando-se os valores de irradiância solar espectral direta normal de ambos MFRSR, tomando como referência o que havia sido calibrado. A idéia na transferência de calibração dos MFRSR é a mesma empregada na estimativa da incerteza instrumental já discutida, com a diferença que agora tem-se interesse em estimar as diferenças entre os canais dos dois MFRSR devido à degradação da calibração. Desta forma é obtida, de uma maneira simples, uma nova constante solar espectral $\left(\mathrm{E}_{0 \lambda}\right)$ para o topo da atmosfera com o radiômetro que se deseja calibrar. Neste método de calibração indireto o ajuste linear foi estimado pelo método estatístico de Mínimos Quadrados.

\subsection{Estimativa da incerteza no cálculo da POA de MFRSR}

A incerteza no valor da profundidade óptica do aerossol (POA), segundo a Teoria dos Erros, é obtida propagando-se a contribuição da incerteza de cada grandeza envolvida na sua estimativa [VUOLO, 1996]. Para tanto, é possível obter a incerteza na POA efetuando a propagação de erros em duas etapas. A expressão 3.19 calcula a incerteza na profundidade óptica total da atmosfera como segue: 


$$
\sigma \tau_{\lambda}=\left\{\left(\frac{1}{m \cdot . E_{0}, \lambda} \cdot \cdot \sigma E_{0 \lambda}\right)^{2}+\left(\frac{1}{m \cdot E_{\lambda, d-n}} \cdot \sigma E_{\lambda, d-n}\right)^{2}+\left(\frac{1}{m} \cdot \tau \lambda \cdot \sigma m\right)^{2}\right\}^{\frac{1}{2}}
$$

A expressão 3.20 representa a incerteza na POA, pois complementa a propagação de erro na incerteza da profundidade óptica total, com as contribuições da profundidade óptica devido ao espalhamento Rayleigh, absorção gasosa pelo ozônio $\left(\mathrm{O}_{3}\right)$ e pelo dióxido de nitrogênio $\left(\mathrm{NO}_{2}\right)$.

$$
\sigma \tau_{\mathrm{a}, \lambda}=\left\{\left(\sigma \tau_{\lambda}\right)^{2}+\left(\sigma \tau_{(\text {Rayleigh })}\right)^{2}+\left(\sigma \tau_{\left(\mathrm{O}_{3}\right)}\right)^{2}+\left(\sigma \tau_{\left(\mathrm{NO}_{2}\right)}\right)^{2}\right\}^{\frac{1}{2}}
$$

As incertezas das grandezas empregadas nas estimativas da POA foram sintetizadas na Tabela 3.7.

Tabela 3.7 - Incertezas espectrais das grandezas que fazem parte da propagação de erro no cálculo da incerteza da profundidade óptica do aerossol $\left(\sigma \tau_{\mathrm{a} \lambda}\right)$, o valor percentual corresponde

\begin{tabular}{|c|c|c|}
\hline Constante solar $\left(\mathrm{E}_{0 \lambda}\right)$ & $1,0 \leq \sigma \mathrm{E}_{0 \lambda} \leq 2,0 \%$ & estimado neste trabalho \\
\hline Irradiância espectral & ireta-normal $1,0 \leq \sigma \mathrm{E}_{\lambda, \mathrm{d}-\mathrm{n}} \leq 1,3 \%$ & abalho tabela 3.6 \\
\hline Massa óptica (m) & $\sigma \mathrm{m} \leq 0,5 \%$ & Kasten \& Young (1989) \\
\hline$\tau_{\lambda, \text { Rayleigh }}$ & $\sigma \tau_{\lambda \text { Rayleigh }}=0,7 \%$ & Fröhlich \& Shaw (1980) \\
\hline$\tau_{\lambda(03)}$ & $5,0 \times 10^{-4} \leq \sigma \tau_{\lambda(03)} \leq 6,0 \times 10^{-4}$ & estimado neste trabalho \\
\hline$\tau_{\lambda(\mathrm{NO} 2)}$ & $\sigma \tau_{\lambda(\mathrm{NO} 2)}=0,0005$ & estimado neste trabalho tabela 3.5 \\
\hline
\end{tabular}
a grandeza apresentada na tabela.

Obs: $\sigma \tau_{\lambda\left(\mathrm{NO}_{2}\right)}$ e $\boldsymbol{\sigma} \tau_{\lambda\left({ }_{3}\right)} \rightarrow$ o valor é apresentado em profundidade óptica

As contribuições da atenuação por ozônio e dióxido de nitrogênio podem ser desconsideradas nas estimativas da incerteza por apresentarem valores muito pequenos de acordo com a propagação de erros, em relação aos dados apresentados na Tabela 3.7. Desta forma, a incerteza no espalhamento Rayleigh, da massa óptica, na constante solar e na irradiância direta normal medida pelo MFRSR serão as grandezas majoritárias para o valor da incerteza espectral da POA

\subsection{Pré-Filtro automático para exclusão de nuvens em dados de MFRSR}

Para o processamento do elevado número de dados obtidos com os MFRSR e obter a profundidade óptica do aerossol, foi necessário aplicar um filtro automático de nuvens que seja eficiente em eliminar dados obtidos com os MFRSR que apresentem variabilidades causadas por nuvens que interferem diretamente nos valores de POA obtidos. A ausência de 
um algoritmo de limpeza de nuvens (cloud screening algorithm) eficiente tem sido sempre um problema para inversões com céu limpo (sem nuvens). O problema é que a variabilidade da POA, além de apresentar uma forte característica do sítio onde se localiza a instrumentação, confunde-se muitas vezes com a contaminação causada por nuvens altas e pouco espessas, como nuvens Cirrus [ALEXANDROV et al., 2004].

Neste trabalho foram aplicados três testes para analisar a possível contaminação por nuvens: a razão entre a irradiância direta-normal pela difusa, empregada em vários trabalhos como os de Long \& Ackerman, [2000]; Alexandrov et al. [2002a]; Augustine et al., [2003], no canal 870nm que foi sugerido por Alexandrov et al. [2004] como traçador da assinatura espectral de nuvens em fotometria espectral. Neste canal tem-se apenas influência de nuvens e do próprio aerossol nas medições. O segundo teste empregado foi a análise da variabilidade do aerossol através do desvio padrão da POA [SMIRNOV et al., 2000; MICHALSKY et al., 2001] e finalmente, a análise do coeficiente de Ångström.

A presença de nuvens gera alta variabilidade nos dados de POA em um curto espaço de tempo, fenômeno que não é característico da variabilidade natural do aerossol observada na atmosfera em dias de céu limpo, pois se espera um comportamento mais estável do aerossol (POA). Assim a passagem de uma nuvem provoca nos valores de POA um incremento significativo da profundidade óptica em um curto intervalo de tempo, bem como um decréscimo acentuado no valor do coeficiente de Ångström.

Portanto, estes três fatores combinados (a razão entre a irradiância direta-normal e a difusa, o coeficiente de Ångström entre os canais 672/870nm e o desvio padrão da POA em $870 \mathrm{~nm}$ ) foram empregados como um filtro de nuvens automático que fosse eficiente o suficiente para eliminar a influência de nuvens dos dados, mas que não fosse extremamente rigoroso a ponto de eliminar uma grande quantidade de valores válidos de POA. Após uma série de avaliações com diversas combinações destes fatores e intervalos de tempo para a avaliação do desvio padrão, foram obtidos os seguintes ajustes (valores) para estes três parâmetros do filtro de nuvens:

- Razão entre a irradiância direta-normal e a difusa (RDN) no canal 870nm: são admitidos como sendo valores válidos aqueles em que a RDN é maior do que 1,5, ou seja, a irradiância direta normal no canal 870nm tem que ser uma vez e meia maior do que a irradiância difusa. Este valor permite filtrar nuvens mais espessas e não elimina nos casos com altos valores de POA (valores de POA no canal $415 \mathrm{~nm}$ acima de 1,5 ou acima de 0,5 no canal 870nm); 
- Coeficiente de Ångström entre os canais 672/870nm deve ser maior do que 0,5. Este valor também permite a eliminação de nuvens e não impede a detecção de plumas de aerossol mais grosso;

- O desvio padrão da POA em 870nm foi calculado em um intervalo de 9 minutos (lembrando que cada dado corresponde à média da irradiância espectral de 4 medidas executadas no intervalo de 1minuto). Assim sendo o valor mínimo admitido para a variabilidade espectral da POA neste canal deve ser menor ou igual a 0,015 (valor da incerteza média da POA neste canal). Este valor permite eliminar variabilidades na POA que se espera não esteja associada ao aerossol e sim à contaminação por nuvens muito tênues.

- É necessário que as três condições sejam satisfeitas simultaneamente, caso não sejam, o algoritmo exclui este período e passa a analisar o próximo período de 9minutos.

A figura 3.8 (de a até f) ilustra a aplicação do filtro de nuvens em dois dias: 29/08/99 figura 3.8(a, c, e) com POA extremamente alta em relação aos valores médios encontrados para São Paulo e o dia 02/06/02 figura 3.8(b, d, f) com valores de POA reduzidos em relação aos valores médios de POA, com dados do MFRSR (MFR-434): 

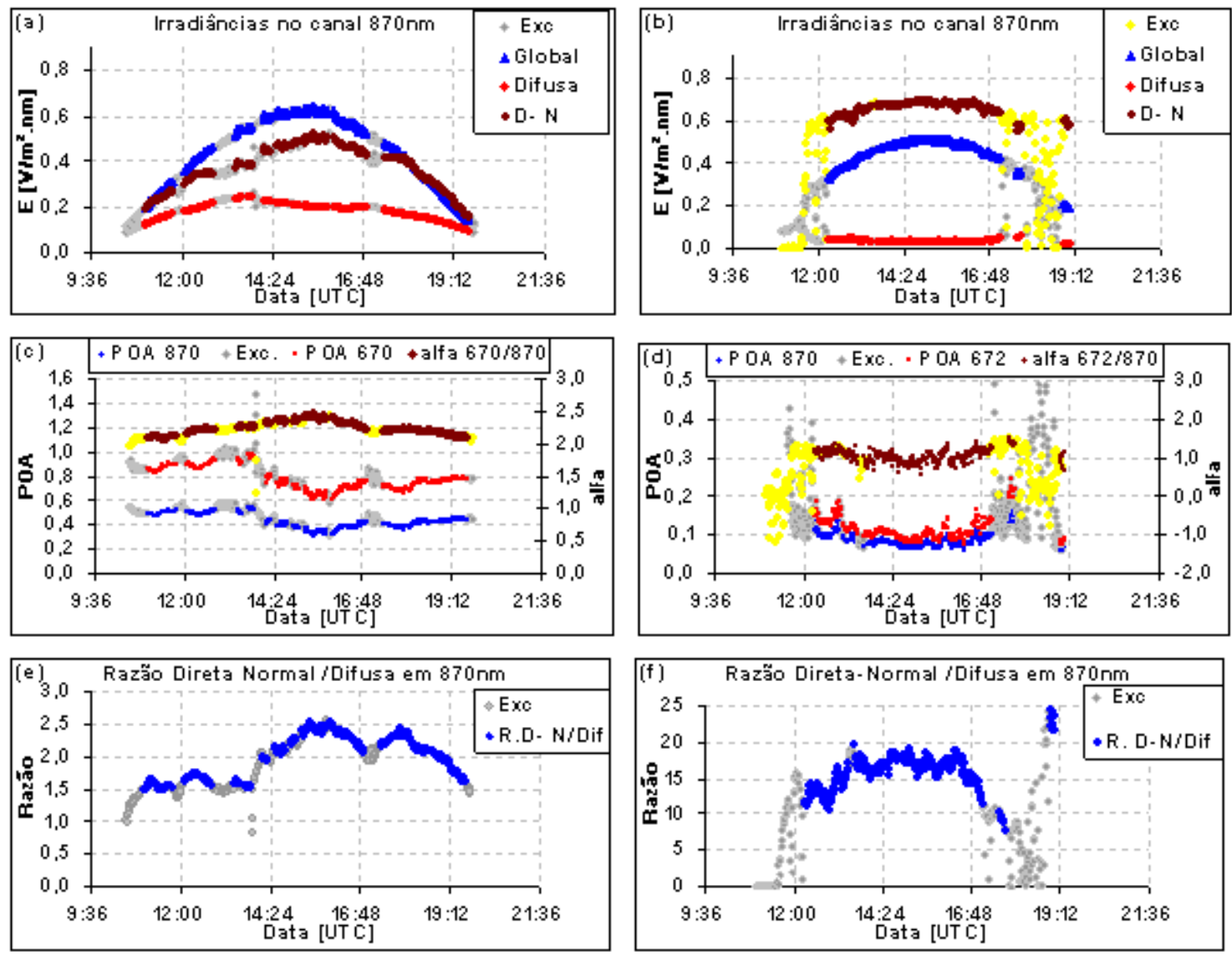

Figura 3.8 ('a' até 'f')- Irradiância global, difusa e direta-normal (D-N) (figuras a, b), POA em 870nm e 672nm e coeficiente de Ångström (alfa) em 672/870nm (figuras c, d), Razão da irradiância Direta-Normal pela Difusa (R.D-N/Difusa) em 870nm (figuras e, f) em dois dias da base de dados medidos na Estação Meteorológica do IAG/USP nos anos de 1999 e 2002. As figuras 2(a, c, e) correspondem ao dia 29/08/99 e as figuras 2(b, d, f) correspondem ao dia 02/06/02. Os pontos em amarelo nas figuras (c, d) correspondem aos pontos excluídos do coeficiente de Ångström.

O filtro consegue excluir a maior parte dos pontos espúrios (contaminados) apresentados em amarelo nas figuras 3.8(c, d) para o coeficiente de Ångström e em cinza para os valores de POA nestes canais. Também são apresentados na figuras 3.8(e, f) o valor da Razão entre a irradiância Direta-Normal /Difusa no canal 870nm e os valores correspondentes aos intervalos excluídos pelo filtro em cinza. Conforme já citado, filtrar nuvens de forma automática em fotometria solar ainda é um problema que está sendo estudado por vários autores e em sua maioria são algoritmos ajustados a cada sítio de operação. Assim ajustar um filtro que elimine apenas nuvens ainda é um desafio. O filtro aplicado e proposto neste trabalho, para São Paulo, mostra-se eficiente ao excluir dados suspeitos de estarem contaminados por nuvens, porém, neste processo, alguns intervalos excluídos podem não ter sido influenciados por nuvens. Entretanto, como o número de pontos excluídos erroneamente não é significativo em relação à 
base de dados válidos que impeça análise da variabilidade do aerossol ao longo do ciclo diurno, o filtro foi considerado satisfatório.

\subsection{Avaliação da POA estimada com os MFRSR e o fotômetro solar da rede AERONET}

Para compararmos as duas bases, os dados do MFRSR foram reduzidos para a frequiência de tempo da AERONET, ou seja, os valores minuto a minuto foram transformados em médias aritméticas em torno do horário do dado da AERONET (4 minutos antes e 4 minutos depois), como sugerido no trabalho de Rosário [2006]. A incerteza do MFRSR correspondendo ao desvio padrão da média do intervalo analisado.

\subsection{Comparação entre variáveis meteorológicas e propriedades ópticas}

Para padronizar a base de dados meteorológica todas as VM (temperatura, pressão, UR e vento) foram consideradas como valores médios horários, quando comparados com as propriedades ópticas estimadas com os MFRSR. Para permitir a comparação entre as VM e as propriedades ópticas estimadas com os MFRSR, que estão em freqüência temporal de minuto em minuto, foi preciso reduzir os dados do MFRSR para a mesma freqüência das VM. Para tanto foi calculado o valor médio horário para as propriedades ópticas do aerossol.

Após a padronização dos dados foi possível selecionar uma série de dados em dias que apresentaram várias horas de céu limpo a partir do período da manhã. Este objetivo em parte é alcançado com o emprego do filtro automático de nuvens descrito neste trabalho e pela inspeção visual dia a dia da variabilidade da irradiância solar global, direta-normal e difusa medidas pelos MFRSR (tanto valor global integrado como o espectral). O período da base de dados analisados compreende o intervalo de agosto de 1999 até dezembro de 2002, período em que os MFRSR estiveram instalados na EM do IAG-USP. 


\section{Capítulo IV: Resultados}




\subsection{A Calibração dos MFRSR}

A calibração dos MFRSR no período de 1999 a 2006 foi obtida de forma independente em relação a outros instrumentos de referência. Ela ocorreu basicamente em duas etapas, uma delas foi calibrar um dos radiômetros pelo Método Langley em sítios localizados a grandes altitudes (topos de montanhas) no Brasil, e com isso obter valores acurados e precisos para a constante espectral solar e a segunda foi estimar estas mesmas constantes com o uso do Método Geral nos sítios de medições dos MFRSR em São Paulo. O instrumento escolhido para ser instalado nos sítios de calibração foi o MFR-434, por que ele foi exposto ao tempo de forma menos freqüente em todo o período de medições analisado, além de não ter sofrido consertos que afetassem a tendência de degradação do conjunto fotodetector como no caso do MFR-435 que foi enviado ao fabricante em 2002 para conserto e aferição.

\subsubsection{Calibração do MFR-434 pelo Método Langley}

\subsubsection{Estimativa para o ano de 2000 em Campos do Jordão - SP}

Para garantir as restrições impostas pelo Método Langley, o MFR-434 foi instalado em julho de 2000, na estação do Departamento de Águas e Energia Elétrica do Estado de São Paulo (DAEE) a 1600 metros de altitude localizada em Campos do Jordão - SP (Latitude $-22^{\circ} 22^{`}$ e Longitude $-45^{\circ} 29^{`}$ ).

Nesta calibração foram selecionados dados de apenas 04 dias de medições do período total no qual o MFR-434 esteve instalado na estação do DAEE, apesar do instrumento ter permanecido em funcionamento de 02 de julho a 03 de agosto de 2000. A maior parte desse período apresentou nebulosidade. Os dias selecionados são do período da tarde do dia 24/07 e as manhãs dos dias 28/07, 29/07 e 30/07 ilustrados na figura 4.1. 

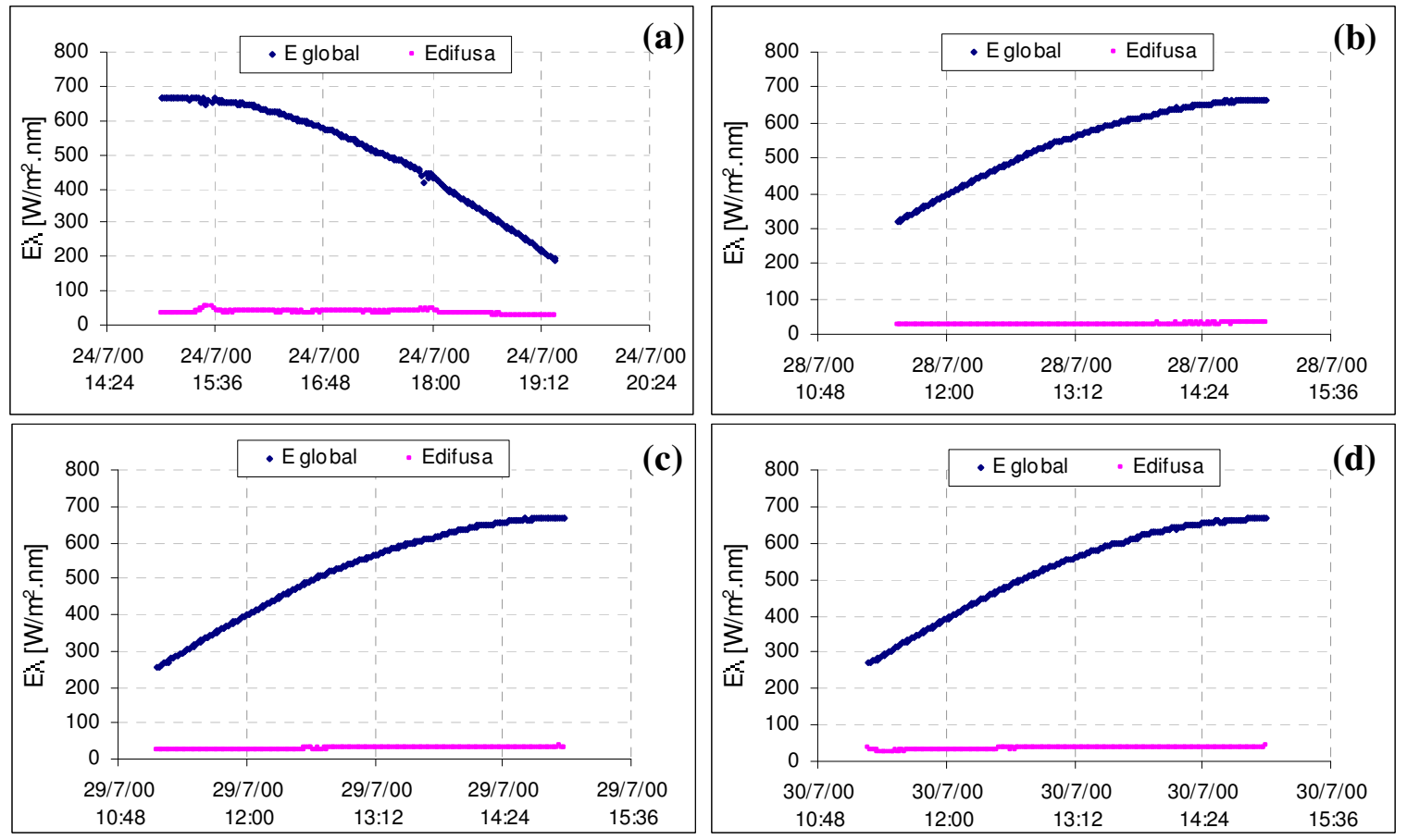

Figura 4.1 - Ciclo diário de irradiâncias global (E global) e difusa (E difusa), para os períodos de medições em: (a) 24/07, (b)28/07, (c) 29/07 e (d) 30/07, efetuadas em Campos do Jordão durante a calibração do MFRSR (MFR-434) no ano de 2000.

A figura 4.1 apresenta períodos com no mínimo de 3 horas de céu limpo verificado pelo ciclo diário das irradiâncias apresentado, que permite a identificação de influências causadas por nuvens nos dados dos radiômetros durante a calibração. Embora o período da manhã seja preferível devido à estabilidade da atmosfera em função do aquecimento da superfície ainda não ser intenso e não provocar valores altos de evaporação de água e fenômenos de turbulência, o período da tarde do dia 24/07/00 se apresentou satisfatório em relação aos obtidos nos demais dias, a não ser próximo de 15:00h e 18:00h (UTC) quando houve uma pequena perturbação nos valores de irradiância (estes valores foram posteriormente excluídos dos cálculos). Os resultados obtidos durante a aplicação do método de Langley em Campos do Jordão para os dias selecionados são apresentados na tabela 4.1 
Tabela 4.1 - Valores da constante solar por canal do MFR-434 ajustados pelo método dos Mínimos Quadrados, sendo apresentado o valor de $\chi^{2}$ Reduzido, o coeficiente angular (a) e o coeficiente linear (b) [adimensional], $[\exp (b)]$ o valor da exponencial do coeficiente angular em $\left[\mathrm{W} / \mathrm{m}^{2} . \mathrm{nm}\right]$, o valor de ajuste para a distância Terra-Sol $\left[(\mathrm{d} / \mathrm{d})^{2}\right]$, o valor obtido para constante solar $\mathrm{E}_{0 \lambda-434}$ e as respectivas incertezas em $\left[\mathrm{W} / \mathrm{m}^{2} . \mathrm{nm}\right]$. O valor médio corresponde ao novo valor para a constante solar $\left[\mathrm{E}_{0 \lambda-434}\right]$.

\begin{tabular}{|c|c|c|c|c|c|c|c|c|c|}
\hline & $\chi_{\text {Red }}^{2}$ & $\mathbf{a}$ & $\boldsymbol{\sigma a}$ & b & $\sigma b$ & $\exp (b)$ & $(\mathrm{d} / \mathrm{d})^{2}$ & $\mathbf{E}_{0 \lambda-434}$ & $\sigma \mathrm{E}_{0 \lambda}$ \\
\hline \multicolumn{10}{|l|}{$415 \mathrm{~nm}$} \\
\hline 24/07/00 & 1,00 & $-0,3501$ & 0,0018 & 0,1852 & 0,0030 & 1,20 & 0,9683 & 1,2428 & 0,0036 \\
\hline 28/07/00 & 1,00 & $-0,3297$ & 0,0011 & 0,1823 & 0,0017 & 1,20 & 0,9691 & 1,2382 & 0,0020 \\
\hline 29/07/00 & 1,01 & $-0,3188$ & 0,0011 & 0,1517 & 0,0018 & 1,16 & 0,9693 & 1,2006 & 0,0021 \\
\hline \multirow[t]{2}{*}{$30 / 07 / 00$} & 1,00 & $-0,3489$ & 0,0010 & 0,1555 & 0,0016 & 1,17 & 0,9696 & 1,2049 & 0,0018 \\
\hline & & & & & & Valor & Médio & 1,222 & \\
\hline $672 \mathrm{~nm}$ & & & & & & \multicolumn{2}{|c|}{ Desvio Padrão da média } & $\mathbf{0 , 0 1 1}$ & \\
\hline $24 / 07 / 00$ & 1,01 & $-0,1053$ & 0,0006 & 0,1935 & 0,0011 & 1,21 & 0,9683 & 1,2531 & 0,0013 \\
\hline 28/07/00 & 1,01 & $-0,0987$ & 0,0008 & 0,2114 & 0,0013 & 1,24 & 0,9691 & 1,2748 & 0,0016 \\
\hline $29 / 07 / 00$ & 1,00 & $-0,0948$ & 0,0007 & 0,2010 & 0,0013 & 1,22 & 0,9693 & 1,2613 & 0,0015 \\
\hline \multirow[t]{2}{*}{$30 / 07 / 00$} & 1,01 & $-0,1039$ & 0,0006 & 0,1909 & 0,0009 & 1,21 & 0,9696 & 1,2484 & 0,0011 \\
\hline & & & & & & Valor & Médio & 1,259 & \\
\hline 870nm & & & & & & \multicolumn{2}{|c|}{ Desvio Padrão da média } & 0,006 & \\
\hline $24 / 07 / 00$ & 1,01 & $-0,0581$ & 0,0004 & $-0,2627$ & 0,0007 & 0,77 & 0,9683 & 0,7941 & 0,0005 \\
\hline 28/07/00 & 1,00 & $-0,0520$ & 0,0007 & $-0,2481$ & 0,0012 & 0,78 & 0,9691 & 0,8051 & 0,0009 \\
\hline 29/07/00 & 1,00 & $-0,0499$ & 0,0006 & $-0,2541$ & 0,0010 & 0,78 & 0,9693 & 0,8001 & 0,0008 \\
\hline \multirow[t]{2}{*}{$30 / 07 / 00$} & 0,99 & $-0,0533$ & 0,0006 & $-0,2657$ & 0,0010 & 0,77 & 0,9696 & 0,7907 & 0,0008 \\
\hline & & & & & & Valor & Médio & 0,798 & \\
\hline $1036 n m$ & & & & & & \multicolumn{2}{|c|}{ Desvio Padrão da média } & $\mathbf{0 , 0 0 3}$ & \\
\hline $24 / 07 / 00$ & 1,00 & $-0,0481$ & 0,0004 & $-0,5631$ & 0,0007 & 0,57 & 0,9683 & 0,5881 & 0,0004 \\
\hline 28/07/00 & 1,01 & $-0,0304$ & 0,0004 & $-0,5808$ & 0,0007 & 0,56 & 0,9691 & 0,5773 & 0,0004 \\
\hline $29 / 07 / 00$ & 1,00 & $-0,0302$ & 0,0003 & $-0,5819$ & 0,0006 & 0,56 & 0,9693 & 0,5765 & 0,0004 \\
\hline \multirow[t]{3}{*}{ 30/07/00 } & 1,00 & $-0,0388$ & 0,0003 & $-0,5776$ & 0,0006 & 0,56 & 0,9696 & 0,5789 & 0,0003 \\
\hline & & & & & & Valor & Médio & $\mathbf{0 , 5 8 0}$ & \\
\hline & & & & & & \multicolumn{2}{|c|}{ Desvio Padrão da média } & $\mathbf{0 , 0 0 3}$ & \\
\hline
\end{tabular}

Outro ponto importante ilustrado nesta tabela é o valor do coeficiente angular (a) cujo módulo corresponde à profundidade óptica total da atmosfera $\left(\tau_{\lambda}\right)$ deste sítio. Este parâmetro óptico espectral apresenta valores baixos em todos os dias de medição e para todos os canais bem como uma flutuação estatística também baixa indicada pelo valor da sua incerteza. Vale lembrar que $\left(\tau_{\lambda}\right)$ recebe contribuições de todos os constituintes atmosféricos e que no canal $415 \mathrm{~nm}$, por exemplo, somente a atenuação pelo espalhamento Rayleigh corresponde a $\left(\boldsymbol{\tau}_{\lambda, \text { Rayleigh }}=0,28\right)$ como apresentado na tabela 3.1 . 


\subsubsection{Estimativa para o ano de 2006 em Brasópolis - MG}

Em 2005 e 2006 foram realizadas campanhas de calibração para os MFRSR, com o transporte e a instalação do MFR-434 no Observatório do Pico dos Dias (OPD) que faz parte do Laboratório Nacional de Astrofísica (LNA) localizado a 1864 metros de altitude entre os municípios de Brasópolis e Piranguçu no estado de Minas Gerais. Vale ressaltar que este novo sítio de calibração apresentou condições melhores do que o do DAEE em Campos do Jordão, principalmente quanto às condições atmosféricas (maior número de dias sem nebulosidade) bem como devido às facilidades oferecidas no OPD-LNA, como o apoio de equipe técnica e logística, instalações e etc. Sobre as condições atmosféricas deste sítio, vale também ressaltar que ele foi escolhido, entre vários outros sítios no Brasil, para abrigar os telescópios do Observatório Astrofísico Brasileiro operado pelo LNA, devido às boas condições atmosféricas lá reinantes. Entre 1970 e 1973 as condições atmosféricas deste sítio foram monitoradas pela equipe técnica da EM do IAG-USP e avaliadas pela Comissão Científica do Observatório Astrofísico Brasileiro durante o processo de escolha do sítio mais apropriado no Brasil para a instalação de seus telescópios [PERIRA FILHO et al., 2007].

Para o cálculo das constantes solares foram selecionados dias que respeitaram os mesmos critérios aplicados no sítio de Campos do Jordão. Como a série de dias é suficientemente grande, foram consideradas apenas as manhãs que atendessem às exigências do Método Langley. A tabela 4.2 apresenta os dias selecionados e os valores obtidos para a constante solar espectral média e suas respectivas incertezas (correspondendo ao desvio padrão da média): 
Tabela 4.2 - Valores da constante Solar obtidos pelo método Langley para o MFR-434 durante a campanha de calibração de 2006. Os valores apresentados na tabela tanto para a constante solar $\left(\mathbf{E}_{\mathbf{0}-\lambda}\right)$ e sua respectiva incerteza $\left(\boldsymbol{\sigma} \mathbf{E}_{\mathbf{0 - \lambda}}\right)$ são apresentados em $\left[\mathrm{W} / \mathrm{m}^{2} . \mathrm{nm}\right]$.

\begin{tabular}{|c|c|c|c|c|c|c|c|c|}
\hline Data & $E_{0 \lambda-415 n m}$ & $\sigma \mathrm{E}_{0 \lambda-415 \mathrm{~nm}}$ & $\mathbf{E}_{0 \lambda-672 \mathrm{~nm}}$ & $\sigma \mathrm{E}_{0 \lambda-672 \mathrm{~nm}}$ & $\mathbf{E}_{0 \lambda-870 \mathrm{~nm}}$ & $\sigma \mathrm{E}_{0 \lambda-870 \mathrm{~nm}}$ & $\mathbf{E}_{0 \lambda-1036 \mathrm{~nm}}$ & $\sigma \mathrm{E}_{0 \lambda-1036 \mathrm{~nm}}$ \\
\hline 27/06/06 & 0,9830 & 0,0029 & 1,1654 & 0,0019 & 0,7657 & 0,0013 & 0,5360 & 0,0008 \\
\hline 28/06/06 & 0,9717 & 0,0010 & 1,1512 & 0,0008 & 0,7548 & 0,0004 & 0,5415 & 0,0004 \\
\hline 03/07/06 & 1,001 & 0,004 & 1,1795 & 0,0012 & 0,7697 & 0,0007 & 0,5464 & 0,0007 \\
\hline 06/07/06 & 0,9672 & 0,0021 & 1,1593 & 0,0012 & 0,7631 & 0,0006 & 0,5493 & 0,0005 \\
\hline 07/07/06 & 0,9653 & 0,0018 & 1,1710 & 0,0015 & 0,7613 & 0,0007 & 0,5455 & 0,0002 \\
\hline 09/07/06 & 1,0014 & 0,0026 & 1,1968 & 0,0015 & 0,7755 & 0,0008 & 0,5468 & 0,0002 \\
\hline $12 / 07 / 06$ & 0,9812 & 0,0009 & 1,1566 & 0,0005 & 0,7581 & 0,0003 & 0,5534 & 0,0002 \\
\hline 13/07/06 & 0,9775 & 0,0019 & 1,1780 & 0,0018 & 0,7638 & 0,0009 & 0,5464 & 0,0002 \\
\hline $14 / 07 / 06$ & 0,9872 & 0,0014 & 1,1654 & 0,0011 & 0,7650 & 0,0008 & 0,5506 & 0,0002 \\
\hline $15 / 07 / 06$ & 0,993 & 0,003 & 1,1694 & 0,0022 & 0,7644 & 0,0012 & 0,5514 & 0,0005 \\
\hline $16 / 07 / 06$ & 0,9721 & 0,0011 & 1,1583 & 0,0007 & 0,7622 & 0,0004 & 0,5498 & 0,0004 \\
\hline 17/07/06 & 1,0034 & 0,0013 & 1,1875 & 0,0010 & 0,7763 & 0,0006 & 0,5527 & 0,0002 \\
\hline 19/07/06 & 0,9641 & 0,0019 & 1,1604 & 0,0011 & 0,7621 & 0,0004 & 0,5502 & 0,0002 \\
\hline 20/07/06 & 0,9874 & 0,0025 & 1,1563 & 0,0018 & 0,7646 & 0,0007 & 0,5502 & 0,0004 \\
\hline 21/07/06 & 1,0093 & 0,0014 & 1,1776 & 0,0009 & 0,7688 & 0,0004 & 0,5542 & 0,0002 \\
\hline 22/07/06 & 0,9766 & 0,0013 & 1,1567 & 0,0013 & 0,7642 & 0,0005 & 0,5523 & 0,0004 \\
\hline 23/07/06 & 0,9813 & 0,0016 & 1,1557 & 0,0011 & 0,7638 & 0,0006 & 0,5559 & 0,0004 \\
\hline 27/07/06 & 1,0002 & 0,0013 & 1,1820 & 0,0007 & 0,7748 & 0,0004 & 0,5531 & 0,0004 \\
\hline V. Médio & 0,985 & & 1,168 & & 0,765 & & 0,549 & \\
\hline $\begin{array}{l}\text { Desv. Pad. } \\
\text { da Média }\end{array}$ & $\mathbf{0 , 0 0 3}$ & & $\mathbf{0 , 0 0 3}$ & & 0,001 & & 0,001 & \\
\hline
\end{tabular}

A tabela 4.2 demonstra que a série de dias escolhida durante a campanha de calibração no OPD-LNA forneceu valores para a constante solar $\left(\mathbf{E}_{\mathbf{0}-\lambda}\right)$ com flutuação estatística pequena refletida no valor do desvio padrão da média bem como nos valores diários para a própria constante solar espectral.

\subsubsection{Transferência de calibração do MFR-434 para o MFR-435 e avaliação da degradação da calibração}

Com as estimativas para a constante solar espectral do MFR-434 $\left(\mathrm{E}_{0-\lambda}\right)$ efetuou-se a transferência da calibração do MFR-434 para o MFR-435. Para isso, foram obtidas equações de calibração espectrais entre os dois radiômetros que permitiram estimar valores calibrados para a constante solar do MFR-435. Vale lembrar que durante o processo de transferência de calibração tanto a função filtro de cada canal do MFRSR quanto a degradação da calibração são levadas em conta. Foram empregados dados em dias nos quais não ocorreram influências significativas de nuvens garantidas pela observação do ciclo diário das irradiâncias, com períodos de céu limpo maior do que 3 horas o que propiciou retas de calibração bem ajustadas 
aos valores de irradiância direta-normal espectral selecionados. Os valores de 2005 apresentados neste trabalho foram estimados por Rosário [2006].

Os períodos selecionados para as transferências de calibração em 2000 e 2006 com o Método Langley correspondem às medições efetuadas com ambos os MFRSR operando lado a lado durante os dias:

$\checkmark$ 06/07 e 07/07/ do ano de 2000;

$\checkmark \quad 27 / 09$ e $28 / 09$ do ano de 2006.

Foram estimadas também mais duas constantes em 1999 e em 2001 para o MFR435, considerando que a calibração do MFR-434 não havia sofrido uma degradação significativa, pois neste período inicial ele havia operado de forma esporádica na EM do IAG-USP. Os dias empregados nesta transferência de calibração foram:

$\checkmark 13 / 08 ; 24 / 08 ; 27 / 08 ; 28 / 08 ; 29 / 08 ; 30 / 08 ; 31 / 08$ e dia $01 / 08$ no ano de 1999 ;

$\checkmark$ 14/04; 15/04; 16/04; 29/04 e dia 05/05 no ano de 2001 .

Os valores obtidos para a constante solar $\left(\mathrm{E}_{0 \lambda}\right)$ tanto para o MFR-435 quanto para o MFR-434 em 2005 são menores que os valores obtidos em 2006, o que caracteriza a degradação da calibração espectral ao longo do tempo de funcionamento, e a necessidade de re-calibração periódica para a estimativa de valores de POA com precisão e acurácia. Esta tendência de redução dos valores de irradiância espectral solar medidos pelos MFRSR, já esperada teoricamente, fica mais acentuada quando se analisa os valores das constantes espectrais do MFR-434 que não tem quebra de continuidade. O MFR-435 também demonstra que sofreu degradação da calibração para o período inicial de medidas, com valores espectrais para a constante solar cada vez menores como ilustra a figura 4.2. Esta figura resume os valores de cada constante solar espectral obtida para cada canal dos MFRSR. 

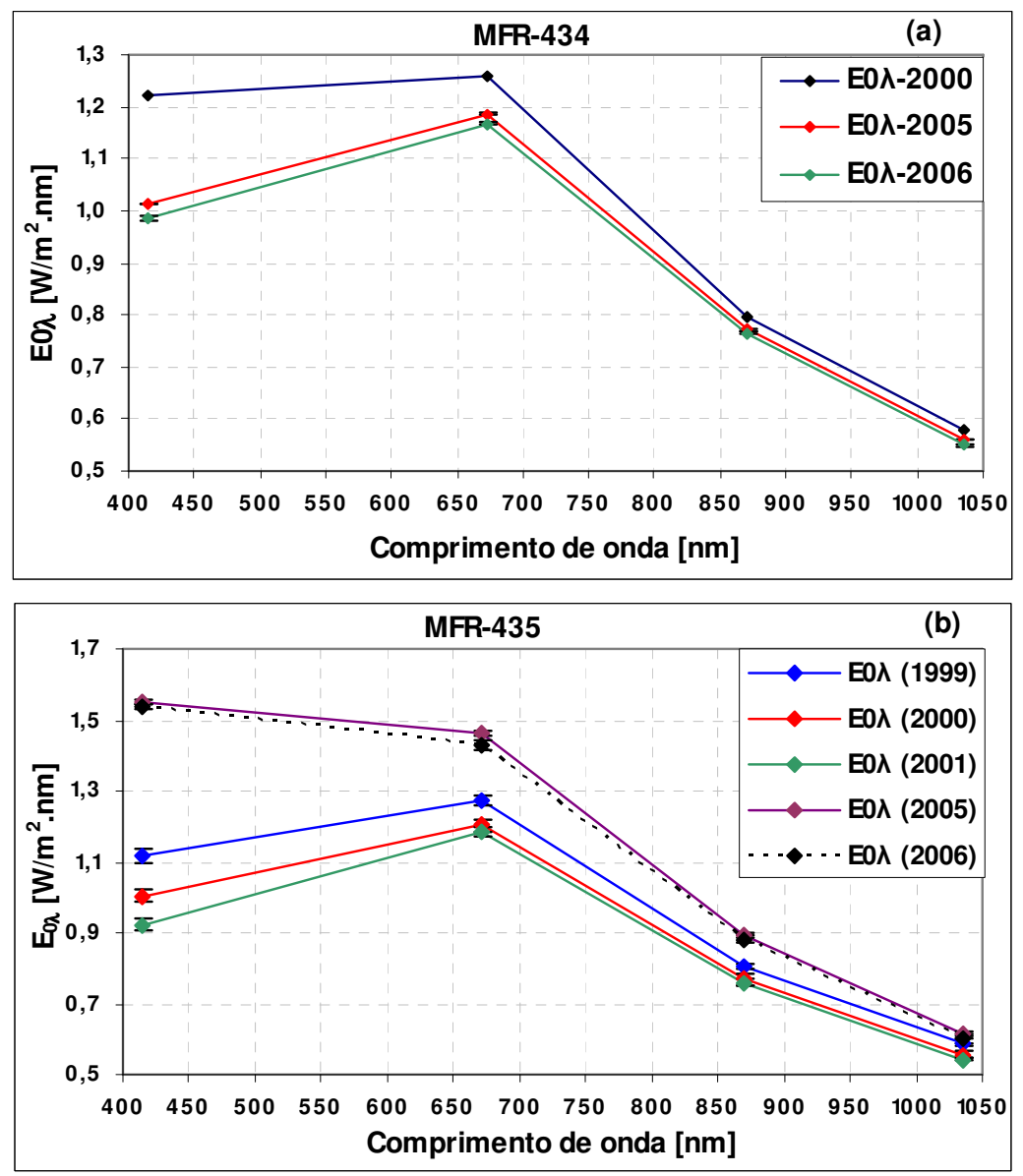

Figura 4.2 - Valores da constante solar $\left(\mathrm{E}_{0 \lambda}\right)$ calculados pelo Método Langley para o MFR434 em (a) nos anos de 2000, 2005 e 2006 e os transferidos para o MFR-435 em (b) para o período entre 1999 a 2006. Os valores em 2005 foram extraídos do trabalho de Rosário [2006].

A figura 4.2 ilustra que os MFRSR apresentaram a maior diferença entre uma calibração e outra no canal $415 \mathrm{~nm}$. A diferença para os anos de 2005 e 2006 neste canal foi de $\sim 3,0 \%$ para o MFR-434 e 1,0 \% para o MFR-435. A menor diferença foi observada no canal $870 \mathrm{~nm}, \sim 0,7 \%$ para o MFR-434 e $\sim 1,5 \%$ para o MFR-435. Vale ressaltar que o MFR435 no período entre 2000 a 2001, representado na figura 4.2b, apresentou uma diferença no canal $870 \mathrm{~nm}$ menor do que 1,0\%. Em suma, apesar das diferenças relativas observadas percebe-se nos valores absolutos da constante solar espectral em $\left[\mathrm{W} / \mathrm{m}^{2} . \mathrm{nm}\right]$ que em ambos os radiômetros os canais mais estáveis e robustos são os canais $870 \mathrm{~nm}$ e o $1036 \mathrm{~nm}$. O salto observado nas calibrações do MFR-435 de 2001 para 2005 se deve ao fato dos reparos no fabricante, com a troca de filtros espectrais e de sensores o que provocou a quebra de continuidade na avaliação da degradação. 


\subsubsection{Calibração do MFR-434 pelo Método Geral}

O Método Geral, segundo Forgan [1994], foi aplicado para todo o período de medições dos MFRSR entre os anos de 1999 e 2006 para ambos os radiômetros. O canal 870 nm foi escolhido como canal de referência do Método Geral aplicado em São Paulo. A escolha deste canal em particular se deve à estabilidade da constante espectral solar em conjunto com o canal 1036nm ilustradas na figura 4.2. Os mesmos apresentaram uma degradação da calibração menos acentuada em relação aos demais canais (415 e $672 \mathrm{~nm}$ ). Outro ponto importante para a escolha do canal $870 \mathrm{~nm}$ é que o canal 1036nm pode sofrer influência maior da atenuação devido ao vapor de água do que o canal $870 \mathrm{~nm}$.

Os valores da constante solar, utilizados para o canal $870 \mathrm{~nm}$ correspondem, para o MFR-434, aos estimados pelo método Langley e aplicados em 2000, 2005 e 2006. Em 2004 foi adotada a calibração de 2005 , visto que a degradação deste canal é menor que $1,0 \%$ entre os anos de 2005 e 2006 e, por hipótese admitiu-se o mesmo também entre os anos de 2004 e 2005. A mesma lógica foi aplicada em dados de 1999 e 2002, ou seja, foi adotada a constante obtida em 2000 pelos motivos já apontados. Para o MFR-435 entre 1999 e 2001 adotou-se as constantes transferidas em 1999, 2000 e 2002 assim como as estimadas para o período de 2004 a 2006. Como o Método Geral exige que a distribuição de tamanho do aerossol se mantenha constante ao longo dos períodos de medição, foi usado como parâmetro de qualidade desta variação o valor do coeficiente de Ångström entre os canais 415/672 nm e 672/870 nm. Desta forma foram admitidos períodos para a aplicação do Método Geral para os quais a variabilidade do coeficiente de Ångström fosse igual ou inferior a 2,0\% simultaneamente entre os canais citados.

Devido à restrição da variabilidade do coeficiente de Ångström, os intervalos selecionados para a aplicação do método Geral possuíram curta duração, embora não inferior a 20minutos e em média foram de 25 minutos. Porém a restrição em 2,0\% de variabilidade resultou em um reduzido número de dias para a aplicação do método em relação ao tamanho da base de dados. Este fato se dá em função da alta variabilidade do aerossol em São Paulo com base nos coeficientes de Ångström analisados. Como já foi discutido anteriormente que, a calibração dos diferentes canais dos MFRSR, degrada ao longo do tempo e o Método Geral combinado com as campanhas de calibração do método Langley em topo de montanha propiciou obtenção de um ajuste linear para as constantes solares espectrais nos canais 415 , 672 e 1036nm, considerando o canal $870 \mathrm{~nm}$ como o canal de referência. Os valores diários 
calculados com o Método Geral foram agrupados mensalmente e, em seguida, foi calculada a média mensal para cada canal dos MFRSR. O resultado final é apresentado na figura 4.3 já em valores médios mensais e suas incertezas correspondendo ao desvio padrão da média, para a constante de calibração desde 1999 a 2006 em função do tempo de funcionamento de cada MFRSR. Estas constantes são do MFR-434, pois os valores do MFR-435 são similares e não serão apresentados:
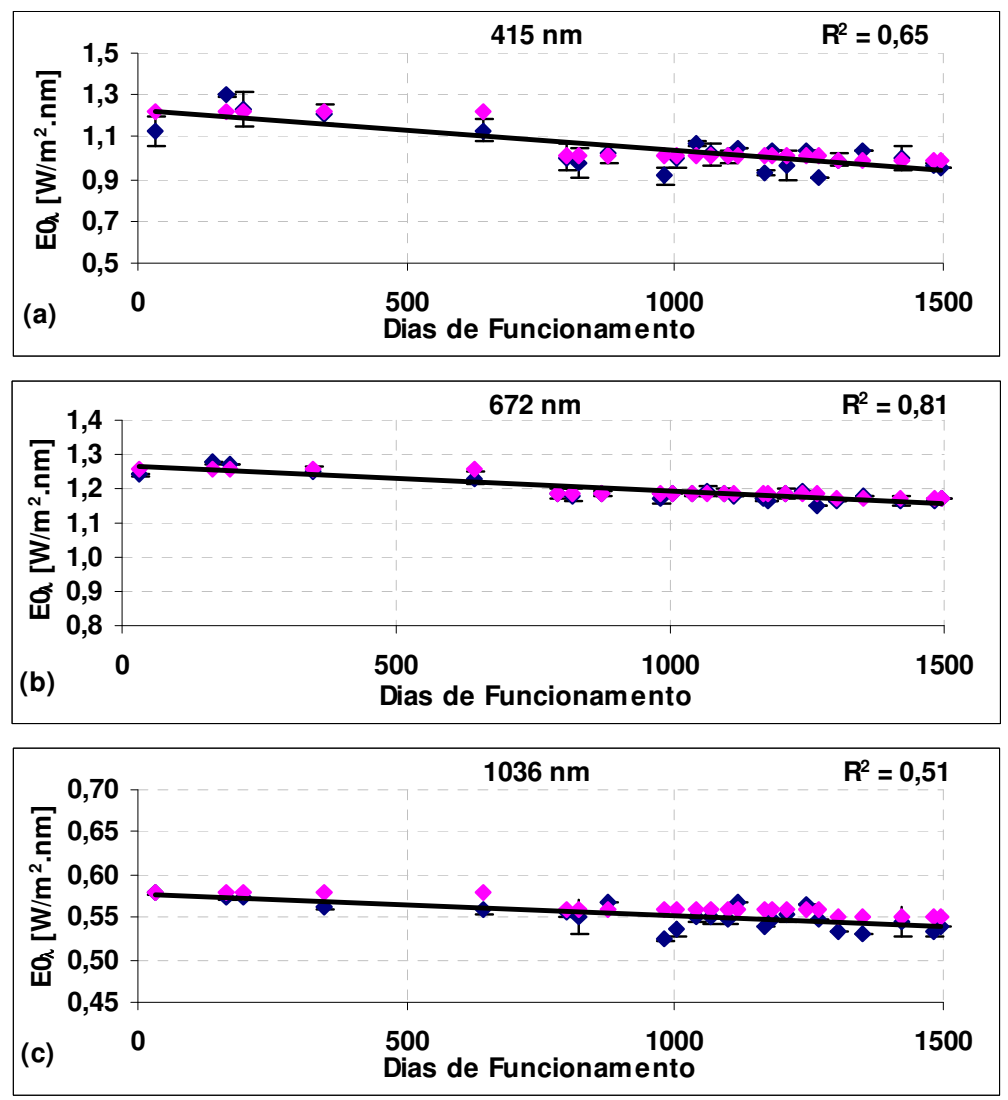

Figura 4.3 - Constante solar espectral média mensal $\left(\mathrm{E}_{0 \lambda}\right)$ do MFR-434 entre 1999 a 2006 pelo Método Geral adotando o canal $870 \mathrm{~nm}$ como referência. No eixo das abscissas é apresentado o número de dias de funcionamento do MFR-434 (o dia de funcionamento 01 corresponde ao dia 14/07/99). As incertezas correspondem ao desvio padrão da média (barras verticais). É apresentado o coeficiente de determinação $\mathrm{R}^{2}$ do ajuste linear. Os valores da constante solar espectral obtida pelo método Langley são ilustrados em rosa para os anos de 2000, 2005 e 2006. Em 1999, 2001 e 2002 os valores de referência são iguais aos obtidos no ano de 2000 e em 2004 corresponde ao valor estimado em 2005. Os canais analisados correspondem a: (a) $415 \mathrm{~nm}$; (b)672 nm; (c)1036 nm.

Os melhores resultados foram obtidos para o canal $672 \mathrm{~nm}$ com diferenças inferiores a $0,4 \%$ como fica ilustrado na figura $4.3 \mathrm{~b}$. Para o canal $1036 \mathrm{~nm}$ observa-se que os valores obtidos com o método Geral subestimam os valores obtidos com o Langley em quase todo o 
período. Esse efeito pode estar relacionado com a variação do conteúdo de vapor de água integrado na coluna atmosférica durante a aplicação do método Geral nesses dias.

O método Geral apresentou um bom resultado frente ao seu emprego em medidas efetuadas em São Paulo podendo contribuir para avaliar a degradação ao longo do tempo de operação dos MFRSR desde que combinado com campanhas de calibração através do método Langley pelo menos uma vez por ano, fornecendo assim valores de referência para a calibração. Um fato também importante é o bom desempenho médio do método Geral em relação ao canal $672 \mathrm{~nm}$ e o seu comportamento em relação às calibrações anuais efetuadas pelo método Langley, demonstrando que as mesmas fornecem valores acurados para a constante solar deste canal.

As retas de calibração, obtidas a partir dos valores médios mensais das constantes espectrais, foram ajustadas pelo método de Mínimos Quadrados e depois empregados no processamento da base de dados com vistas a fornecer valores mais acurados e precisos de POA, levando em conta a degradação da calibração da constante solar espectral ao longo do tempo de operação dos MFRSR. As constantes obtidas com estas retas de calibração possuem incertezas menores ou iguais a 2,0\% dependendo do canal (2,0\% para o canal $415 \mathrm{~nm}$ e $\sim 1,0 \%$ para o $1036 \mathrm{~nm})$.

\subsubsection{Avaliação da calibração com o Método Geral em relação aos dados fornecidos pela rede AERONET}

A avaliação da calibração da constante solar em função do tempo de funcionamento do MFRSR obtida com a aplicação do Método Geral foi feita comparando valores de POA da rede AERONET e os calculados com os MFRSR. O intuito é o de avaliar a qualidade dos ajustes lineares para corrigir a degradação da calibração dos MFRSR ao longo do tempo de operação dos radiômetros. A comparação não foi restrita a um determinado período do ano como para os invernos de 2004 e 2005 no trabalho de Rosário [2006] ou apenas em dias absolutamente sem nuvens como no trabalho de Alexandrov et al. [2002a]. Ela se estendeu a toda a base de dados válidos (filtrados e re-calibrados) do nível 2.0 da rede AERONET, com o intuito de avaliar e verificar também se curtos intervalos de dados são bem representados pelos MFRSR em comparação com uma metodologia independente de calibração e filtro de 
nuvens como a da AERONET. Neste período de coleta de dados os dois instrumentos estavam instalados junto ao sítio da rede AERONET no IF-USP.

A figura 4.4 ilustra os valores selecionados para as comparações entre as duas bases de dados nos anos de 2004 a 2006.
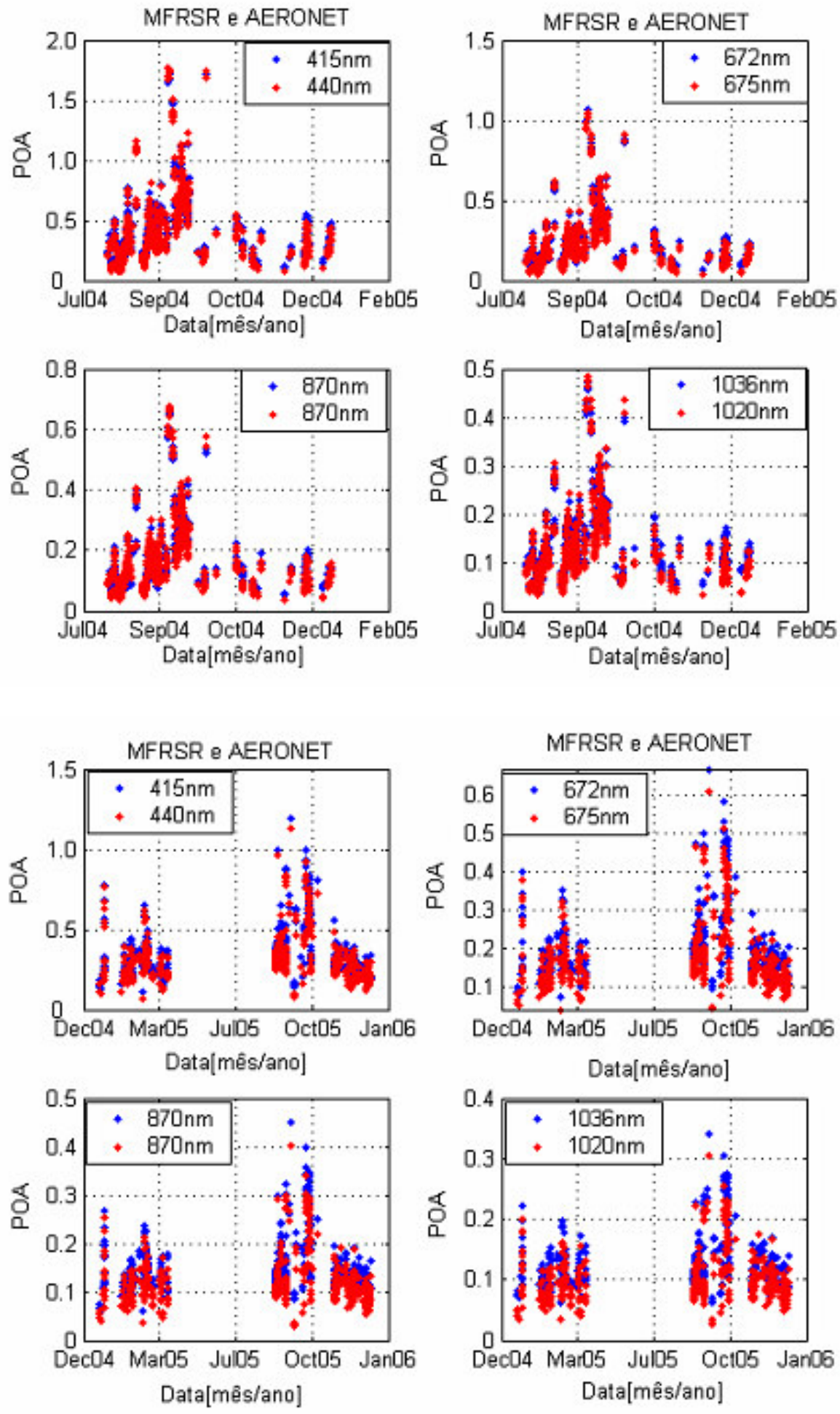

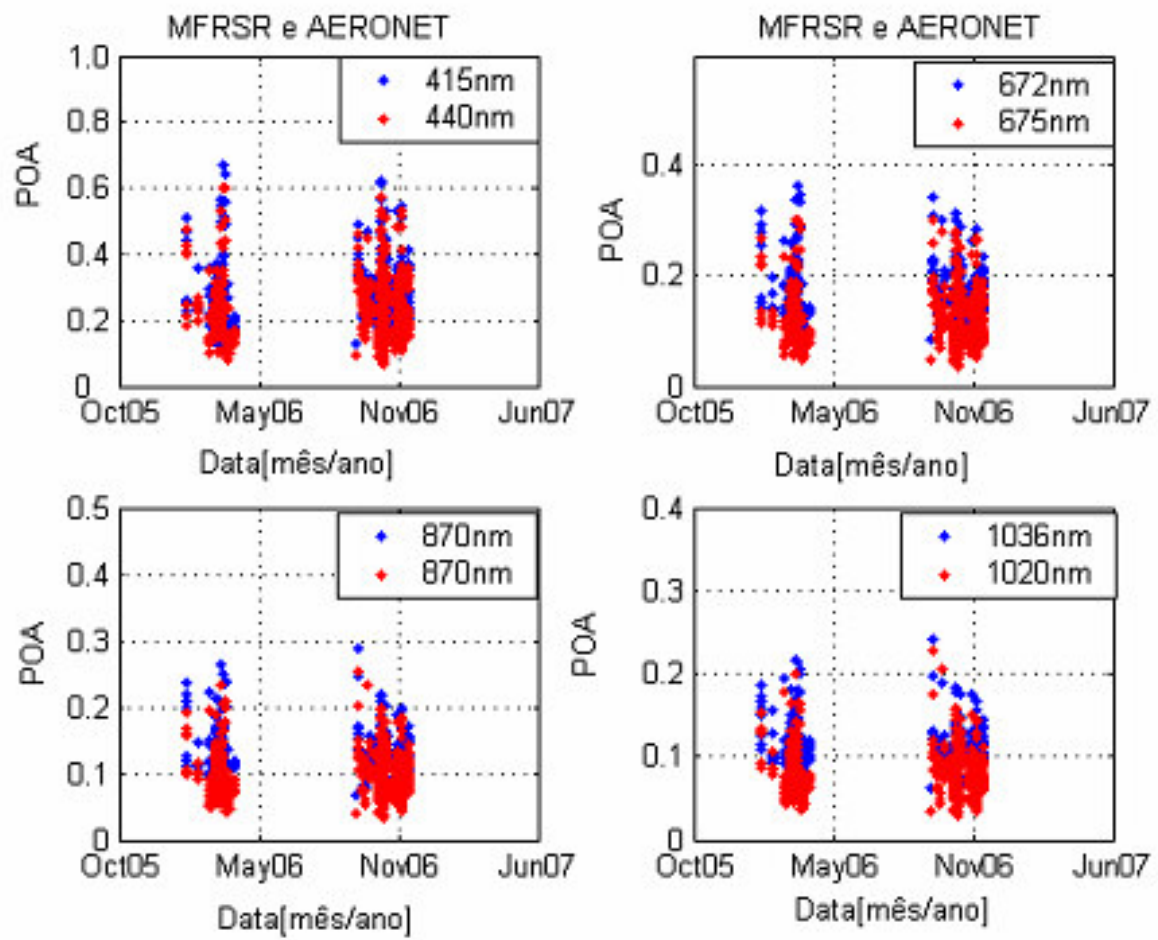

Figura 4.4 - Ciclo anual dos valores espectrais simultâneos de POA da rede AERONET (440, 675, 870 e $1020 \mathrm{~nm})$ e MFRSR $(415,672,870$ e $1036 \mathrm{~nm})$ para os anos de 2004, 2005 e 2006. São apresentados na figura em vermelho a POA da rede AERONET e em azul a POA do MFRSR (MFR-434) instalados no edifício Pelletron no IF/USP.

A figura 4.4 ilustra tanto a variabilidade quanto a amplitude dos dados selecionados para a comparação entre os dois instrumentos em todos os canais de interesse. No ano de 2004 nos canais 415nm (MFRSR) e 440nm (AERONET) é observada a maior amplitude da POA para a base de dados selecionados entre os dois instrumentos. Neste exemplo, para estes dois canais, os valores apresentam uma amplitude de 0,10 $<\mathrm{POA}<1,70$. Para estes mesmos canais a menor amplitude se deu no ano de 2006 em um intervalo de $0,10<\mathrm{POA}<0,65$. A figura 4.4 ilustra também a boa correlação entre os dados obtidos com os dois instrumentos, ou seja, apresentando, qualitativamente, amplitude de valores e variabilidade da POA ao longo do tempo muito similares. A primeira análise quantitativa entre os dados selecionados neste trabalho é apresentada na figura 4.5 ('a' até 'm') e é feita através da diferença absoluta dos valores de POA em cada canal (MFRSR menos AERONET) ao longo da evolução diurna, para os anos de 2004 a 2006: 
MFRSR-AERONET em 2004
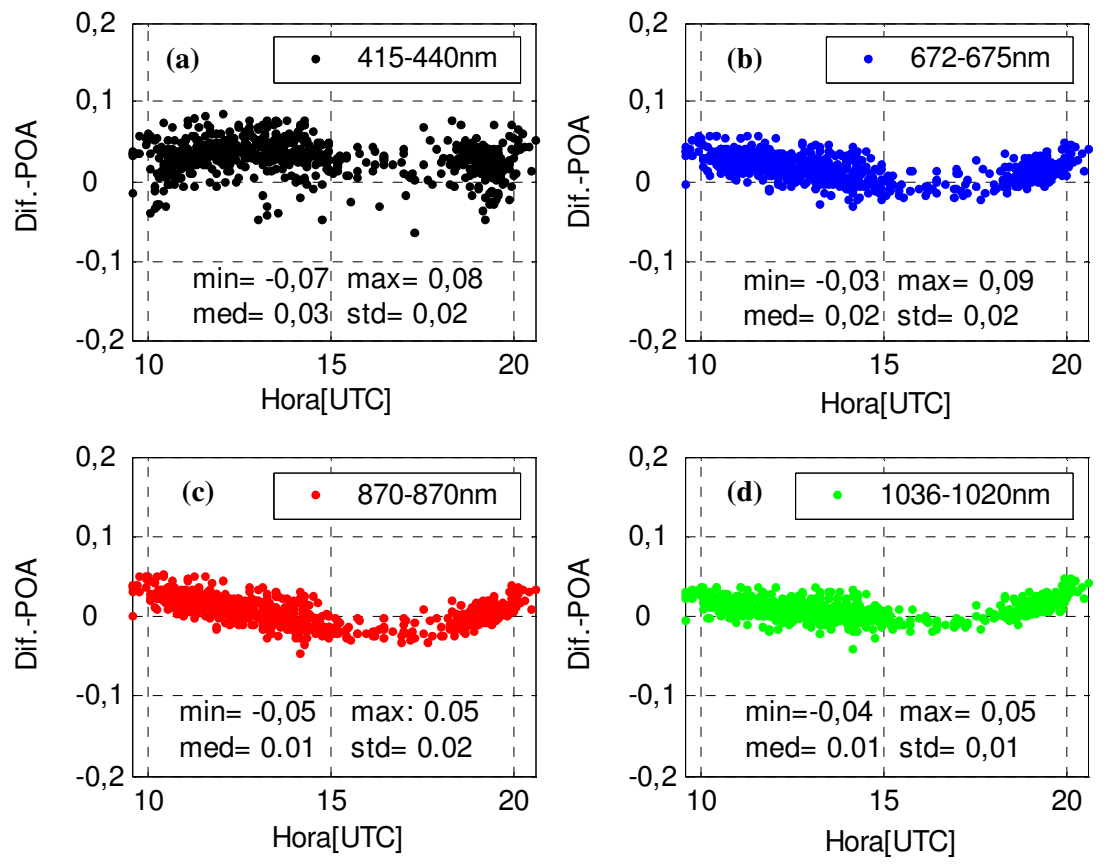

MFRSR-AERONET em 2005
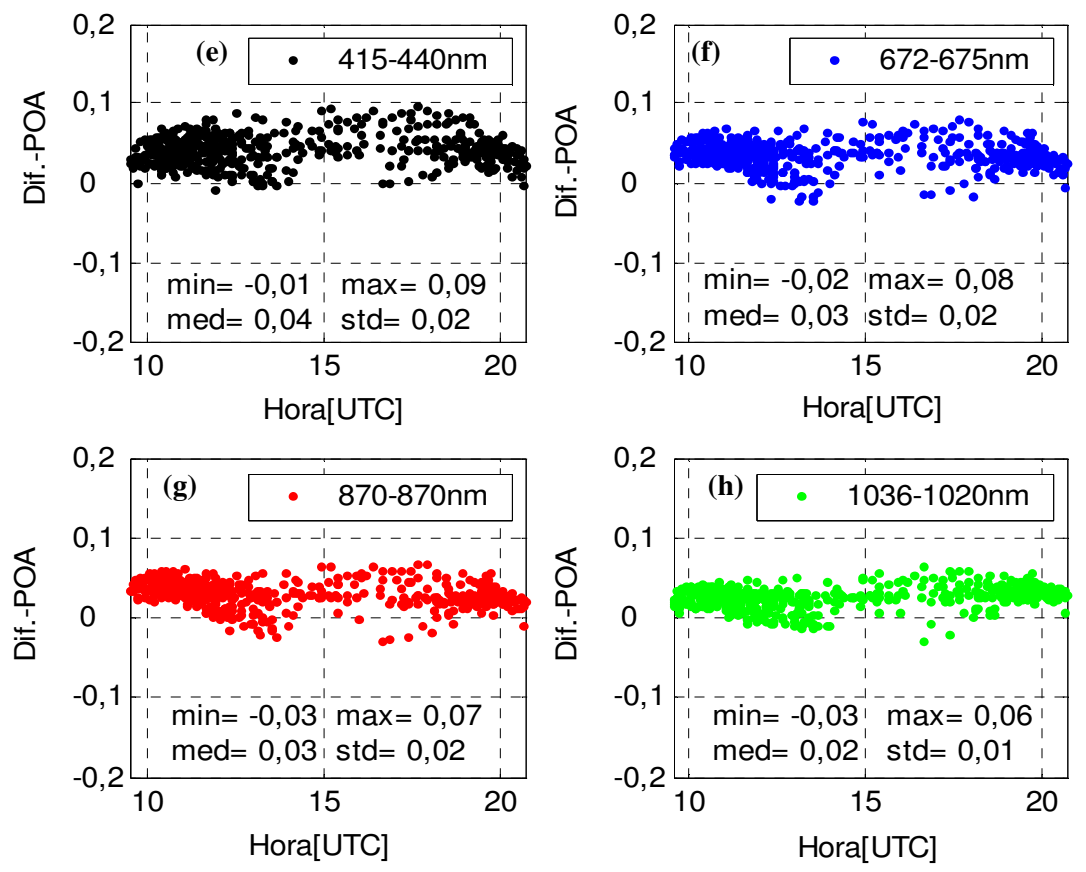

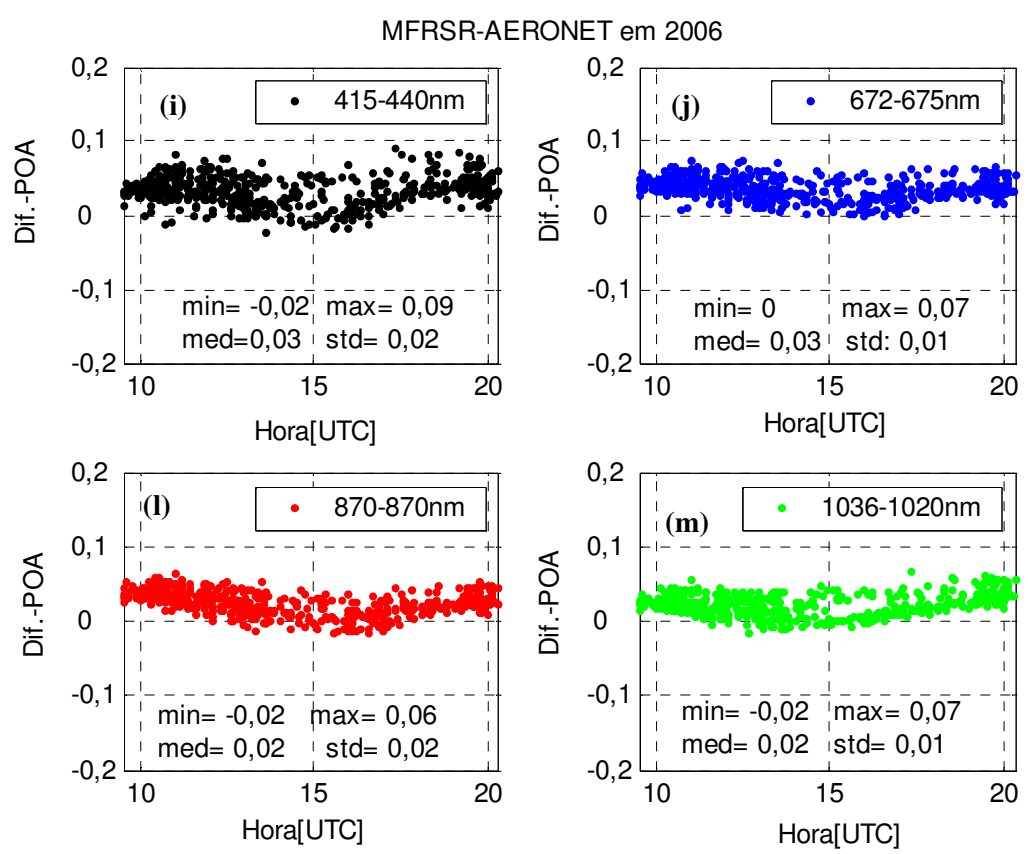

Figura 4.5 (de "a" a "m") - Evolução diurna da diferença na POA entre os dados da rede AERONET e os MFRSR para os anos de 2004, 2005 e 2006.

A diferença absoluta calculada entre os dados espectrais da POA para a evolução diurna aponta um fato observado também por Rosário [2006] que é a redução do número de dados ao redor do meio dia solar (aproximadamente às 15:00h UTC) quando ocorre a maior incerteza associada a POA.

A diferença média observada para todos os canais ao longo dos três anos de comparação, ilustrada na figura 4.5 foi no máximo de 0,04 entre os canais 415-440 nm e 0,03 no canal 672-670 nm no ano de 2005. Nos anos de 2004 e 2006 entre os canais 870-870 nm e 1036-1020 nm são encontradas as menores diferenças médias. As maiores diferenças são observadas entre os canais 415-440 nm o que teoricamente é esperado devido à diferença espectral existente, da ordem de $25 \mathrm{~nm}$ para o comprimento de onda central entre as bandas e à dependência espectral da POA.

As maiores diferenças foram observadas no início e no final do dia, para os maiores valores de massa óptica, caracterizando uma dependência com o ciclo diurno que pode sugerir que um dos dois instrumentos pode estar com sua constante solar ainda imprecisa como discutido em Forgan [1994] e Rosário [2006]. O canal $415 \mathrm{~nm}$ apresenta o mesmo comportamento nos três anos, porém em 2005, a diferença média também aumenta em relação aos resultados da AERONET.

Segundo Alexandrov et al. [2002a], os fatores que influenciam a calibração dos MFRSR's incluem a estabilidade da função resposta dos filtros espectrais e a transmissão dos 
filtros. Segundo os autores, extensivas calibrações em laboratório têm mostrado que a resposta espectral dos filtros é estável, mas que sua transmissão muda com o tempo daí a necessidade de calibrações contínuas e o desenvolvimento de técnicas alternativas de calibração.

Quanto à calibração dos dados do MFRSR (MFR-434) é importante frisar também que o mesmo sofreu campanhas de calibração com o Método Langley em 2005 e 2006 no OPD-LNA fornecendo valores acurados para a constante solar nestes anos que serviram como referência (canal 870nm) para os ajustes lineares através do Método Geral. Cabe também ressaltar que estes ajustes lineares, em função do tempo de funcionamento do MFRSR, ofereceram valores de constante solar que se diferenciaram no máximo $1,1 \%$ no canal 1036nm para o ano de 2005 e 0,6\% em 2006. O ajuste linear forneceu valores para a constante solar com diferenças menores do que 1,7\% para os demais canais em 2005 e 2006 em relação aos obtidos com método Langley. Cabe também lembrar que o MFR-434 nunca foi enviado ao fabricante para troca de filtros, avaliação da resposta espectral, correções angulares ou recalibração, mas que mesmo assim fornece valores próximos aos da rede AERONET que freqüentemente sofre um rígido processo de calibração na sua sede, com instrumentos de referência e esferas integradoras, instrumentos estes calibrados no Observatório de Mauna Loa - Havaí / EUA segundo Holben et al., [1998].

No artigo de Cachorro et al. [2004] é discutida a dependência da POA com o ciclo diurno para dados de um fotômetro solar Cimel da rede AERONET localizada em El Arenosillo - Espanha. Os autores lembram que a incerteza na calibração do fotômetro Cimel é estimada entre 1 a $2 \%$ (erro mínimo), mas que pode ser maior dependendo da demora na recalibração, a qual é sugerida a cada seis meses. Dada a dificuldade em se colocar em prática tal rotina, em muitos casos as constantes espectrais têm incertezas maiores do que $2 \%$. Os autores após aplicarem um método de calibração chamado de KCICLO observaram que as constantes espectrais anteriores do fotômetro Cimel nos canais $1020 \mathrm{~nm}$ e 870nm chegavam a diferir desta nova calibração, a correta, em 5,0\% e 4,0\% respectivamente.

Outra forma de comparar os resultados do MFRSR com os da AERONET é a partir de gráficos de regressão. Na figura 4.6 são apresentados os ajustes lineares entre os dados médios de 09 minutos do MFRSR e o valor correspondente da AERONET para os anos de 2004, 2005 e 2006 para cada canal. 


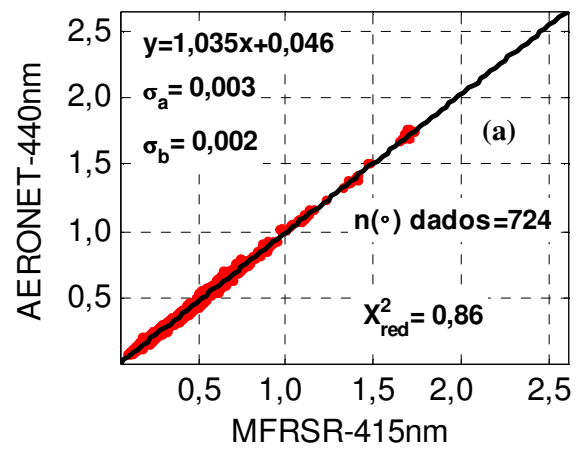

2004
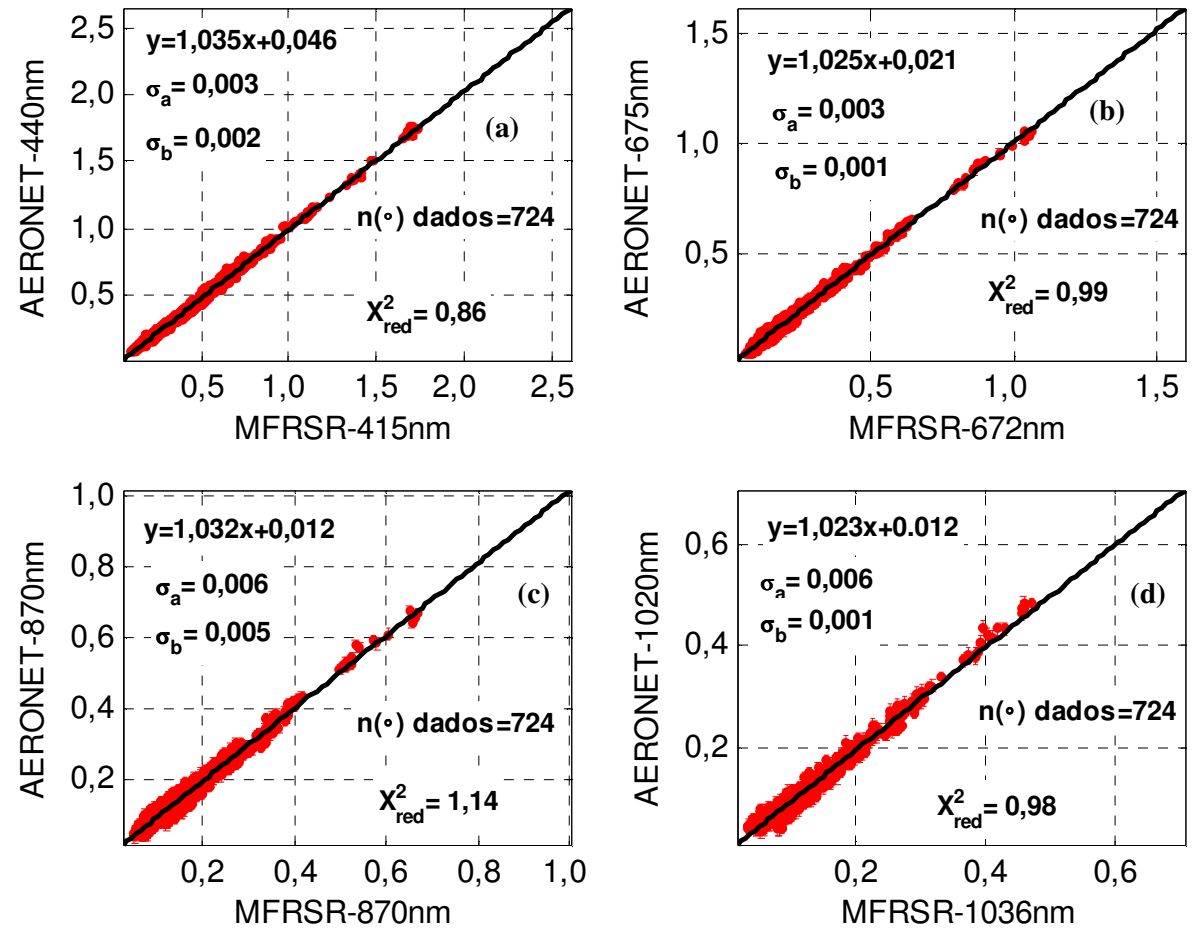

2005
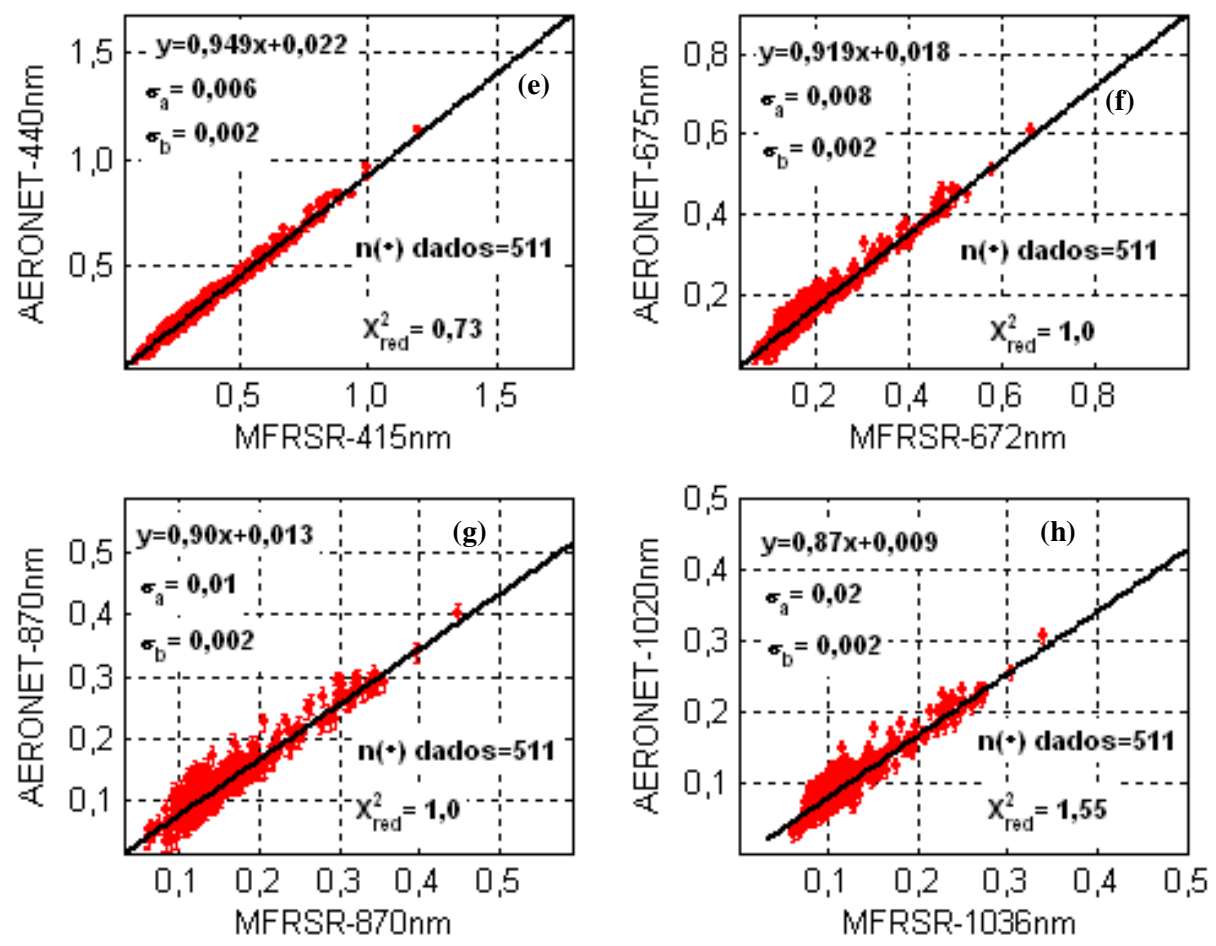
2006
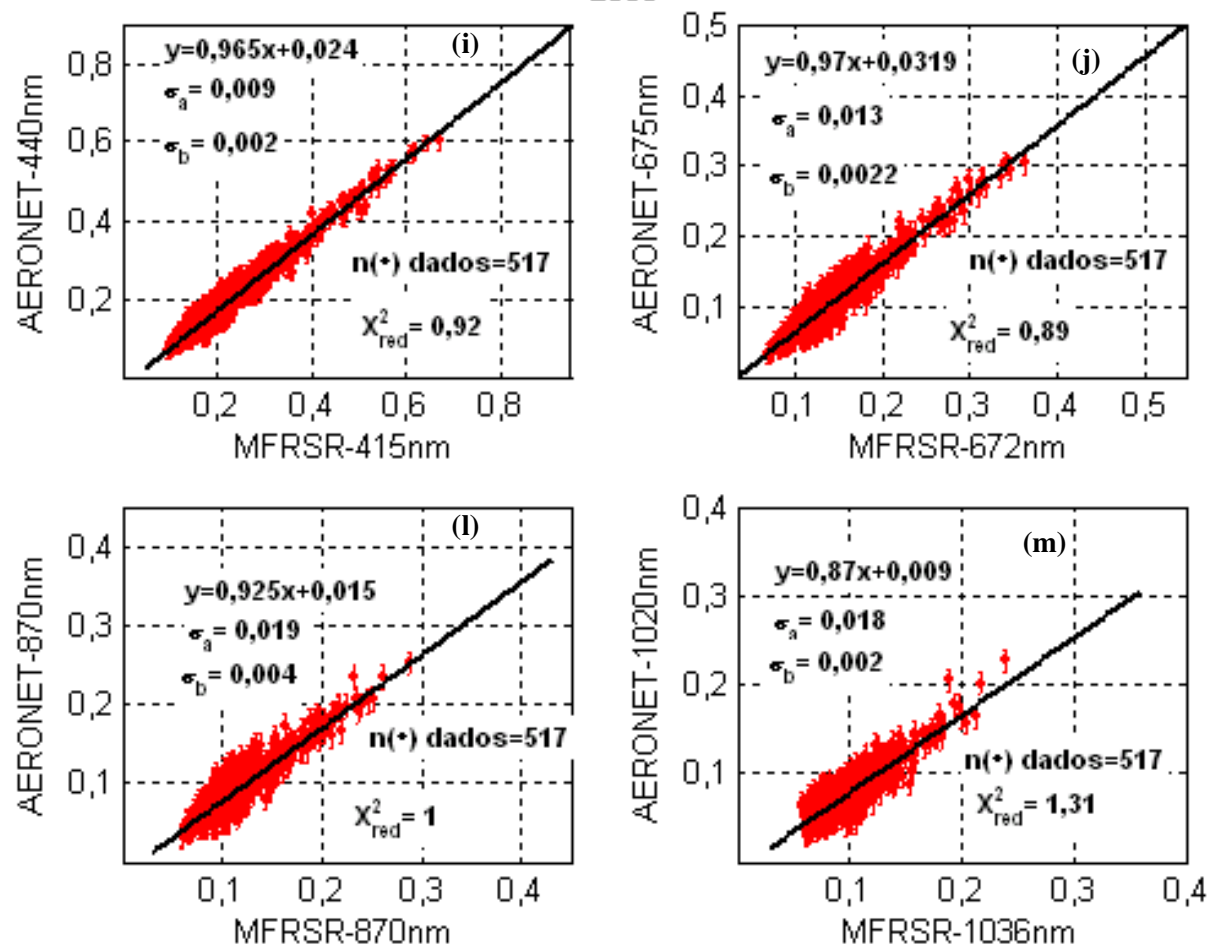

Figura 4.6 - Comparação entre os valores espectrais de POA com operação simultânea da rede AERONET e MFRSR nos anos de 2004 a 2006. São apresentados na figura a equação do ajuste linear por MMQ (Método dos Mínimos Quadrados), a incerteza no coeficiente angular $(\sigma a)$ e linear $(\sigma b)$, o número de dados empregados no ajuste [n $(*)$ dados] e o valor do QuiQuadrado Reduzido.

Os ajustes lineares espectrais entre os dois instrumentos ano a ano com o emprego do Método Estatístico dos Mínimos Quadrados, demonstram que a base de dados está bem correlacionada através da análise do valor do $\chi^{2}$ reduzido. Segundo Vuolo [2002] a qualidade do ajuste de uma função pode ser avaliada pelo valor do $\chi^{2}$ reduzido obtido para o ajuste, sendo considerados estatisticamente significativos valores próximos a 1. Como referido anteriormente, a incerteza no valor dos dados comparados do MFRSR corresponde ao desvio padrão da média calculada. A incerteza do fotômetro Cimel da AERONET para os canais com $\lambda<440 \mathrm{~nm}$ é de 0,02 nos valores de POA e da ordem de 0,01 para os demais canais [Holben et al.,1998].

Nota-se, pelos coeficientes angulares, que os valores de POA estimados pela AERONET são sistematicamente mais altos que os do MFRSR em 2004, invertendo nos demais anos. 
4.2. Avaliação da sazonalidade das propriedades ópticas do aerossol de São Paulo

A figura 4.7 ilustra os valores médios diários para a POA obtidos para os anos de 1999 a 2006. O que se observa é que em geral os valores mais altos são medidos nos meses de agosto a outubro. Os períodos nos quais apresentou os menores valores foram ao redor do mês de janeiro. Este aspecto de variabilidade sazonal é melhor caracterizada a partir das médias mensais. As médias mensais são ilustradas na figura 4.9.

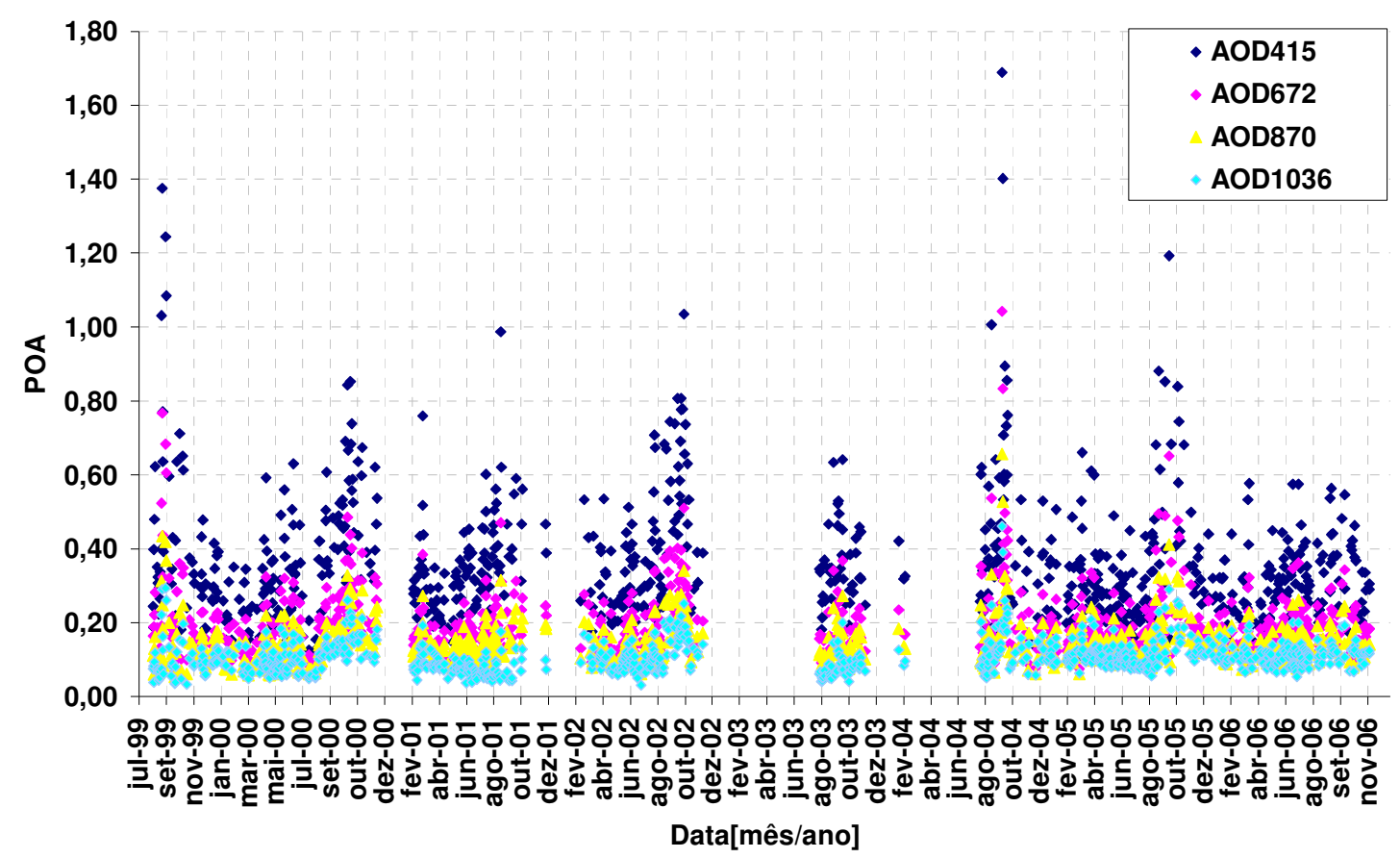

Figura 4.7 - Valores médios diários de POA (profundidade óptica espectral do aerossol) (medidos na Estação Meteorológica do IAG-USP localizada no bairro da Água Funda capital - SP) para o período de agosto de 1999 a dezembro de 2002 e para os valores medidos no IF-USP entre agosto de 2003 até dezembro de 2006.

A figura 4.8 apresenta as médias diárias do valor do coeficiente de Ångström calculado entre os canais $415 / 870 \mathrm{~nm}$. 


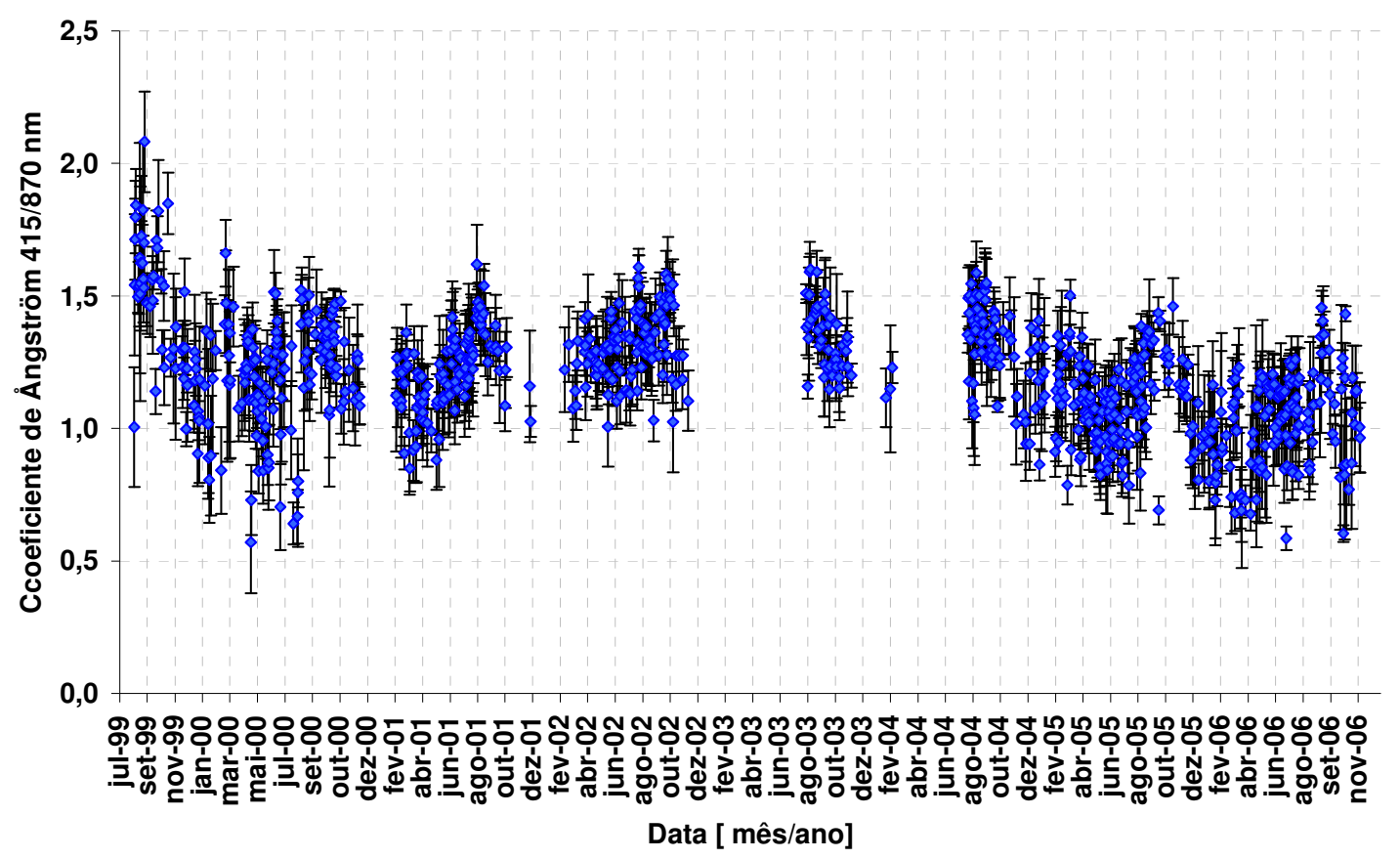

Figura 4.8 - Valores médios diários do coeficiente de Ångström entre 415/870nm para São Paulo - SP (Estação Meteorológica do IAG-USP localizada no bairro da Água Funda) para o período de agosto de 1999 a dezembro de 2002 e valores medidos no IF-USP entre agosto de 2003 até dezembro de 2006. As barras de erros representam o desvio padrão dos dados nos dias analisados.

Os valores do coeficiente de Ångström ilustrados na figura 4.8, apresentam valor médio da ordem de 1,4 indicando a predominância de partículas de médias a finas. Ainda podemos observar pela figura que há uma sazonalidade nos valores do coeficiente de Ångström, apresentando os maiores valores em torno dos meses de agosto a setembro e os menores entre os meses de dezembro a março. Essa sazonalidade indica a presença de distintos tipos de aerossol nas diferentes épocas do ano, por exemplo, no inverno pode ocorrer transporte de aerossol proveniente de queimadas na Amazônia ou ser um efeito da umidade relativa. No verão, a umidade relativa do ar tende a ser maior, o que pode acarretar o crescimento das partículas de aerossol, devido à sua natureza higroscópica, diminuindo o valor do coeficiente de Ångström. Uma análise mais detalhada, incluindo variáveis meteorológicas, será feito no próximo tópico. 


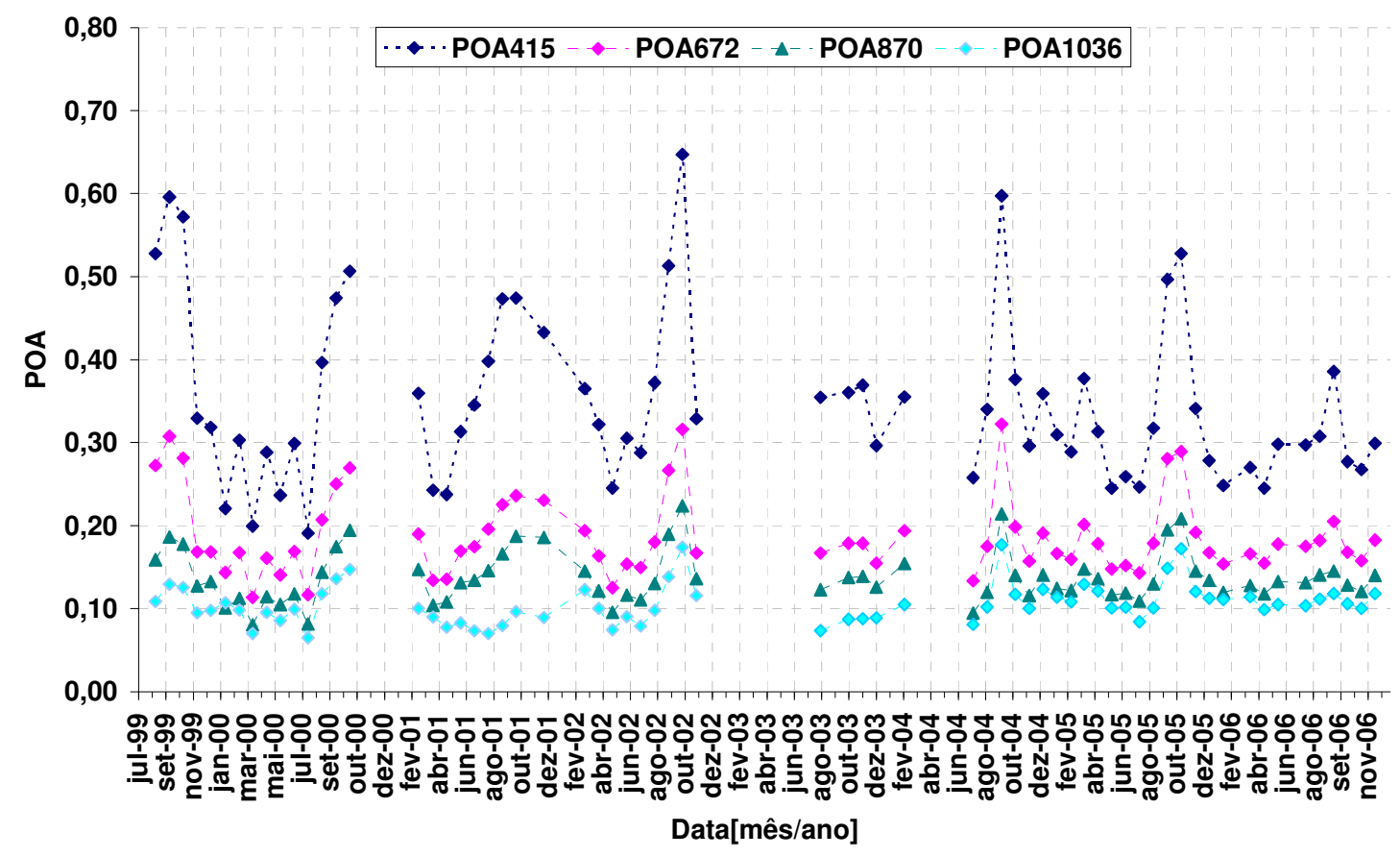

Figura 4.9 - Valores médios mensais de POA (profundidade óptica espectral do aerossol) para São Paulo - SP (medidos na Estação Meteorológica do IAG-USP localizada no bairro da Água Funda - capital - SP) para o período de agosto de 1999 a fevereiro de 2003. As barras de erro foram suprimidas para facilitar a visualização dos dados. As linhas unindo os pontos são apenas para também ajudar na visualização.

Na figura 4.9 fica caracterizada a variabilidade sazonal da POA ao longo da série temporal entre 1999 a 2006. Percebe-se que a POA tem uma característica cíclica na amplitude dos valores médios mensais com os maiores valores de POA encontrados no inverno e os menores observados nos meses de verão em São Paulo.

\subsection{Relação entre variáveis meteorológicas e as propriedades ópticas do aerossol}

Verificar a relação existente entre variáveis meteorológicas (VM) com propriedades ópticas espectrais do aerossol foi um dos objetivos deste trabalho em conjunto com a estimativa da sua variabilidade sazonal em São Paulo, a partir de medidas de radiação solar com MFRSR.

O intuito desta etapa é de caracterizar a relação entre os parâmetros físicos analisados, verificando qual a relação entre as VM medidas no nível da superfície e as propriedades ópticas espectrais do aerossol, integradas na coluna atmosférica, estimadas em 
área urbana da cidade de São Paulo. Trabalhos como os de O’Neill et al. [1993] em áreas urbanas, Smirnov et al. [1995] e Glantz et al. [2006] sobre o oceano e Yamasoe [1999] e Martins [1999] para aerossóis de queimadas também tentam relacionar parâmetros de qualidade do ar e meteorológicos com propriedades ópticas do aerossol.

\subsubsection{Caracterização da base de dados selecionada}

A partir da combinação de filtro automático e inspeção visual, foi obtida uma série de dados que compreende 312 medições (valores horários) que pertencem a 63 dias sem nuvens constituídos na sua maioria em períodos de inverno com predomínio de manhãs. Esta restrição nos dados visa permitir que a influência nas VM seja apenas do aerossol e vice versa.

A freqüência absoluta da distribuição dos valores médios horários das propriedades ópticas espectrais do aerossol para a série selecionada é ilustrada na figura 4.10, para a POA, e na figura 4.11, para o coeficiente de Ångström:
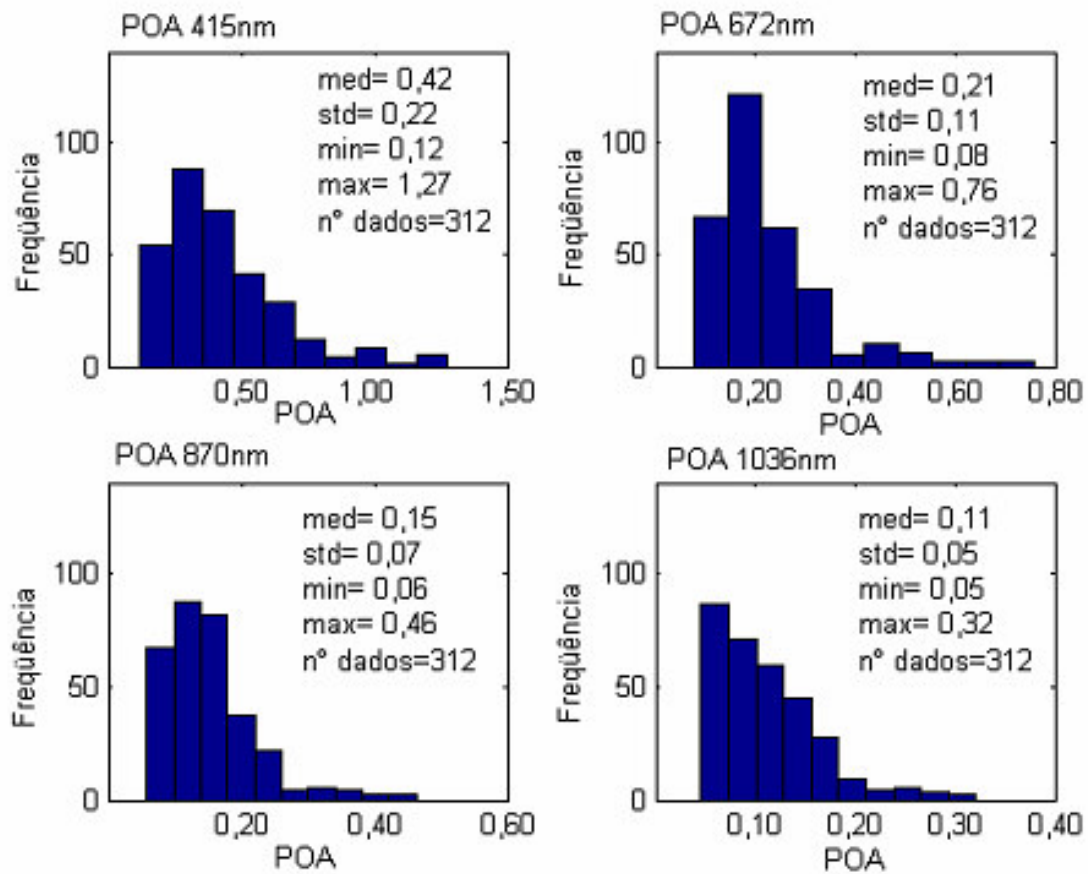

Figura 4.10 - Histograma da profundidade óptica do aerossol entre agosto de 1999 até dezembro de 2002 para os canais do MFRSR. São apresentados os valores estatísticos: média (med), desvio padrão (std), mínimo (min), máximo (max) e número de dados empregados ( ${ }^{\circ}$ dados) para os períodos selecionados sem nuvens. 

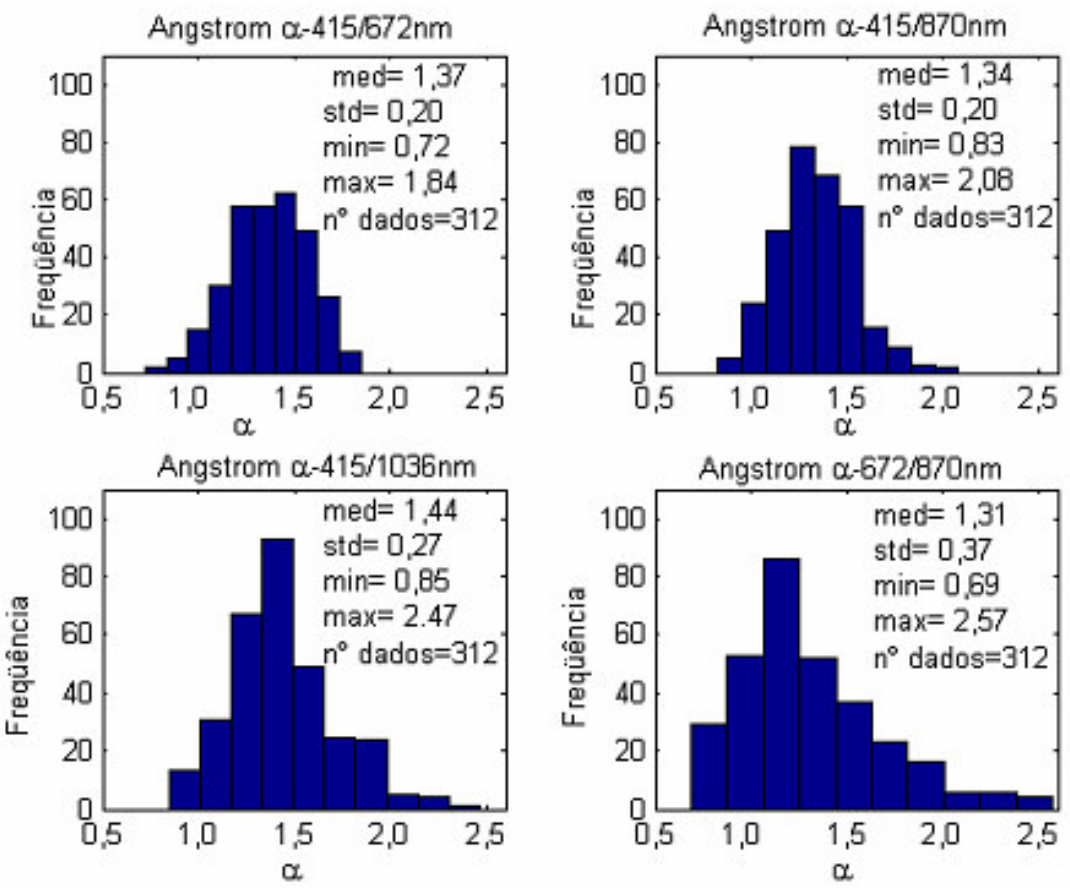

Figura 4.11 - Histogramas do coeficiente de Ångström entre agosto de 1999 até dezembro de 2002. São apresentados os valores estatísticos: média (med), desvio padrão (std), mínimo (min), máximo (max) e número de dados empregados ( $n^{\circ}$ dados) para os períodos selecionados sem nuvens.

A figura 4.10 ilustra a frequiência absoluta da distribuição dos valores médios horários de POA para o período selecionado em cada canal do MFRSR. Os histogramas ilustram também os valores médios horários extremos para a POA em São Paulo representados pelo valor mínimo e máximo em cada canal. No canal $415 \mathrm{~nm}$ a profundidade óptica do aerossol variou de 0,12 a 1,27 e no canal $672 \mathrm{~nm}$ de 0,08 a 0,76 respectivamente. Desta forma, a série de dados selecionados representa tanto dias com valores baixos de POA associados a baixas concentrações de material particulado quanto a períodos com POA próximos ao valor unitário no canal $415 \mathrm{~nm}$, podendo estar associados a altas concentrações devido a fenômenos de transporte de aerossóis de queimada para a cidade de São Paulo.

O valor médio de POA obtido para a série analisada no canal $415 \mathrm{~nm}$ é de 0,42 sendo um valor típico neste canal em meses com baixa precipitação na cidade de São Paulo. Este valor médio se aproxima dos obtidos por Rosário [2006] no IF-USP no período de agosto a outubro de 2004 que foi de 0,36 para o canal $415 \mathrm{~nm}$ do MFRSR e de 0,37 para o canal equivalente da rede AERONET em $440 \mathrm{~nm}$.

$\mathrm{Na}$ figura 4.11 foram construídos histogramas com os valores médios horários calculados para o coeficiente de Ångström $(\alpha)$ entre os canais dos MFRSR. Os valores de coeficiente de Ångström apresentados representam tanto a variabilidade média dessa grandeza 
quanto o espectro de valores encontrados para São Paulo, onde o valor médio estimado foi de 1,31 entre os canais $672 / 870 \mathrm{~nm}$ e de 1,34 entre os canais $415 / 870 \mathrm{~nm}$. A distribuição do coeficiente de Ångström apresentada mostra que em média a pluma de aerossol na atmosfera de cidade de São Paulo em dias sem nuvens tem predomínio de partículas de tamanho de médio a aerossol da moda fina.

A figura 4.12 ilustra o coeficiente de Ångström ( $\alpha$ ) em 415/870 nm em função da POA em $415 \mathrm{~nm}$. Este gráfico sugere que existe uma dependência entre o valor do $\alpha$ e o da POA em São Paulo para os dados analisados. Vale lembrar que o $\alpha$ representa a dependência espectral da interação da radiação solar com as partículas de aerossol. Variações em $\alpha$ indicam variações no tamanho das partículas, isto é, valores menores indicam que as partículas têm tamanho maior e vice versa. Segundo Martins [1999] a grande importância de $\alpha$, considerado um parâmetro intensivo do aerossol tanto quanto outros parâmetros ópticos, é que ele representa uma propriedade intrínseca das partículas de aerossol permitindo que a mesma possa ser comparada diretamente com resultados de outros tipos de aerossol independentemente da concentração de massa dos mesmos.

A figura 4.12 aponta para um comportamento médio de redução do tamanho das partículas com o aumento da POA apesar da dispersão observada nos dados. Esta tendência ocorre até valores de POA da ordem de 0,70 no canal $415 \mathrm{~nm}$. Após este valor limite, o coeficiente de Ångström não apresenta mais essa tendência, passando a um comportamento médio mais estável em torno de 1,50.

Eventos locais podem explicar os valores altos do coeficiente de Ångström, observados nas datas: 31/08/99 ( $\alpha \sim 1,80$ ), 01/09/99 ( $\alpha$ entre 1,77 a 2,10), 28/09/99 ( $\alpha$ entre 1,71 a 1,84) e dia 25/08/01 ( $\alpha$ entre 1,73 a 1,84). Analisando para o mês de agosto de 1999, as observações rotineiras feitas pelos técnicos da EM-IAG-USP, registraram a presença de névoa seca durante todo o mês de agosto e fumaça ao lado da estação tanto no dia 22/08/99 ("fumaça ao Norte dentro da mata") quanto no dia 25/08/99 ("fumaça a Norte e a Oeste da estação"). Estes dias não fazem parte dos dados selecionados, porém, ajudam explicar alguns eventos locais que podem alterar as condições atmosféricas reinantes no sítio de medição. A condição de névoa seca foi observada pelos técnicos da EM até o dia 31/08/99 inclusive. Já para o mês de setembro, no dia 01/09/99 foi observada "névoa seca e fumaça a Leste da estação", justamente durante o período analisado quando ocorreram os maiores valores do coeficiente de Ångström. Para o dia 28/09/99 foi apenas registrada a presença de "névoa seca" e para os dados do dia 25/08/01 os registros da EM-IAG-USP não relatam condições atmosféricas que influenciassem o tamanho das partículas. Estes registros podem indicar que 
contribuições de fontes e condições locais podem ser significativas em relação às propriedades ópticas integradas na coluna atmosférica, em alguns dias, principalmente naqueles para os quais o coeficiente de Ångström foi muito alto não seguindo o padrão com relação à POA. Estes casos foram observados na EM principalmente no ano de 1999.

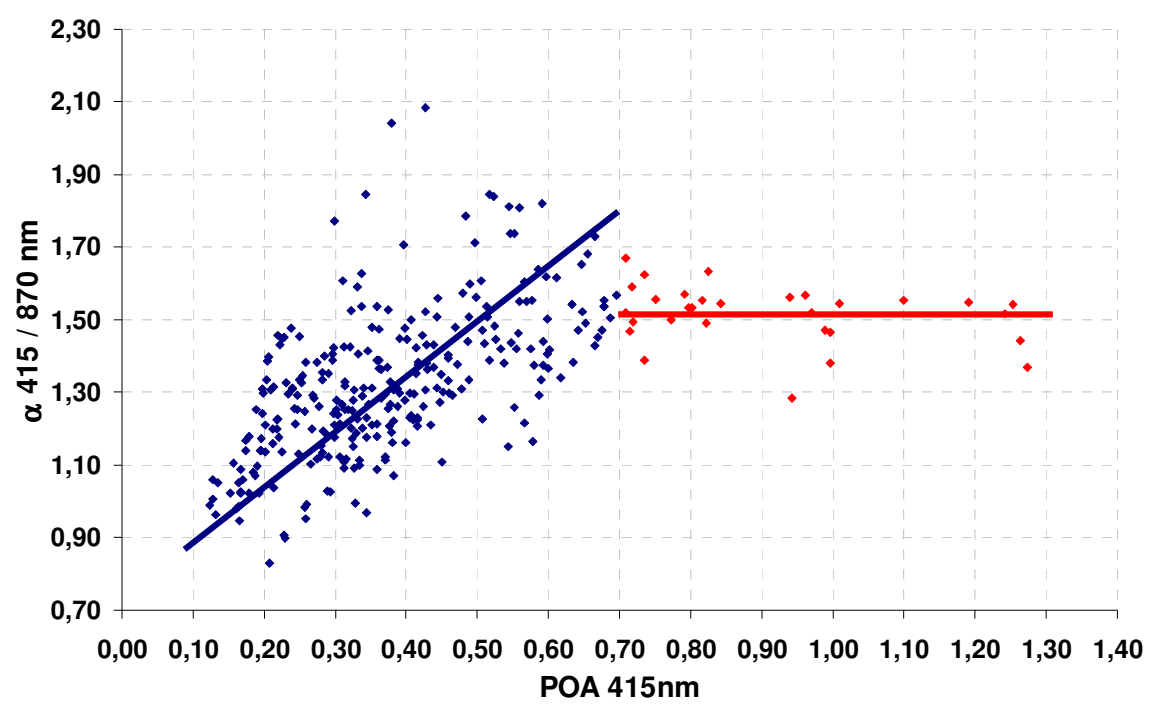

Figura 4.12 - Avaliação do coeficiente de Ångström entre os canais 415/870 nm do MFRSR em função da POA em 415 nm para o período selecionado sem nuvens entre agosto de 1999 a dezembro de 2002.

A figura 4.12, em suma, sugere um duplo comportamento na pluma de aerossol em São Paulo. O primeiro comportamento médio é para os valores de POA até 0,70 no qual há a predominância de aerossóis de fontes locais em relação ao aerossol transportado de fontes mais distantes da região metropolitana de São Paulo (RMSP). Já os valores superiores a 0,70 apesar de ocorrerem em menor freqüência na série analisada, podem ter recebido uma contribuição mais significativa do transporte de aerossol de queimada já envelhecido, porém ainda com predominância de partículas da moda fina.

Yamasoe [1999] analisou o aerossol característico de queima de biomassa em Alta Floresta, na região Amazônica durante a estação seca, quanto ao raio efetivo da moda fina e o raio efetivo total do aerossol. A autora constatou que ocorre uma diminuição de ambos os raios efetivos com o aumento da POA no canal $438 \mathrm{~nm}$. A autora concluiu que a diminuição do raio efetivo total se deve ao aumento da população de aerossóis da moda fina em relação aos demais. Assim para o caso de regiões de queimadas, os maiores valores de POA estão associados a partículas jovens da moda fina que contribuem para a redução do raio efetivo total da pluma de aerossol da região. O tamanho das partículas apresentou também um aumento do seu raio efetivo conforme as partículas permaneceram na atmosfera e sofreram 
um processo de envelhecimento por transformações tais como coagulação e condensação de gases

O comportamento observado entre o coeficiente de Ångström em relação à POA, tanto para a tendência de crescimento quanto da mudança de tendência com o aumento da POA, já foi mencionado por outros autores. O’Neill et al. [1993] observou este comportamento em sítios no Canadá (Toronto e Hamilton) que são áreas urbanas com influência de aerossol marinho e, no Brasil, Dubovik et al. [1998] observaram dependência semelhante no perfil entre os dois parâmetros, sob influência de aerossol de queimada em Cuiabá (Mato Grosso).

\subsubsection{Características Meteorológicas}

O mesmo período analisado pôde ser caracterizado também com relação às variáveis meteorológicas locais. A figura 4.13 ilustra a distribuição da freqüência absoluta para a temperatura do ar, pressão atmosférica e umidade relativa medidas no nível da superfície:

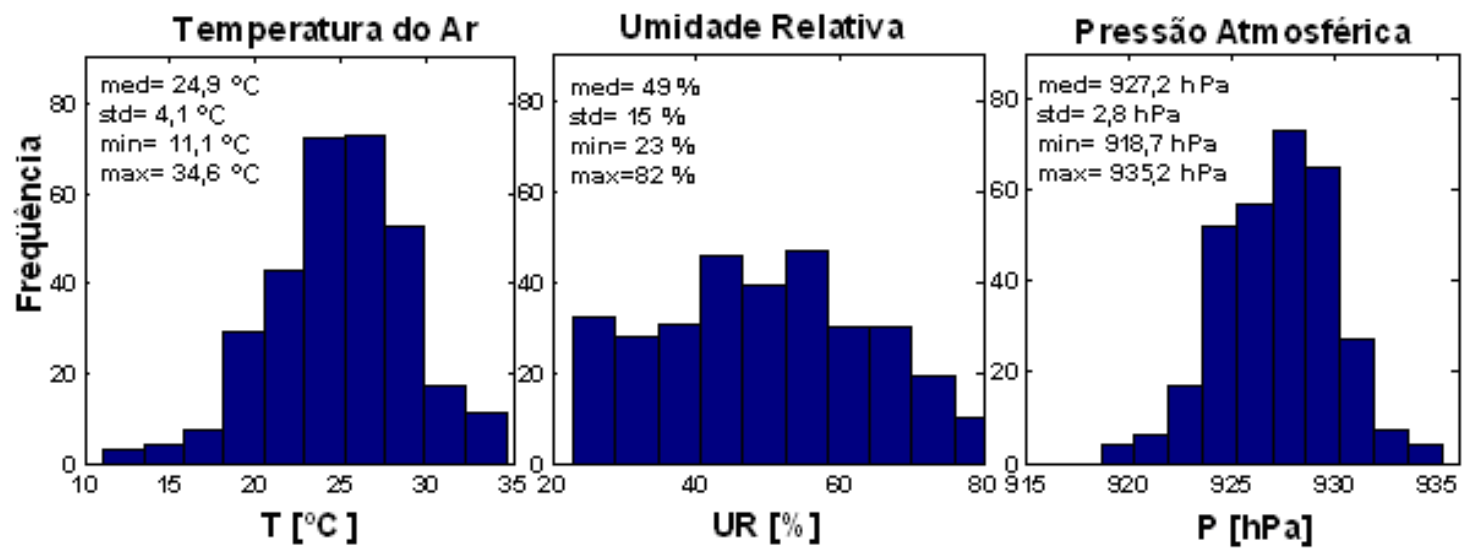

Figura 4.13 - Histogramas de temperatura do ar, umidade relativa e pressão atmosférica no período selecionado sem nuvens entre agosto de 1999 a dezembro de 2002 medidos na EMIAG-USP. São apresentados os valores: médio (med), desvio padrão (std), mínimo (min), máximo (max) para um espaço amostral de 312 dados.

A série de dados de propriedade ópticas dos aerossóis selecionados foi obtida com as condições meteorológicas ilustradas na figura 4.13, na qual a temperatura média foi em torno de $25^{\circ} \mathrm{C}$, umidade relativa de $49 \%$ e pressão atmosférica de $927 \mathrm{hPa}$. A forma de distribuição dos dados selecionados também mostra que a temperatura e a pressão apresentam uma forma de distribuição semelhante à gaussiana com valores distribuídos em torno do valor médio. A distribuição da umidade relativa apresentou-se mais larga. Nota-se que nos dias sem 
nebulosidade, a umidade relativa foi sempre menor que $85 \%$. Ressalta-se que somente os dados observados durante o dia foram considerados, o que também justifica a ausência de resultados com valores mais altos de umidade relativa.

Uma característica importante da série selecionada das VM é o valor médio da pressão atmosférica, pois o mesmo pouco difere do valor climatológico de 926,0 $\mathrm{hPa}$ empregado para corrigir a contribuição do espalhamento Rayleigh no valor da profundidade óptica do aerossol. Este fato também corrobora para empregarmos um valor climatológico para esta correção, principalmente se levarmos em consideração que a variabilidade encontrada na pressão atmosférica em relação ao valor máximo e mínimo não causa uma diferença significativa na correção da contribuição do espalhamento Rayleigh.

A figura 4.14 ilustra a característica do vento em São Paulo quanto à direção predominante e a magnitude do vento (velocidade do vento) para a série de dados selecionados:
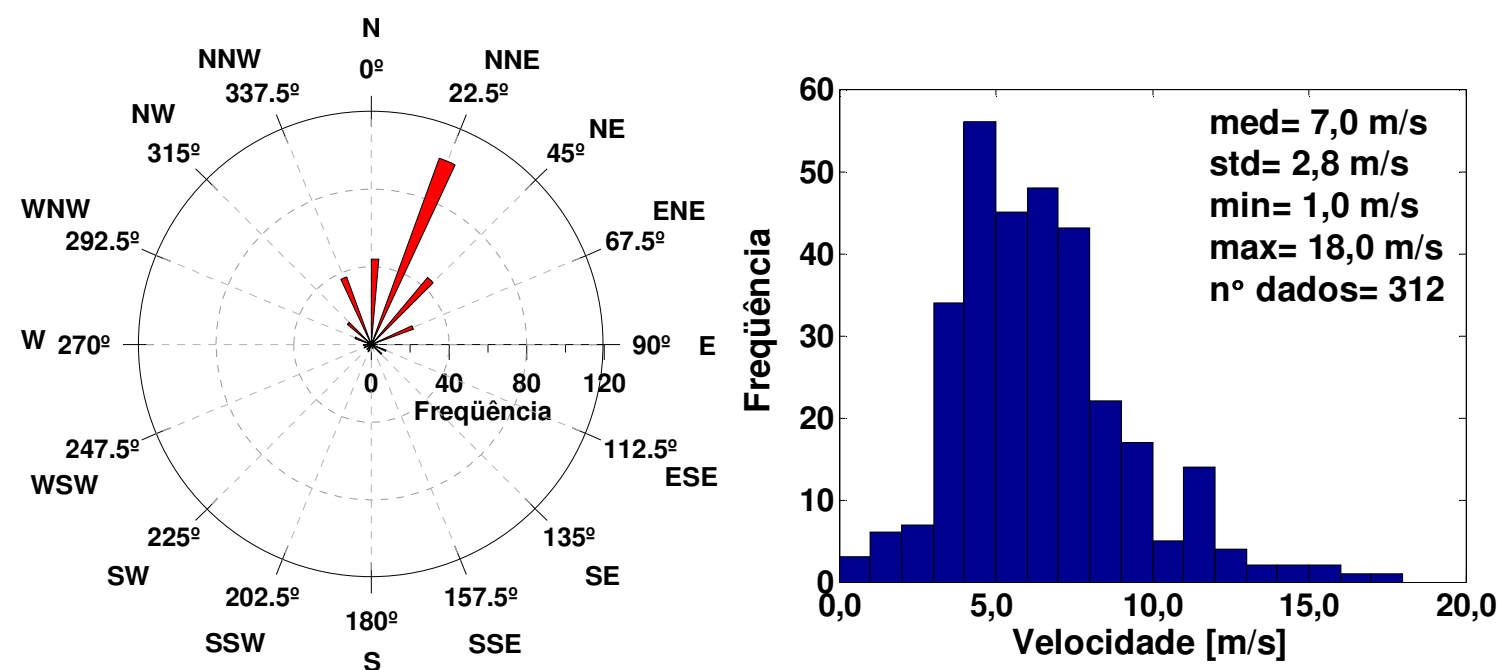

Figura 4.14 - Distribuição absoluta da orientação (direção e sentido) do vento e a distribuição da velocidade, respectivamente. A orientação do vento é apresentada em [graus] e segundo a sigla da nomenclatura em inglês. A magnitude do vento é apresentada na forma de histograma com a velocidade do vento em [m/s] para a série analisada, medida pela EM - IAG-USP entre agosto de 1999 até dezembro de 2002.

Os dados de vento, ilustrados na figura 4.14, apresentam ventos oriundos de orientações Norte $(\mathrm{N})$ e suas combinações (N, NW, NNW, NNE, NE e ENE) como sendo as orientações mais significativas da série, ou seja, a distribuição dos dados em relação à orientação apresenta ventos de Noroeste $\left(337,5^{\circ}\right)$ a ventos de Leste-Nordeste $\left(67,5^{\circ}\right)$ como os mais significativos nas condições analisadas. $\mathrm{O}$ vento proveniente de Norte-Nordeste $\left(22,5^{\circ}\right)$ são os predominantes para esta série de medidas na EM IAG-USP em dias de céu limpo por 
longos períodos de tempo. Quanto à magnitude do vento, ilustrada na figura 4.14, o valor médio encontrado foi de $7,0 \pm 2,8 \mathrm{~m} / \mathrm{s}$.

A figura 4.15 mostra a distribuição das orientações do vento em relação ao período do dia, ou seja, os dados foram separados em dois períodos manhã e tarde como segue:

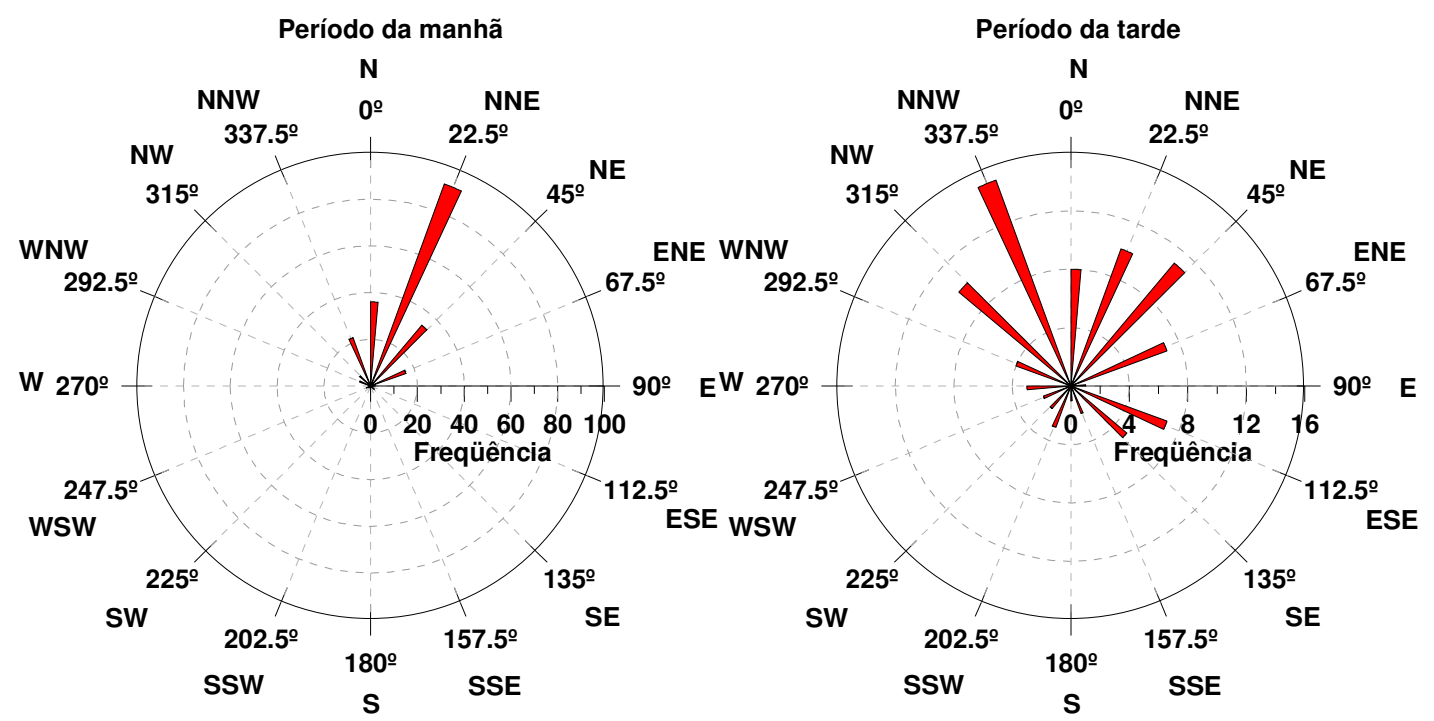

Figura 4.15 - Distribuição absoluta da orientação (direção e sentido) do vento para o período da manhã e da tarde. A orientação do vento é apresentada em [graus] e segundo a sigla da nomenclatura em inglês, a série analisada foi medida pela EM - IAG-USP entre agosto de 1999 a dezembro de 2002.

As orientações do vento ilustradas na figura 4.15 também mostram que as combinações com a direção de Norte são predominantes, principalmente a de NNE para o período da manhã. Já no período da tarde, levando em conta o número menor de dados em relação ao período da manhã, a orientação de Norte - Noroeste (NNW) é a que apresenta a maior freqüência. No período da tarde observamos que existem outras orientações de vento e que devido a sua baixa frequiência não são visíveis na figura 4.14. No período da tarde em São Paulo a freqüência de dados sem nuvens é menor devido ao aumento da nebulosidade ao longo do dia. Quanto à magnitude média do vento tanto para o período da manhã quanto para o da tarde foram observados valores da mesma ordem de grandeza do vento médio estimado para toda a série de dados e por este motivo não foram apresentados. 


\subsubsection{Avaliação da relação entre as propriedades ópticas do aerossol e as variáveis meteorológicas}

A umidade relativa pode contribuir para o crescimento das partículas de aerossol, enquanto que a magnitude do vento pode contribuir para aumentar a concentração ou para dispersar as partículas de aerossol em determinado sítio. Os parâmetros mencionados são comparados de forma quantitativa com as propriedades ópticas do aerossol como a POA e o coeficiente de Ångström.

A figura 4.16 ilustra esta comparação quantitativa da POA com umidade relativa e com a magnitude do vento medidos no nível da superfície na EM - IAG-USP. Não foi observada, entre esses parâmetros analisados, uma tendência ou relação aparente significativa que possa explicar o crescimento da POA com a variabilidade das variáveis meteorológicas e vice-versa. A magnitude do vento, que poderia de forma mais significativa se relacionar com o valor da POA, não apresenta uma tendência significativa nos gráficos da figura 4.16.
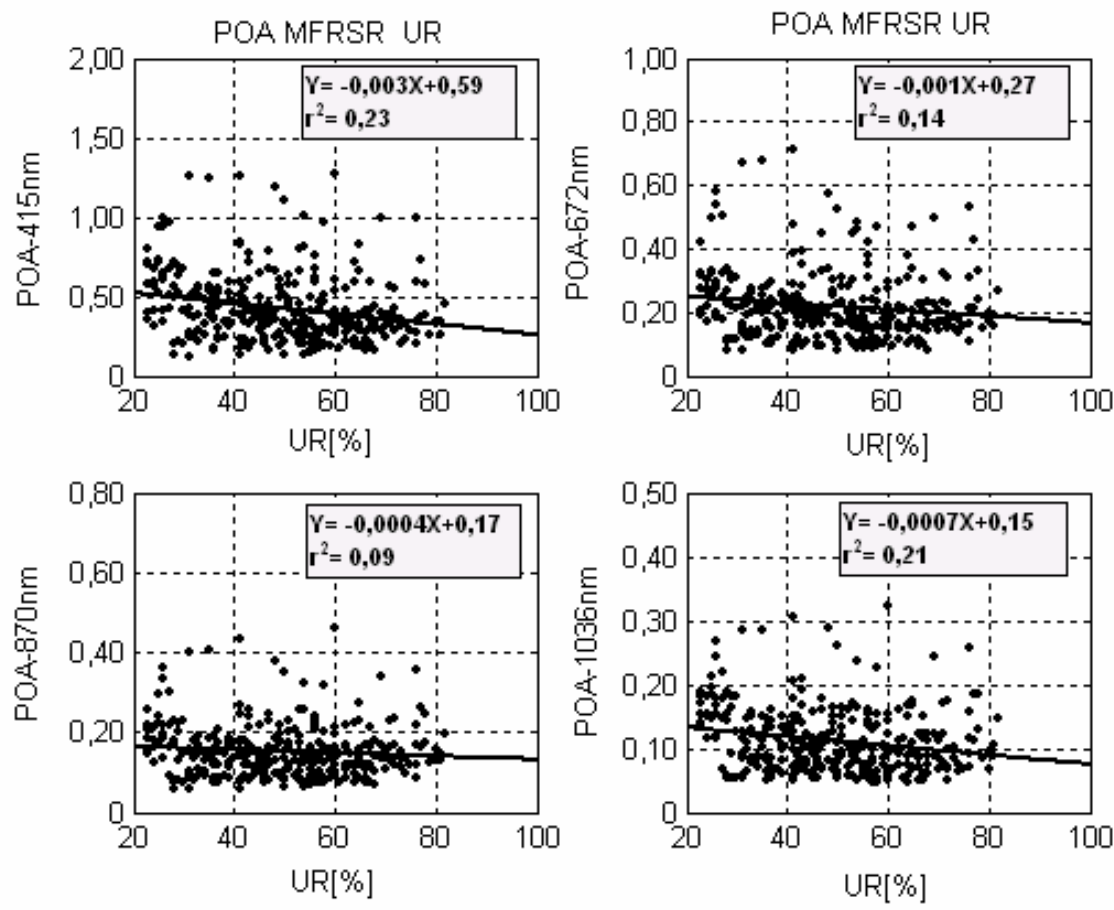

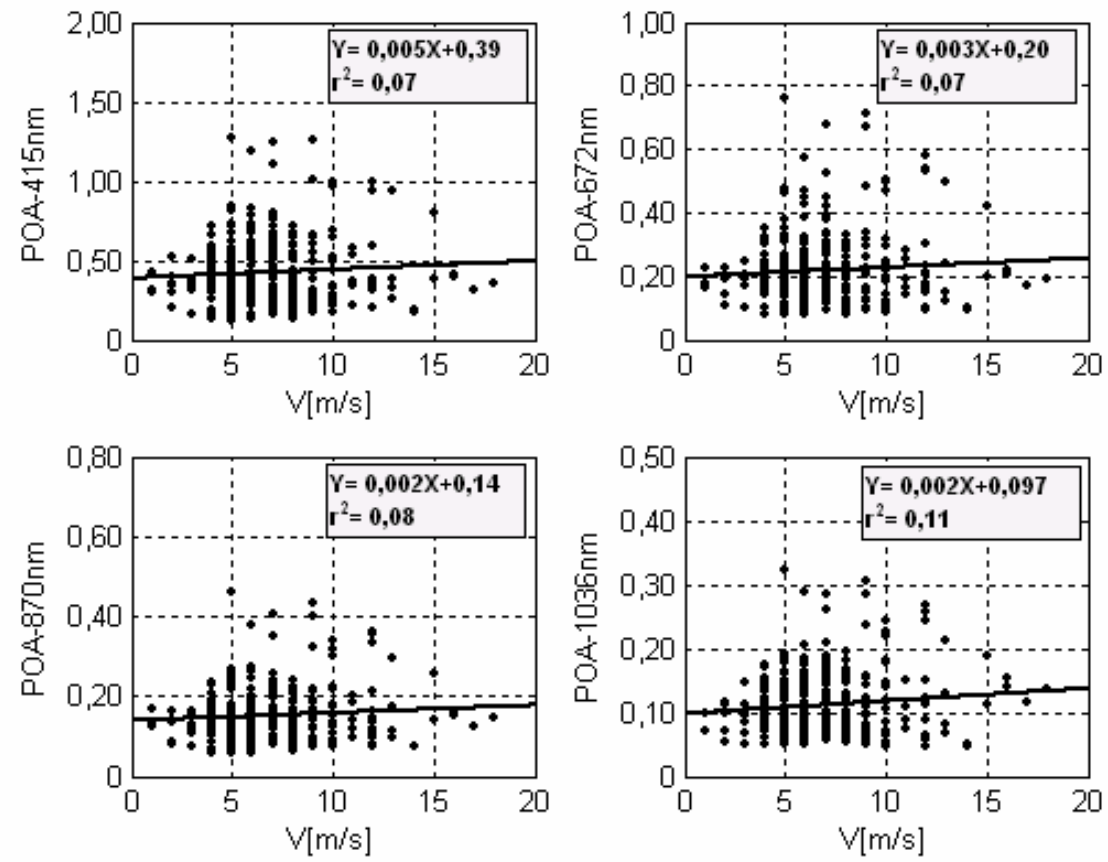

Figura 4.16 - Comparação da POA em (415; 672; 870 e 1036nm) com a umidade relativa (UR[\%]) e a velocidade do vento. É apresentado no gráfico o ajuste linear obtido entre os parâmetros analisados $(\mathrm{y}=\mathrm{a} \cdot \mathrm{x} \pm \mathrm{b})$ e o módulo do coeficiente de correlação $\left(\mathrm{r}^{2}\right)$ para o período de dados selecionados, entre agosto de 1999 a dezembro de 2002. Dados coletados na EM - IAG-USP.

No que diz respeito à direção do vento em São Paulo, para a série selecionada, foi verificado se existia uma direção que apresente uma tendência com a POA quanto à dispersão ou quanto o seu aumento. Assim, a série de dados selecionados foi separada por direção do vento, já apresentada anteriormente. Novamente não foi observada uma tendência entre as VM e a POA que fosse significativa. Também foram comparadas as VM e a POA com relação ao horário em que foram feitas as medidas e da mesma forma como as comparações anteriores não foi observada nenhuma relação ou tendência entre os dados que se mostrasse significativa. Por apresentarem resultados semelhantes apenas com um número menor de valores do que a figura 4.16 estas comparações entre as VM e a POA não serão apresentadas. Desta forma, em suma, não foi encontrada, entre a UR e o vento, grandezas medidas na superfície, uma relação direta com a POA, que é uma grandeza integrada na coluna atmosférica.

O coeficiente de Ångström também foi comparado com a magnitude do vento nas mesmas condições que a POA e também não apresentou um resultado significativo em relação a nenhum dos testes realizados. Desta forma, para a série de dados analisada, a mudança no tamanho médio das partículas de aerossol integrados na coluna atmosférica 
inferida através do coeficiente de Ångström não apresenta uma relação direta com o vento medido na superfície. Quando comparado com a umidade relativa, o coeficiente de Ångström estimado através dos MFRSR apresentou um comportamento médio significativo que é ilustrado na figura 4.17 .

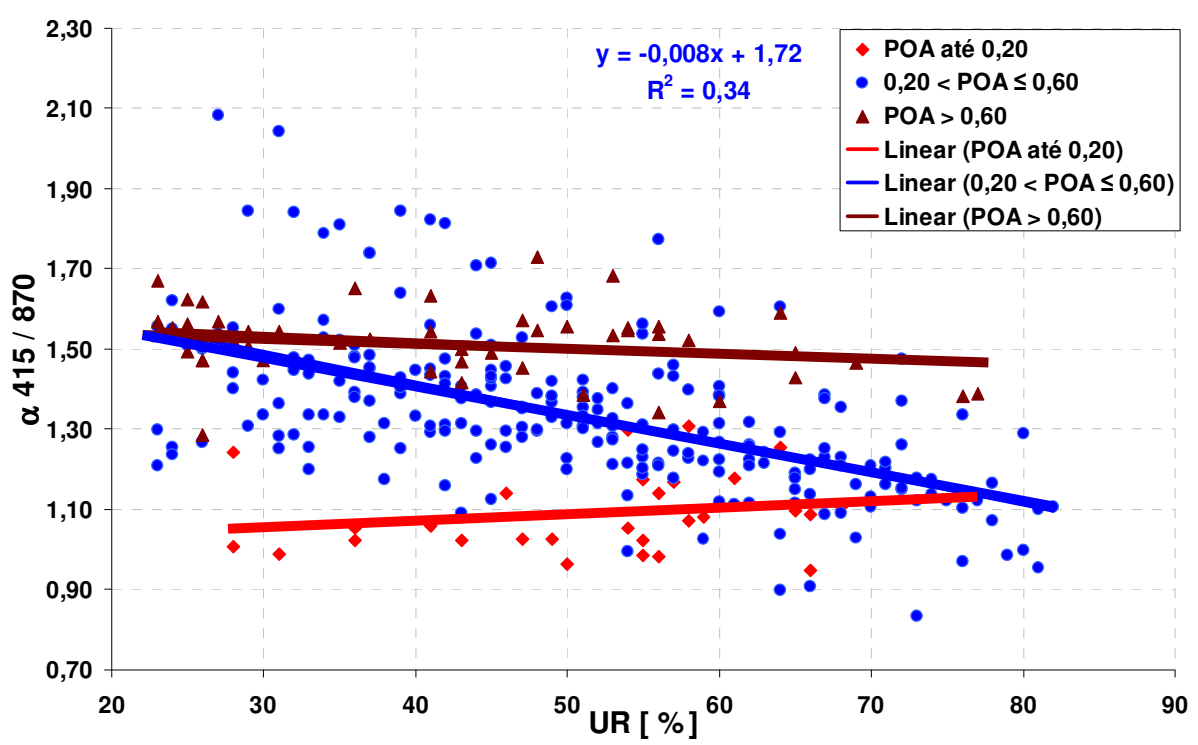

Figura 4.17 - Coeficiente de Ångström ( $\alpha$ ) entre os canais 415/870 do MFRSR versus umidade relativa (UR[\%]). No gráfico, o $\alpha$ foi separado em três grupos de dados em relação ao valor da POA no canal 415nm: grupo 1 em vermelho para a POA até 0,20 , grupo 2 em azul para o intervalo entre $0,20<\mathrm{POA} \leq 0,60$ e grupo 3 em marrom para os valores com $\mathrm{POA}>0,6$. É apresentado no gráfico o ajuste linear $(\mathrm{y}=\mathrm{ax} \pm \mathrm{b})$ e o coeficiente de determinação $\left(\mathrm{R}^{2}\right)$ para o conjunto principal de pontos em azul. Dados no período de agosto de 1999 a dezembro de 2002 coletados na EM - IAG-USP

A figura 4.17 apresenta os dados selecionados, distribuídos em três grupos, separados por faixa de magnitude de POA no canal $415 \mathrm{~nm}$. Os dados agrupados em cada faixa apresentaram comportamento médio semelhante de $(\alpha)$ em relação à UR.

O primeiro grupo é formado por valores de $(\alpha)$ estimados com $\mathrm{POA} \leq 0,20$. Assim este grupo representa os menores valores médios horários de POA na cidade de São Paulo em relação à base de dados analisada (figura 4.10), isto é condições de atmosfera limpa. A figura 4.17 ilustra que este conjunto de dados apresenta uma tendência de redução de tamanho médio do aerossol integrado na coluna atmosférica com o aumento da UR, pois o valor do $(\alpha)$ cresce acompanhando o aumento da UR. Este comportamento provavelmente não está relacionado a um fenômeno físico da interação do aerossol com a UR. Valores muito pequenos de POA geram incertezas associadas à estimativa do $(\alpha)$ [Wagner \& Silva, 2007] tão grandes que a tendência e a variabilidade observada pode não representar uma alteração do tamanho do aerossol devido à UR. Por este motivo estes valores de $(\alpha)$ estimados foram 
analisados separadamente dos outros dois grupos. Este conjunto de dados apresentou o menor valor médio de $(\alpha)\left(\alpha_{\text {med }}=1,09 \pm 0,02\right)$ e, para UR $>70 \%$, o $(\alpha)$ dos dois grupos ( 1 e 2$)$ converge para os mesmos valores.

O segundo grupo é formado por $(\alpha)$ obtido entre $0,20<\mathrm{POA} \leq 0,60$ no canal $415 \mathrm{~nm}$. Este fato pode também ajudar a caracterizar este intervalo como sendo a faixa típica para o aerossol em São Paulo, em valores médios horários. O comportamento médio observado foi de que o coeficiente de Ångström apresenta uma tendência negativa em relação à UR, isto é, em média o aerossol aumenta de tamanho com o aumento da UR. Este fato pode indicar um caráter higroscópico do aerossol médio na cidade de São Paulo. Esta característica do aerossol em agregar vapor de água da atmosfera em sua superfície, além de alterar o tamanho das partículas pode também provocar uma alteração de suas propriedades ópticas como índice de refração e albedo simples. Martins [1999] verificou, para o material particulado total, o aumento do coeficiente de espalhamento devido ao aumento na umidade relativa e, segundo o autor, esta característica é típica de aerossóis com comportamento higroscópico. Yamasoe [1999] analisou a parte real do índice de refração para Cuiabá e Alta Floresta (MT) e Porto Nacional (TO) durante a estação seca verificando uma ligeira diminuição desta com o aumento da quantidade de vapor de água precipitável na atmosfera.

Por fim a figura 4.17 também apresenta um terceiro grupo formado por dados com POA>0,60 no canal $415 \mathrm{~nm}$. Este grupo não apresentou uma tendência significativa entre o $(\alpha)$ e a UR. Os pontos obtidos entre as duas grandezas se distribuíram de forma aleatória e dispersa em relação à reta ajustada. Assim o grupo 3 pode ser caracterizado por uma pluma de aerossóis pouco higroscópica ou hidrofóbica devido a possíveis contribuições de aerossol de queimadas das regiões central do Brasil e amazônica em São Paulo.

Ainda em relação aos dados do grupo 3, eles majoritariamente pertencem a dias entre os meses de agosto a outubro dos anos analisados, o que coincide com o período em que ocorrem eventos de queimada na região central do Brasil e Amazônia. Segundo Yamasoe [1999] as partículas de aerossol das regiões centrais do Brasil afetadas pela queima de biomassa apresentaram uma correlação pouco significativa com a quantidade de vapor de água precipitável, o que corrobora para o seu baixo fator de higroscopicidade. A autora ainda afirma que em relação às propriedades intrínsecas das partículas de aerossol, a análise durante três anos consecutivos indicou que partículas provenientes de queima de biomassa apresentaram pouca variabilidade de ano para ano. Outro fato que vale ressaltar é que para valores de UR $<30 \%$ a pluma de aerossol dos grupos 2 e 3 se aproximam de um valor de $(\alpha)$ em torno de 1,55. 
Ainda sobre os dados analisados, o intervalo compreendido entre $0,60<\mathrm{POA} \leq 0,70$ se mostrou pouco relacionado com a UR, se ajustando ao comportamento médio do grupo 3 . Esta faixa de POA no canal $415 \mathrm{~nm}$ pode representar uma transição entre o aerossol majoritariamente de fontes locais e aquele que é transportado no período de queimadas até São Paulo assim, espera-se que o comportamento do mesmo seja semelhante aos demais dados do grupo 3 do que com o aerossol típico de São Paulo do grupo 2. Vale lembrar que podem ocorrer eventos meteorológicos como sistemas de bloqueio e inversões térmicas, entre outros fenômenos meteorológicos, em meses fora do período de agosto a setembro, que contribuam para a dificuldade na dispersão do aerossol na atmosfera levando a pluma de aerossol de São Paulo a valores altos de POA. Desta forma, elevados valores de POA em São Paulo (POA >0,60 no canal 415nm) não necessariamente estão associados com eventos de queimadas da região amazônica e do Brasil central.

\subsubsection{Identificação do transporte de aerossol de queimadas na série analisada}

Alguns trabalhos recentes já indicaram a influência de transporte de aerossol de queimada na pluma de aerossóis de São Paulo. Nesses trabalhos distintos equipamentos e metodologias foram empregados. Entre os trabalhos cabe ressaltar o de Landulfo et al. [2003] com o emprego, entre outros, de um sistema LIDAR (Light Detection And Ranging) instalado no Laboratório de Aplicações Ambientais do Centro de Laser e Aplicações do IPEN (Instituto de Pesquisas Energéticas e Nucleares) e o de Castanho [2005] empregando um fotômetro solar Cimel da rede AERONET instalado no Instituto de Física da USP em conjunto com dados de sensoriamento remoto do sensor MODIS (Moderate Resolution Imaging Spectroradiometer) a bordo dos satélites TERRA e AQUA. Segundo Castanho [2005] existe um aumento significativo observado nas médias de POA no período de setembro e outubro, devido ao transporte em longa distância de material particulado de queimadas na Amazônia nesta época de seca e queimadas na região.

O transporte de aerossol de queimadas até São Paulo pode ser identificado a partir de mudanças no padrão das propriedades ópticas do aerossol típico de São Paulo. Na série de dados analisada também foram identificados alguns dias que sofreram esta influência. Ela se deu principalmente nos dias nos quais a POA foi alta e o $(\alpha)$ apresentou valores também altos $(\alpha \sim 1,50)$, característicos de partículas finas. Os casos atribuídos ao fenômeno de transporte de 
aerossol na série analisada pertencem ao grupo 3 (POA>0,60 no canal $415 \mathrm{~nm}$ ) em particular nos dias $06,11,16$ e 19 de outubro de 2002.

Os dias citados compõem um período de 13 dias em que ocorreram alguns dos maiores valores de POA média horária da série analisada que variaram entre 0,60 a 1,19 no canal $415 \mathrm{~nm}$. Castanho [2005] já havia sugerido em seu trabalho uma série de dias (dias 09, 11, 13, 15, 16 e 19/10/02 entre outros) como sendo alguns dos dias com forte indício de passagem de pluma de aerossóis proveniente de queimadas na Amazônia. Um fato que corrobora também para que este período seja de transporte de aerossóis de queimadas sobre a cidade de São Paulo é que mesmo estando o fotômetro Cimel da rede AERONET e o MFRSR a cerca de $15 \mathrm{~km}$ um do outro eles detectara a atuação do mesmo fenômeno citado.

Um meio de verificar de forma qualitativa o fenômeno de transporte de aerossóis de queimadas até São Paulo pode ser feita pela análise da POA via sensoriamento remoto por satélite o qual propicia a observação da distribuição espacial dos valores de POA dia a dia em cada passagem do satélite. Assim foram analisados os valores da POA em 550nm, obtidos com o sensor MODIS abordo do satélite TERRA para o Brasil e parte da América do Sul, disponibilizados pela NASA, no período de interesse sendo ilustrados nas figuras 4.18 e 4.20. Nestas imagens os maiores valores de POA são ilustrados em cores que tendem ao vermelho e os menores valores em cores tendendo ao azul conforme a escala ao lado das figuras.

As regiões fontes do aerossol de queimadas estão localizadas, principalmente, em partes do Brasil central e região amazônica que apresentam altos valores de POA nesta época do ano (período seco) como pode ser observado nas figuras 4.18 e 4.20. As plumas, ainda muito espessas, ocasionam altos valores de POA (POA 0,90) sobre uma vasta região da América do Sul (Brasil, Paraguai, Bolívia e Argentina como no dia 06/10/2002) devido a atuação das correntes de ar atmosférica. Este fato é encontrado de forma mais intensa nos dias iniciais da análise, dias 06 e 07 de outubro de 2002 nos quais os valores de POA são maiores do que 0,90 nessas regiões citadas.

No dia 07/10/2002 uma ramificação desta pluma inicial de aerossóis próxima ao litoral de São Paulo apresenta valores de POA também maiores do que 0,90 além de valores em suas adjacências da ordem de 0,50 inclusive sobre a cidade de São Paulo como indica a 4.18. Nos dias 08 e 09/10/2002 a influência desta primeira pluma continua atuando em São Paulo com valores de POA também da ordem de 0,50. 

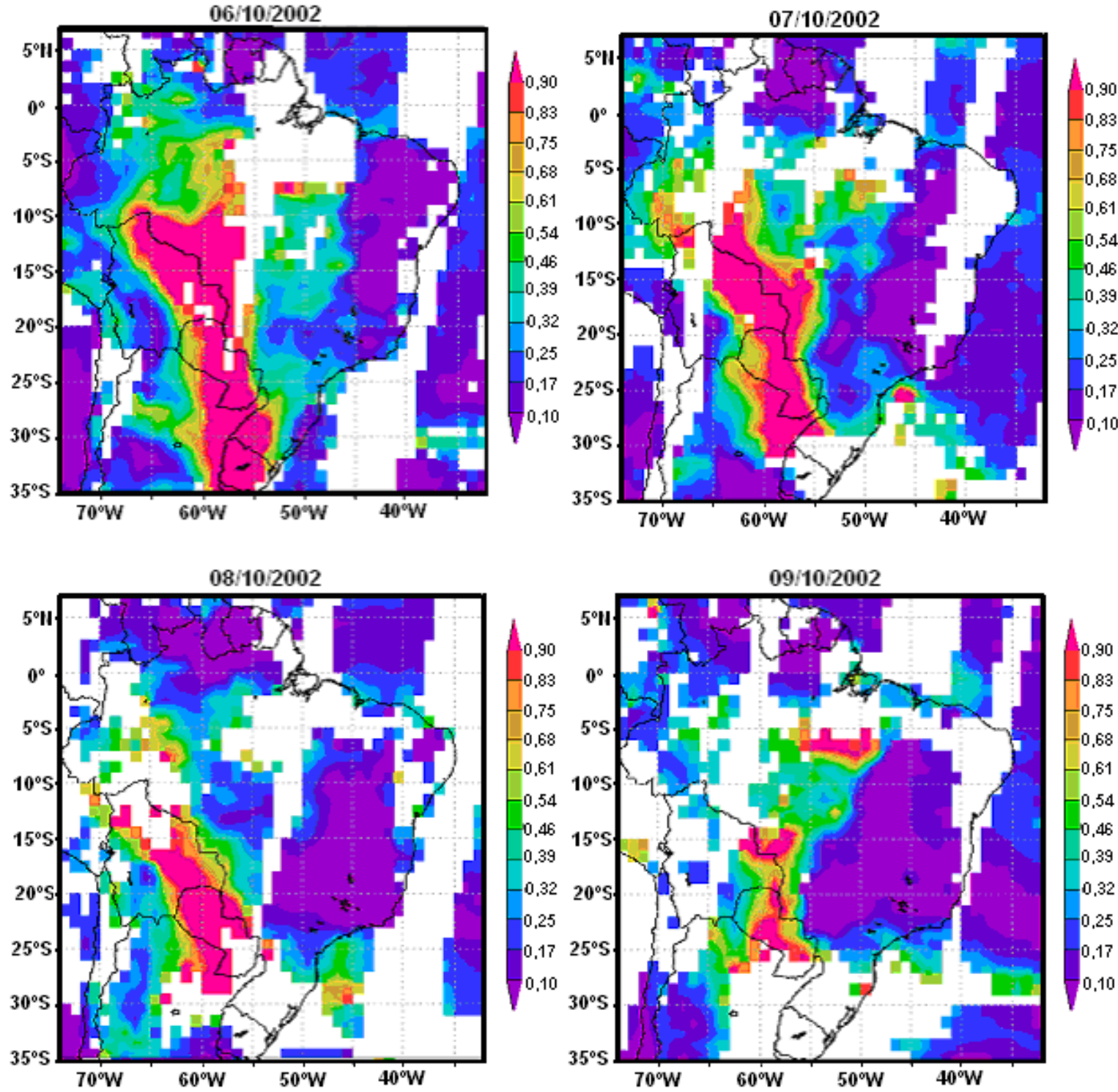

Figura 4.18 - Distribuição espacial da POA através do sensor MODIS abordo do satélite Terra em $0,55 \mu \mathrm{m} \quad(550 \mathrm{~nm})$ disponíveis no site NASA-Giovanni (http://disc1.sci.gsfc.nasa.gov/daac-bin/G3/gui.cgi).As figuras correspondem ao intervalo entre 06 a 09 de outubro de 2002, a latitude e longitude são apresentadas em [graus] e a régua de cores ao lado da figura indica o valor da POA correspondente nos mapas.

A figura 4.19 ilustra novamente a pluma de aerossóis cobrindo a região oeste e sul do Brasil e alguns países vizinhos (dia 06/10/2002), mas mostra também que o transporte de aerossóis de queimadas se dá entre as nuvens, o que prejudica o monitoramento por satélites tanto quanto o monitoramento em solo por fotometria solar. Este fato ajuda a explicar a falta de dados nas imagens geradas pelo sensor MODIS, bem como os poucos dias sem nebulosidade, obtidos com os MFRSR, apesar dos altos valores de POA no período analisado. O fenômeno também ajuda a esclarecer o aparecimento de ramificações da pluma original 
com valores altos de POA em locais distantes das fontes e da pluma original, como ilustrado na figura 4.19 .

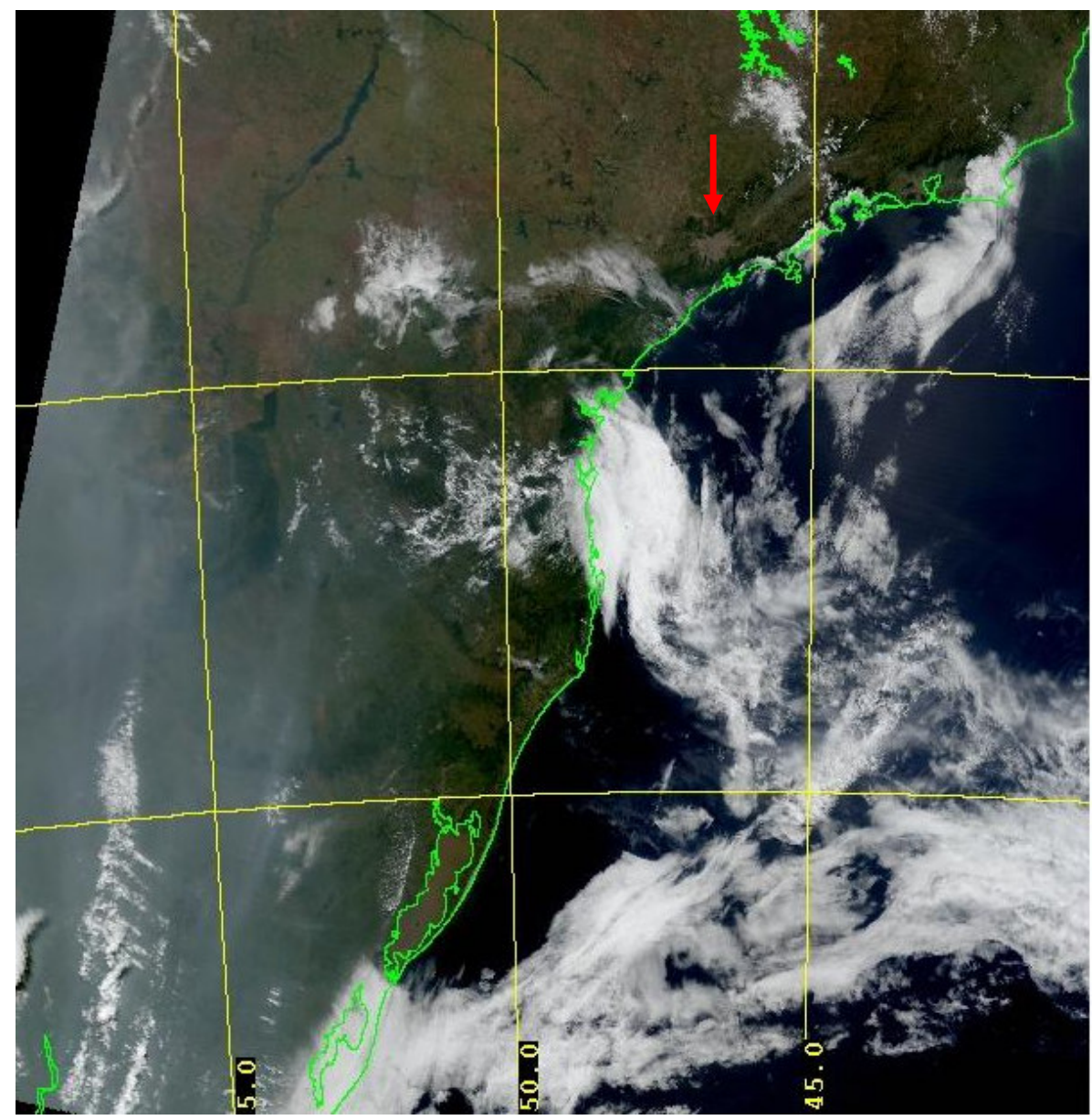

Figura 4.19 - Imagem RGB no espectro do visível (Visible Composite) através do sensor MODIS a bordo do satélite TERRA, ampliação, para o dia 06/10/2002 na qual é possível observar uma grande pluma de aerossol cobrindo o Uruguai, Rio Grande do Sul, Santa Catarina, Paraná, Mato Grosso do Sul e São Paulo. A seta indica a região metropolitana de São Paulo. Imagem disponível no site LAADS endereço: http://ladsweb.nascom.nasa.gov.

Ainda contribuindo com a caracterização do transporte de aerossóis de queimada até a cidade de São Paulo a figura 4.18 ilustra que a pluma gerada por volta do dia 06/10/2002 nas regiões de queimadas foi sendo dissipada e transportada até o dia 09/10/2002 com ramificações chegando a São Paulo em todo este período de forma menos intensa. No dia 10/10/2002 (figura 4.20) São Paulo continua a sofrer influências desta primeira pluma, porém na região de queimadas uma nova pluma começa a se formar e se propagar pela região favorecida pelas condições atmosféricas reinantes do período seco. Em 11/10/2002 o transporte é evidenciado mais claramente por uma pluma com POA da ordem de 0,50 que se 
estende das regiões mais próximas às fontes de queimadas, passando pelo norte do estado do Rio Grande do Sul e se estendendo até São Paulo. Também neste dia, na região central e amazônica do Brasil, uma nova pluma de queimadas começa a ser formada e a se intensificar, de acordo com a POA observada.
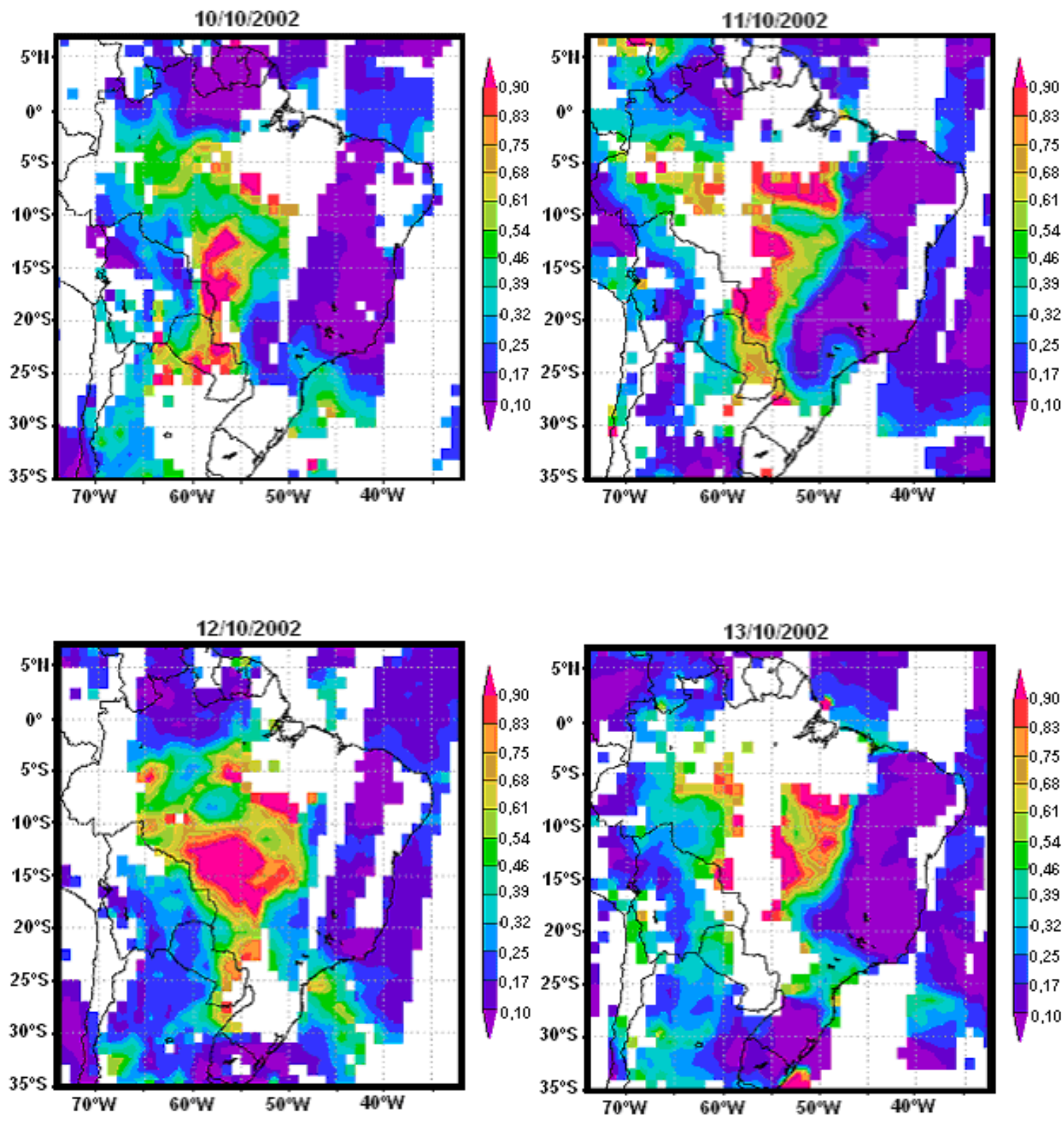

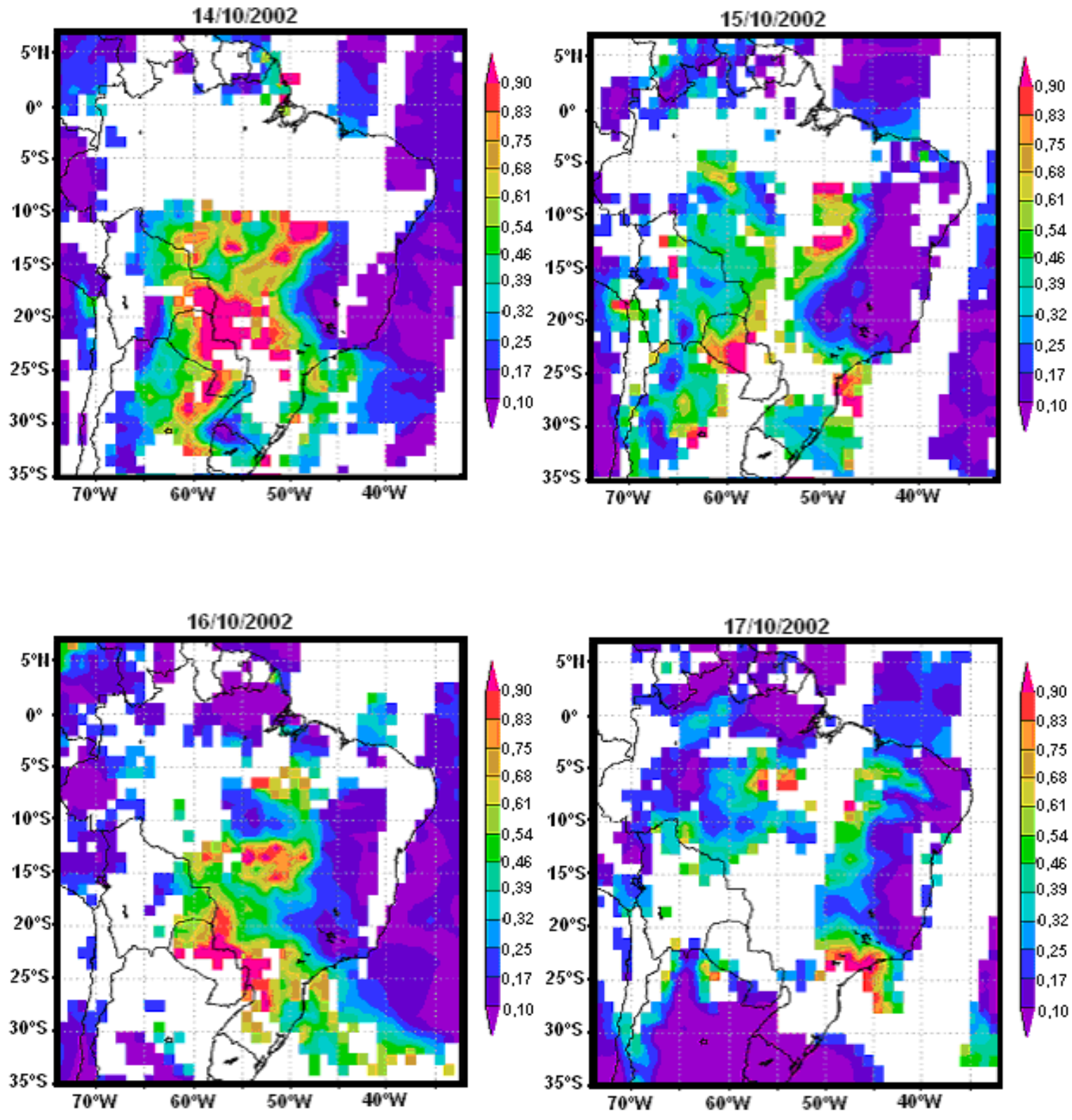

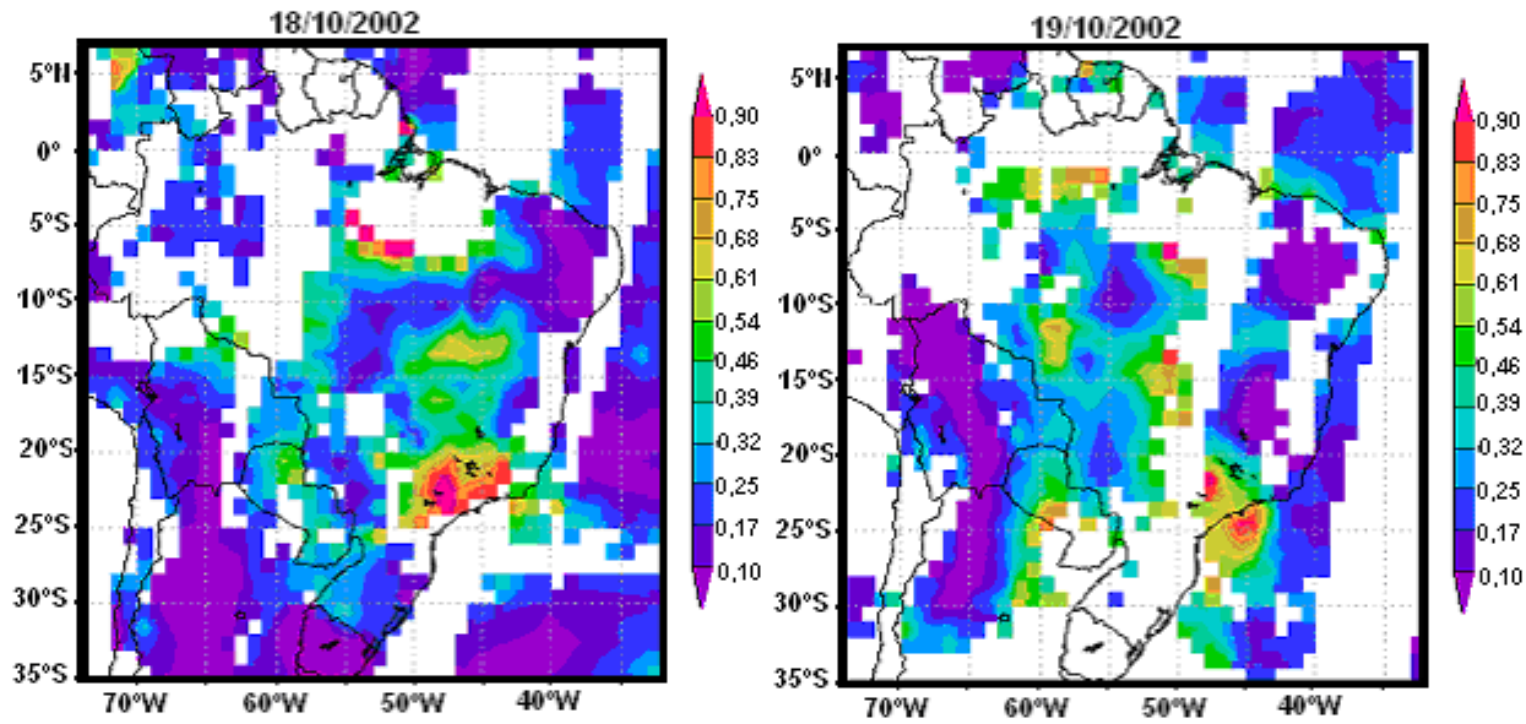

Figura 4.20 - Distribuição espacial da POA através do sensor MODIS abordo do satélite Terra em $0,55 \mu \mathrm{m} \quad(550 \mathrm{~nm})$ disponíveis no site NASA-Giovanni (http://disc1.sci.gsfc.nasa.gov/daac-bin/G3/gui.cgi). As figuras correspondem ao intervalo entre 10 a 19 de outubro de 2002, a latitude e longitude são apresentadas em [graus] e a régua de cores ao lado da figura indica o valor da POA correspondente nos mapas.

No dia 15/10/2002 (figura 4.20) já é possível visualizar uma intensa pluma secundária de aerossol cobrindo o litoral do Paraná, Santa Catarina e sul de São Paulo com valores de POA maiores do que 0,83. Em 16/10/2002 esta pluma secundária aparentemente sofreu uma atenuação, porém volta a evoluir nesta mesma região chegando a São Paulo nos dias 17, 18 e 19 com valores também maiores do que 0,83 cobrindo uma vasta área do estado de São Paulo e norte do Paraná. Um fato que cabe ressaltar é que as medições do sensor MODIS apontam que nos dias 18 e 19/10/2002 a pluma de aerossóis é mais intensa em valores de POA sobre o estado de São Paulo do que na região de queimadas. Isto sugere que esta pluma secundária é parte da pluma gerada inicialmente e que a mesma foi novamente se dissipando com o passar dos dias durante o transporte da fonte até a região de estudo. 


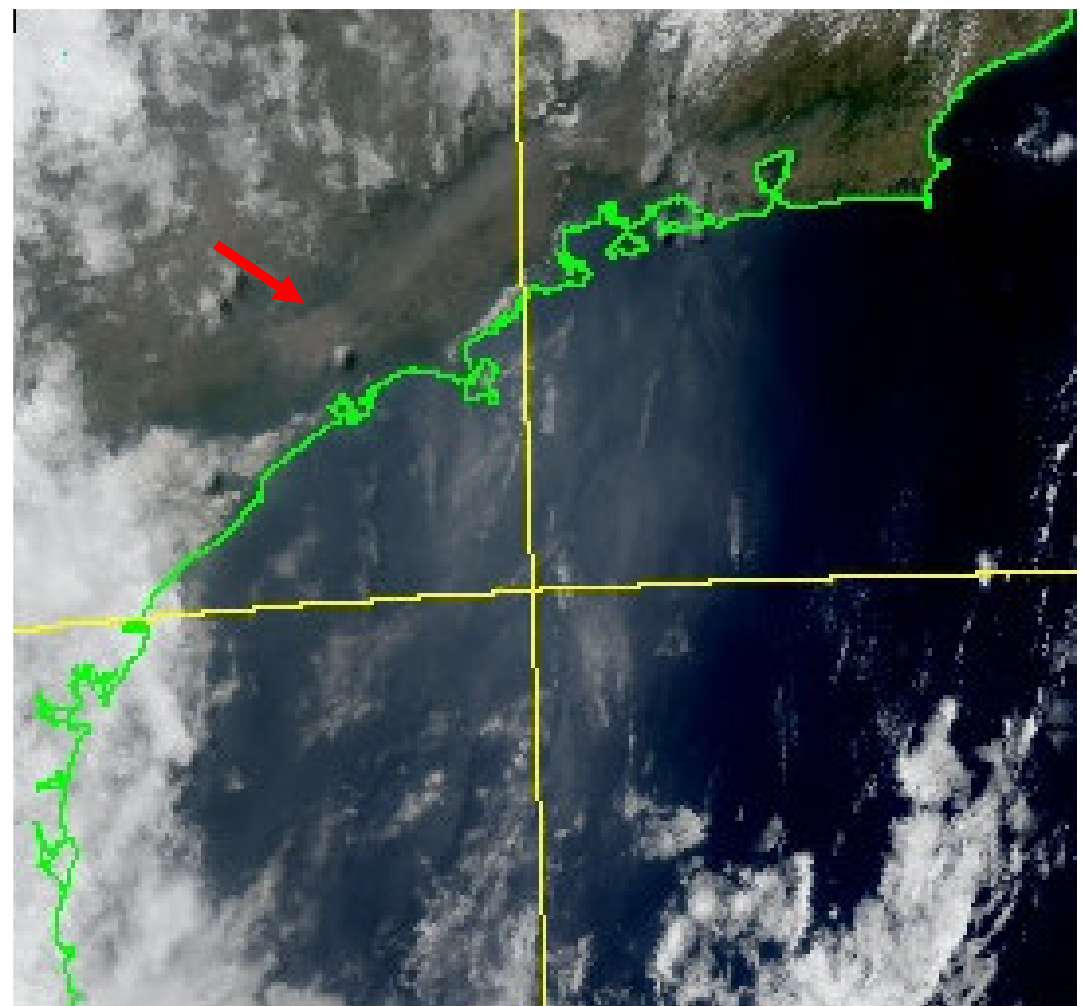

Figura 4.21 - Imagem RGB no espectro do visível (Visible Composite) através do sensor MODIS abordo do satélite TERRA, ampliação, para o dia 19/10/2002 onde é possível observar uma grande pluma de aerossol cobrindo parte do oceano na costa do Paraná e de São Paulo bem como a região metropolitana de São Paulo. A seta indica a região metropolitana de São Paulo. Imagem disponível no site LAADS Web: (http://ladsweb.nascom.nasa.gov).

Na figura 4.21 é apresentada uma imagem do tipo RGB composta por canais no visível do sensor MODIS para o dia 19/10/2002, quando, em São Paulo, o valor médio horário máximo obtido para a POA com o MFRSR foi de 1,19. Nesta imagem é possível observar a intensa pluma de aerossóis cobrindo uma vasta área do litoral de São Paulo e Região Metropolitana confirmando a influência observada nos valores de POA gerados com o MFRSR em solo.

As análises com as imagens do sensor MODIS colaboram no entendimento do comportamento espacial e temporal do aerossol de queimadas até chegar à cidade de São Paulo. O comportamento da POA observado neste período também pode apontar para um ciclo que envolve desde a queima da biomassa, a formação do aerossol de queimadas e o seu transporte até a região da cidade de São Paulo. O fato de que a região de queimadas pode ter apresentado novos focos ao longo do tempo ofereceu as condições necessárias para que em todo o período analisado, a cidade de São Paulo sofresse a sua influência devido ao transporte de aerossóis de queimadas de forma mais ou menos intensa na pluma local, principalmente entre os meses de agosto a outubro. 


\section{Capítulo V - Conclusões}


As campanhas de calibração pelo método Langley no DAEE em Campos do Jordão em 2000 e no OPD-LNA em Brasópolis em 2005 e 2006, com o MFR-434, forneceram as condições necessárias para uma avaliação do emprego do método Geral no sítio de operação dos MFRSR na cidade de São Paulo. As calibrações pelo método Langley para o MFR-434, e por transferência para o MFR-435 indicaram o canal $870 \mathrm{~nm}$ como o canal mais estável em relação à degradação da calibração dos MFRSR, o que permitiu a avaliação da calibração no sítio de operação dos MFRSR de forma independente.

O método geral requer a restrição do tamanho médio dos aerossóis. Neste trabalho, o tamanho médio foi inferido a partir do coeficiente de Ångström, limitando a sua variabilidade em no máximo $2,0 \%$, o que possibilitou a construção de retas de calibração formada por médias mensais dos valores diários obtidos através do método Geral. Esta restrição na variabilidade do tamanho do aerossol reduz, no caso de São Paulo, o número de dias aptos para a aplicação do método. Mesmo assim, as retas de calibração forneceram estimativas para a constante solar espectral de cada MFRSR que, comparadas em períodos próximos às campanhas de calibração pelo método Langley em 2005 e 2006, apresentaram bons resultados. As diferenças são menores do que $0,4 \%$ no canal $672 \mathrm{~nm}$ e menores do que 1,7\% para o canal $415 \mathrm{~nm}$ para ambos os MFRSR.

Quando foram avaliados os valores de POA estimados com a nova calibração aplicada aos MFRSR, em relação a valores de POA da rede AERONET, que passa por um rígido controle de qualidade e calibração, foram observadas diferenças não muito significativas entre os resultados fornecidos por ambos os instrumentos. As diferenças médias encontradas, em valores de POA, de 0,03 no canal $672 \mathrm{~nm}$ e de 0,04 para o canal $415 \mathrm{~nm}$ entre 2004 e 2006 ilustram a eficiência da calibração empregada. Analisando ainda as diferenças absolutas encontradas em cada canal deve-se levar em consideração também a diferença instrumental dos radiômetros, tanto na resolução espectral de cada canal quanto na técnica de detecção empregada. Os resultados apontam também que os MFRSR e a rede AERONET apresentam variabilidade temporal de POA similar ao longo do ano, embora sejam observadas diferenças com relação ao ciclo diurno, indicando a possibilidade de ainda existir problemas com a calibração dos instrumentos.

No trabalho também é apresentado um filtro automático de nuvens para dados dos MFRSR. Este filtro, que está sendo aplicado e proposto para São Paulo, se mostra eficiente ao excluir dados suspeitos de estarem contaminados por nuvens, mesmo excluindo alguns dados não contaminados, em princípio. Porém levando-se em conta que seu número não é significativo 
em relação à base de dados válidos, que impeça a observação da variabilidade do aerossol ao longo do ciclo diurno, o filtro se mostra satisfatório em sua aplicabilidade e funcionalidade.

A análise da série temporal média diária com dados de POA e do coeficiente de Ångström dos MFRSR mostrou a existência de sazonalidade destes parâmetros ópticos em medidas feitas em São Paulo. O aerossol apresenta, ao longo do ano, partículas menores nos meses de inverno e maiores nos meses próximos ao verão. Os dados analisados mostraram também que o coeficiente de Ångström entre 415/870 nm sugere que a pluma de aerossóis de São Paulo seja formada em média por partículas de tamanho médio a partículas da moda fina. A sazonalidade da POA fica mais bem caracterizada nos valores médios mensais para os quais se evidenciam os máximos em torno dos meses de agosto a outubro de cada ano quando eventos de transporte de aerossóis de queimadas são identificados para São Paulo, além das próprias condições locais de dispersão de poluentes que são prejudicadas em tal época do ano.

A avaliação dos parâmetros ópticos estimados com os MFRSR e variáveis meteorológicas apontaram para uma relação linear entre a UR e o coeficiente de Ångström para uma determinada população de aerossóis presentes na atmosfera de São Paulo. Esta relação sugere que este grupo pode estar associado à predominância de fontes locais de aerossóis com característica higroscópica. Houve uma diminuição do coeficiente de Ångström, indicando o crescimento do tamanho da partícula, com o aumento da umidade relativa. Outras variáveis como vento, temperatura não apresentaram relação significativa com os parâmetros ópticos analisados. Outros estudos com maior impacto espacial e temporal são necessários para complementar e ampliar este estudo.

\section{Sugestão de trabalhos futuros}

$\checkmark$ Estudar o impacto espacial da POA em São Paulo a partir dos MFRSR, com a instalação e monitoramento dos mesmos em vários pontos da Região Metropolitana de São Paulo e se possível com a ampliação do número de MFRSR em operação. Este estudo poderia ser estendido à comparação com dados de satélite como os do sensor MODIS;

$\checkmark$ Avaliar parâmetros ópticos dos aerossóis como a POA e o coeficiente de Ångström com variáveis meteorológicos em alta resolução temporal.

$\checkmark$ Estudo mais profundo do impacto do $\mathrm{NO}_{2}$ no valor da POA com dados de satélites e estimativas de perfis de concentração com instrumentação em solo; 


\section{Capítulo VI - Referências Bibliográficas}


ALEXANDROV, M. D.; LACIS, A. A.; CARLSON, B. E. \& CAIRNS, B. - Remote sensing of atmospheric aerosols and trace gases by means of Multifilter Rotating Shadowband Radiometer. Part I: retrieval algorithm. Journal of the Atmospheric Sciences, 59(3): 524-543; 2002a.

ALEXANDROV, M.D.; LACIS, A.A.; CARLSON, B.E.; CAIRNS, B. - Remote sensing of atmospheric aerosols and trace gases by means of Multifilter Rotating Shadowband Radiometer. Part II: climatological applications. Journal of the Atmospheric Sciences, 59(3): 544-566, 2002b.

ANDRADE, M. F. - Caracterização das Fontes de Material Particulado e Ozônio Troposféricos na Região Metropolitana de São Paulo. Tese de Livre-Docente apresentada ao Instituto de Astronomia, Geofísica e Ciências Atmosféricas da Universidade de São Paulo, Abril de 2006.

ANDREAE, M. O.; ROSENFELD, D.; ARTAXO, P.; COSTA, A. A.; FRANK, G. P.; LONGO, K. M.; SILVA-DIAS, M. A. F. - Smoking Rain Clouds over the Amazon SCIENCE, 303, 1337-1342, 27 FEBRUARY 2004.

AUGUSTINE, J. A.; CORNWALL, C. R.; HODGES, G. B.; LONG, C. N.; MEDINA, C. I.; DE LUISI. J. J. - An automated method of MFRSR calibration for aerosol optical depth analysis with application to an Asian dust outbreak over the United States, J. App. Meteor., 42, 266- $278,2003$.

BUCHOLTZ, A. - Rayleigh-scattering calculations for the terrestrial atmosphere. Applied Optics, v. 34, p. 2765-2773, 1995.

CACHORRO, V. E.; ROMERO, P. M.; TOLEDANO, C.; CUEVAS, E. \& FRUTOS, A. M. DE. - The fictitious diurnal cycle of aerosol optical depth: A new approach for "in situ" calibration and correction of AOD data series. Geophysical Research Letters, Vol. 31, L12106, Doi:10.1029/2004 g1019651, 2004. 
CASTANHO, A. D. A. - Propriedades ópticas das partículas de aerossol e uma nova metodologia para a obtenção de profundidade óptica via satélite sobre São Paulo. Tese de Doutorado, Instituto de Física, Universidade de São Paulo, São Paulo, 2005.

CASTANHO, A. D. A. - A Determinação Quantitativa de Fontes de Material Particulado na Atmosfera da Cidade de São Paulo. Dissertação de Mestrado, Instituto de Física da Universidade de São Paulo; 1999.

CORRÊA, M. P. - Índice ultravioleta: avaliações e Aplicações. Tese de doutorado, Instituto de Astronomia, Geofísica e Ciências Atmosféricas da Universidade de São Paulo, 2003.

DUBOVIK, O.; HOLBEN, B. N.; KAUFMAN, Y.J.; YAMASOE, M. A.; SMIRNOV, A. J.; TANRÉ, D. and SLUTSKER, I. - Single-scattering albedo of smoke retrieved from the skyradiance and solar transmittance measured from the ground. Journal of Geophysical Research, v. 103, n. D24, 31903-31923, 1998.

FORGAN, W. B. - General method for calibrating Sun photometer - Applied Optics, 33(21): 4841-4850, 1994.

FRÖHLICH, C. \& SHAW, G. E. - New determination of Rayleigh scattering in the terrestrial atmosphere, APPLIED OPTICS, 19, 1773-1775; 1980.

GLANTZ, P., NILSSON, D. E.; VON HOYNINGEN-HUENE, W. - Estimating a Relationship Between Aerosol Optical Thickness and Surface Wind Speed Over The Ocean. Atmos. Chem. Phys. Discuss., 6, 11621-11651, 2006.

GOODY, R. M. \& YUNG, Y. L. - Atmospheric Radiation - Atmospheric Radiation: Theoretical Basis. Oxford University Press, $2^{\mathrm{a}}$ edição, New York, 1989.

HALLIDAY, D.; RESNICK, R.; KRANE, K. S. - Física 4. Livros Técnicos e Ciêntíficos LTC, $4^{\mathrm{a}}$ edição, 270 - 271, 309 - 325; 1996.

HANSEN, J. E., \& TRAVIS, L. D. - Light scattering in planetary atmospheres. Space Sci. Rev., 16: 257-610; 1974. 
HANSEN, J.; SATO, M. \& RUEDY, R. - Radiative forcing and climate response. Journal of Geophysical Research 102 (D6), 6831-6864; 1997.

HARRISON, L.; MICHALSKY, J. \& BERNDT, J. - Automated multifilter rotating shadowband radiometer: an instrument for optical depth and radiation measurements. Applied Optics, 33(22): 5118-5125; 1994.

HOLBEN, B. N.; SETZER, A.; ECK, T. F.; PEREIRA, A. \& SLUTSKER - I. Effect of dryseason biomass burning on Amazon basin aerosol concentrations and optical properties, 19921994. Journal of Geophysical Research, 101 (D14), 19465-19481; 1996.

HOLBEN, B. N.; ECK, T.F.; SLUTSKER, I.; TANDARÉ, D.; BUIS, J. P.; SETZER, A.; VERMOTE, E.; REAGAN, J. A.; KAUFMAN, Y.J.; NAKAJIMA, T.; LAVENU, F.; JANJOWIAK, I.; SMIRNOV, A. - A federated instrument network and data archive for aerosol characterization. Remote Sensing of Environment, v. 66, p. 1-16, 1998.

HORVATH, H. - Aerosols an introduction. Journal of Environmental Radioactivity, v. 51, p. $5-25,2000$.

IQBAL, M. - An Introduction to Solar Radiation. Academic Press, San Diego, Califórnia. 1983.

IPCC 1996 - Intergovernmental Panel on Climate Change. Climate Change 1995. The Science of Climate Change: Contribution of Working Group I to the Second Assessment Report of the Intergovernmental Panel on Climate Change. Edited by Houghton, J.T. et al. Cambridge University Press, Cambridge, United Kingdom and New York, NY, USA; 1996.

IPCC 2001 - Intergovernmental Panel on Climate Change. Climate Change 2001. The Scientific Basis: Contribution of Working Group I to the Third Assessment Report of the International Panel of Climate Change. Edited by Houghton, J. T. et al. Cambridge University Press, New York; 2001.

IPCC 2007 - Intergovernmental Panel on Climate Change. Climate Change 2007. The Scientific Basis: Contribution of Working Group I to the Fourth Assessment Report of the 
International Panel of Climate Change. Edited by Houghton, J. T. et al. Cambridge University Press, New York; 2007.

KOREN, I.; KAUFMAN, Y. J.; REMER, L. A. \& MARTINS, J. V. - Measurement of the effect of Amazon smoke on inhibition of cloud formation, Science 303: 1342-1345; 2004.

KASTEN, F. \& YOUNG, A. T. - Revised optical air mass tables and approximation formula. Applied Optics, 28(22): 4735-4738; 1989.

KEPLER, S. O.; SARAIVA, M. F. O. - Astronomia e Astrofísica. Editora Livraria da Física, $2^{\mathrm{a}}$ ed. São Paulo, Brasil; 2004.

LANDULFO, E.; PAPAYANNIS, A.; ARTAXO, P.; CASTANHO, A. D. A.; DE FREITAS, A. Z.; SOUZA, R. F.,;VIEIRA JUNIOR, N. D.; JORGE, M. P.; S`ANCHEZ-CCOYLLO, O. R.; MOREIRA, E D. S. - Synergetic measurements of aerosols over São Paulo, Brazil using LIDAR, sunphotometer and satellite data during the dry season. Atmospheric Chemistry and Physics, vol. 3, p. 1523-1539, 2003.

LIOU, K. N. - An Introduction to Atmospheric Radiation. Academic Press. New York, Oxford. $2^{\mathrm{a}}$ edição; 2002.

LONG, C. N.; \& ACKERMAN, T.P. - Identification of clear skies from broadband pyranometer measurements and calculation of downwelling shortwave cloud effects, J. Geophys. Res., 105(D12), 15,609-15,626, 2000.

MACARTHUR, J. L.; HALLIWELL, D.H.; O. J. N.; N. T. O.; J. R. S.; C. W. - Field comparison of network Sun promoters. J. of Geophysical Research.108, NO. D19:4596; 2003.

MARTINS, J. V. - O efeito de partículas de aerossol de queimadas da Amazônia no balanço radioativo da atmosfera. Tese de Doutorado, Instituto de Física da Universidade de São Paulo, 1999.

MICHALSKY, J. J.; LILJEGREN, J. C. \& HARRISON, L. C. - A comparison of Sun photometer derivations of total column water vapor and ozone to standard measures of same 
at the Southern Great Plains Atmospheric Radiation Measurement site. Journal of Geophysical Research, 100(D12): 25995-26003; 1995.

MICHALSKY, J. J.; SCHLEMMER, F. A.; BERKHEISER, W. W.; BERNDT, J. L.; HARRISON, L. C.; LAULAINEN,N. S.; LARSON, N. R.; BARNARD,J. C. - Multiyear measurements of aerosol optical depth in the Atmospheric Radiation Measurement and Quantitative Links programs, J. Geophys. Res., 106(D11), 12,099- 12,107, 2001.

MIRANDA, R. M. - Caracterização físico-química e propriedades ópticas do aerossol urbano na Região Metropolitana de São Paulo. Tese de doutorado, Instituto de Astronomia, Geofísica e Ciências Atmosféricas da Universidade de São Paulo; 2001.

NOBRE, C. A. - Mudanças climáticas globais e o Brasil: Porque devemos nos preocupar. Boletim da Sociedade Brasileira de Meteorologia - Desafios Associados às Mudanças Climáticas. Vol.31, nº1, 7-11. Abril de 2007.

O’NEILL, N. T.; ROYEER, A.; COTÉ, P.; MACARTHUR, L. J. B. - Relations between Optically Derived Aerossol Parameters, Humidity and Air-Quality in an Urban Atmosphere. J. App. Meteor, 32, 1484- 1498, 1993.

ORPHAL, J. - A critical review of the abortion cross-sections of $\mathrm{O}_{3}$ and $\mathrm{NO}_{2}$ in the ultraviolet and visible. J. of Photobiology A: Chemistry. 157:185-209; 2003.

PALTRIDGE, G. W. \& PLATT, C. M. R. - Radiative Processes in Meteorology and Climatology, Amsterdam; Oxford; New York;: Elsevier Scientific Pub. Co.5-32; 53-66; 1976.

PLANA-FATTORI, A.; DUBUISSON, P.; FOMIN, B.A. \& CORRÊA, M. P. - Estimating the atmospheric water vapor content from multi-filter rotating shadow-band radiometry at São Paulo, Brazil. Atmospheric Research. Vol. 71, no. 3, pp. 171-192. Aug.; 2004.

PANDIS, N. S. \& SEINFELD, J. H. - Atmospheric Chemistry and Physics, From Air Pollution to Climate Change. John Wiley \& Sons INC, Canadá; 1998. 
PEREIRA FILHO, A.; SANTOS, P. M.; XAVIER, T. M. B. S. - Evolução temporal do tempo e do clima na Região Metropolitana de São Paulo. Instituto de Astronomia, Geofísica e Ciências Atmosféricas da Universidade de São Paulo; 2007.

ROLLIN, E. M. - An introduction to the use of Sun-photometry for the atmospheric correction of airborne sensor data. Disponível em: http://www.soton.ac.uk/ ejm/pdfs/. Acesso em: 10 de janeiro de 2008.

ROSÁRIO, N. M. E do. - Comparação de profundidades ópticas espectrais do aerossol obtidas para São Paulo a partir de um Multifilter Rotating Shadowband Radiometer e do fotômetro solar da AERONET. Dissertação Mestrado, Instituto de Astronomia, Geofísica e Ciências Atmosféricas, Universidade de São Paulo, 2006.

SEEP- SECRETARIA DE ESTADO DE ECONOMIA E PLANEJAMENTO, GOVERNO DO ESTADO DE SÃO PAULO. - Região Metropolitana de São Paulo. www.planejamento.sp.gov.br/AssEco/DadosSocio_Eco.asp - Acessado em janeiro de 2008.

SHAOCAI, Y.; SAXENA, V. K.; WENNY, B.N.; DELUISI, J.J.; YUE, G. K.; PETROPAVLOVSKIKH, I. V. - A study of the aerosol radiative properties needed to compute direct aerosol forcing in the southeastern United States. J. of Geophysical Research , Vol. 105, NO (D20): 24739-24749; 2000.

SHAW, G.E. - Error analysis in multi-wavelength sun photometry. Pure and Applied Geophysics, 114: 1-14; 1976.

SHAW, G.E. - Nitrogen Dioxide - Optical Absorption in visible. Journal of Geophysical Research , 81: No 83: 5791-5792; 1976 b.

SHAW, G.E. - Sun photometry. Bulletin of the American Meteorological Society, 64(1): 4$10 ; 1983$.

SHETTLE \& ANDERSON - New Visible and near IR ozone absorption cross-section for MODTRAN. Proceedings of the 17th Annual Review Conference on Atmospheric Transmission Models, 8-9 June. pp: 335-345; 1994. 
SMIRNOV, A.; VILLEVALDE, Y.; O'NEILL, N. T.; ROYER, A.; TARUSSOV, A. Aerosol optical depth over the oceans: Analysis in terms of synoptic air mass types. Journal of Geophysical Research, 100, NO. D8,16.639-16.650, 1995.

SMIRNOV, A. et al., Cloud-sreening and quality control algorithms for the AERONET database. Remote Sensing Environment, v. 73, p. 337-349. 2000.

SOKOLIK, I. Lectures Notes (graduate course on "Radiative Processes in Planetary Atmospheres). Disponível em: <http://irina.eas.gatech.edu/ATOC5560_2002.htm>. Acesso em: 09 de dezembro 2008.

TOMASI, C.; VITALE, V.; DE S. - Relative Optical Mass Functions for Air, WATER Vapour, Ozone and Nitrogen Dioxide in Atmospheric Models Presenting Different Latitudinal and Seasonal Conditions. Meteorology and Atmospheric Physics, 65: 11-30; 1998.

TROSNIKOV, I.V. \& NOBRE, C.A. - Estimation of aerosol transport from biomass burning áreas during the SCAR-B esperiment. Journal of Geophysical Research, 103, NO. D24,32.129-32.137, December 27, 1998.

VUOLO, J. H. - Fundamentos da Teoria dos Erros, Editora Edgard Blücher, $2^{\text {a }}$ Edição, SPSP; 1996.

WAGNER, F. \& SILVA, A. M. - Some considerations about Ångström exponent distributions. Atmos. Chem. Phys. Discuss., 7, 12781-12805, 2007.

WALLACE, J. M. \& HOBBS, P. V. - Atmospheric science: an introductory survey, International Geophysics Series, Academic Press, Elsevier Inc., 2 edição, 09-177, 2006.

WENNY, B. N.; SCHAFER, J. S.; DELUISI, J. J.; SAXENA, V. K.; BARNARD, W. F.; PETROPAVOLVSKIKH, I. V. \& VERGAMINI, A. J. - A study of regional aerosol radiative properties and effects on ultraviolet-B radiation. Journal of Geophysical Research, 103(D14): 17083-17097; 1998. 
WENNY, B. N.; SAXENA; V. K. \& FREDERICK, J. E. - Aerosol optical depth measurements and their impact on surface levels of ultraviolet-B radiation. Journal of Geophysical Research, 106(D15): 17311-17319; 2001.

YAMASOE, M. A. - Estudo de propriedades ópticas de partículas de aerossóis a partir de uma rede de radiômetros. Tese de Doutorado, Instituto de Física, Universidade de São Paulo, São Paulo, 1999. 